Portland State University

PDXScholar

\title{
The relationship between a pre-departure training program and its participants' intercultural communication competence
}

Daniel Timothy Ferguson

Portland State University

Follow this and additional works at: https://pdxscholar.library.pdx.edu/open_access_etds

Part of the Education Commons, and the International and Intercultural Communication Commons Let us know how access to this document benefits you.

Recommended Citation

Ferguson, Daniel Timothy, "The relationship between a pre-departure training program and its participants' intercultural communication competence" (1996). Dissertations and Theses. Paper 3791.

https://doi.org/10.15760/etd.5675

This Thesis is brought to you for free and open access. It has been accepted for inclusion in Dissertations and Theses by an authorized administrator of PDXScholar. Please contact us if we can make this document more accessible: pdxscholar@pdx.edu. 


\section{THESIS APPROVAL}

The abstract and thesis of Daniel Timothy Ferguson for the Master of Arts in Teaching English to Speakers of Other Languages were presented on November 6, 1996 and accepted by the thesis committee and the department.

COMMITTEE APPROVALS:

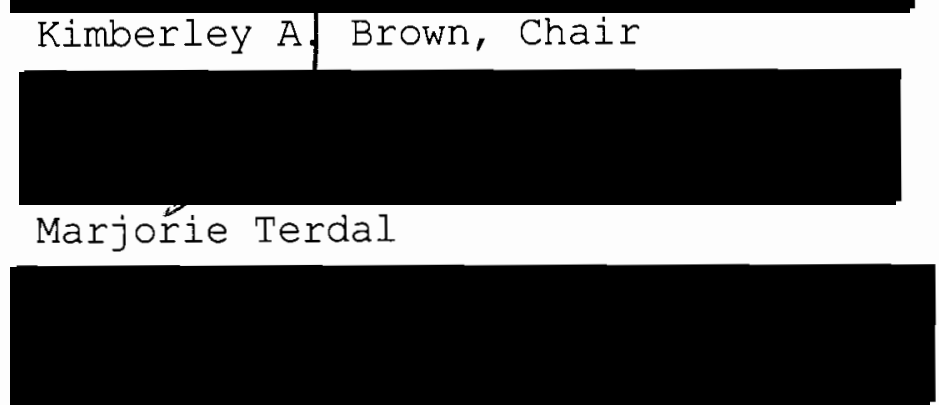

Devorah A. Lieberman

DEPARTMENT APPROVAL:
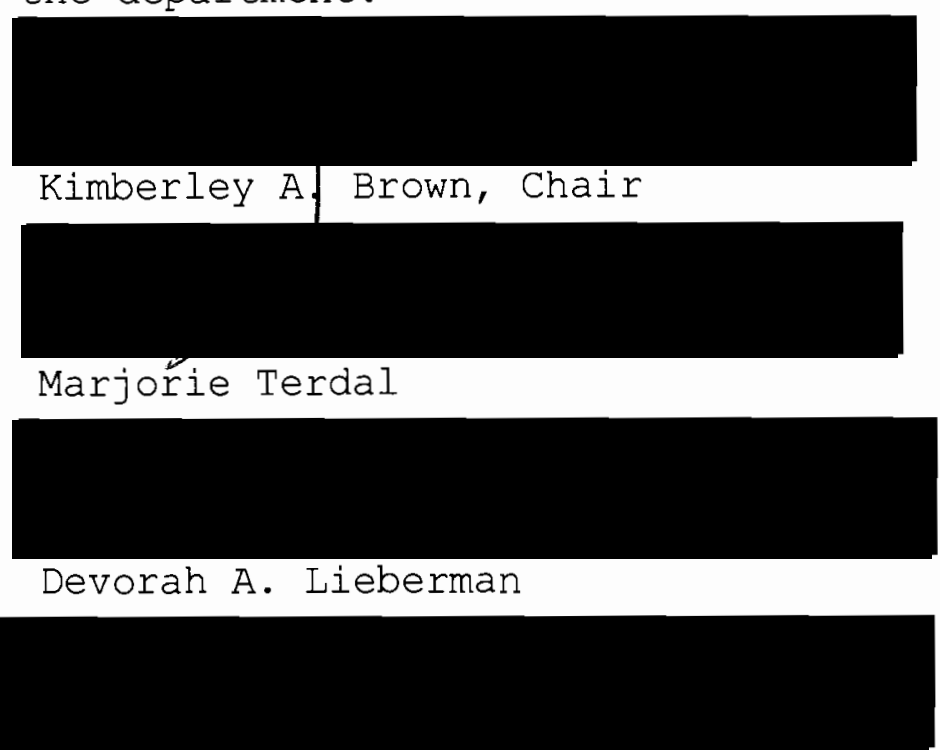

Dalton Miller-Jones

Representative of the Office

of Graduate Studies

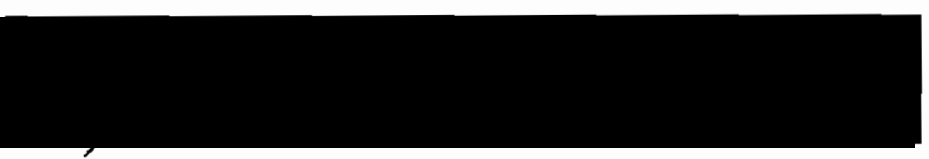

Beátrice T. Oshika

Department of Applied Linguistics

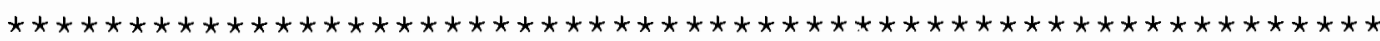

ACCEPTED FOR PORTLAND STATE UNIVERSITY BY THE LIBRARY 


\section{ABSTRACT}

An abstract of the thesis of Daniel Timothy Ferguson for the Master of Arts in Teaching English to Speakers of Other Languages presented November 6, 1996.

Title: The Relationship Between a Pre-departure Training Program and its Participants' Intercultural Communication Competence.

Self-reported behaviorally-based intercultural communication competence inventories are one way to understand the relationship between a pre-departure training program and its participants' intercultural communication competence (ICC). One such inventory, called the CrossCultural Adaptability Inventory (CCAI), was chosen to explore this relationship.

This research sought to confirm or reject the following three hypotheses: 1) experimental subjects will demonstrate higher levels of ICC than control subjects, 2) experimental subjects will demonstrate higher levels of ICC after they 
take the pre-departure class at Walla Walla College, and 3) there will be relationships among all subjects' ICC and the demographic variables involved in this research. Fifty seven subjects from Walla Walla College participated in the research, 23 as experimental subjects, and 34 as control subjects. Experimental subjects took the cross-cultural ministry class at Walla walla College and were given the inventory twice, once before and once after the course. Control subjects had never been SMs, had not taken any previous pre-departure training, and were administered the inventory once.

Mean scores were computed for subjects in the study and statistical significance was set at $p<.05$ for all tests. Two tests, nonparametric and parametric, were done on the data to determine if differences existed between experimental and control subjects: analysis of variance (ANOVA) and the Mann-Whitney U test. Statistically significant differences were found in both tests between treatment and the following CCAI dimensions: emotional resilience (ER), perceptual acuity $(P A C)$, and the total CCAI score. Statistically significant differences were found in the ANOVA between treatment and flexibility/openness (FO). 
Nonparametric (Wilcoxon sign rank) and parametric (ANOVA) tests determined if differences exist between repeated CCAI measures. In both tests, statistically significant differences were found in repeated FO and repeated total CCAI scores. The ANOVA of repeated PAC also revealed statistical significance, while the Wilcoxon test revealed results leading to statistical significance. Spearman (nonparametric) and Pearson (parametric) correlation studies determined the relationship between demographic variables and the CCAI. Both tests revealed correlations among gender and total CCAI, gender and FO, gender and $\mathrm{PAC}$, treatment and $\mathrm{ER}$, treatment and FO, treatment and PAC, and treatment and the total CCAI. 
THE RELATIONSHIP BETWEEN A PRE-DEPARTURE TRAINING PROGRAM AND ITS PARTICIPANTS' INTERCULTURAL COMMUNICATION COMPETENCE

by

DANIEL TIMOTHY FERGUSON

A thesis submitted in partial fulfillment of the requirements for the degree of

MASTER OF ARTS

in

TEACHING ENGLISH TO SPEAKERS OF OTHER LANGUAGES

Portland State University

1996 
TABLE OF CONTENTS

PAGE

LIST OF TABLES . . . . . . . . . . . . . . . . . . . . . vi vi

CHAPTER

I INTRODUCTION . . . . . . . . . . . . . . . 1

Background. . . . . . . . . . . . . 1

Walla Walla College's Pre-Departure

Program . . . . . . . . . . . . . 6

Purpose of the Research . . . . . . 6

Operational Definitions . . . . . . 8

II LITERATURE REVIEW. . . . . . . . . . . . 13

Introduction. . . . . . . . . . . 13

PART I: INTERCULTURAL COMMUNICATION AND

CULTURE' S INFLUENCE

ON COMMUNICATION . • . . . . . . . . 14

Definitions . . . . . . . . . . . 14

PART II: THE PROCESSES OF INTERCULTURAL

ADUUSTMENT AND ADAPTATION. . . . . 26

Adjustment Processes. . . . . . . . 26

Adaptation Processes. . . . . . . 29 
PART III: INTERCULTURAL COMMUNICATION COMPETENCE . . . . . . . . . . . 31

Definitions . . . . . . . . . . 31

Trait Approach. . . . . . . . . . . 39

Attitudinal/Perceptual Approach . . . . 40

Behavioral Approach . . . . . . . . . 44

Culture Specific Approach . . . . . . 48

Walla Walla College's Approach. . . . . 51

PART IV: INTERCULTURAL TRAINING AND

INTERCULTURAL TRAINING APPROACHES. . 53

Definitions . . . . . . . . . . . 53

Intellectual Approach . . . . . . . 57

Area Training Approach. . . . . . . 59

Self-Awareness Approach . . . . . . 62

Culture Awareness Approach. . . . . . 63

Integrated Approach . . . . . . . . . 65

Walla Walla College' s Approach. . . . . 67

Conclusion. . . . . . . . . . . 68

A Description of the SM Program

and the Participant Subjects. . . . . . 72

Experimental and Control Populations. . . 77 
CHAPTER

PAGE

Demographic Survey. . . . . . . . . . 84

Data Analysis... . . . . . . . 87

Research Method ........... . 89

IV RESULTS. . . . . . . . . . . . . . . . . 94

Research Hypothesis One . . . . . . . 99

Research Hypothesis Two . . . . . . 103

Research Hypothesis Three. . . . . . 109

V DISCUSSION, LIMITATIONS, UNEXPECTED RESULTS, AND SUGGESTIONS. . . . . . . . . . . . . . . 117

Research Hypothesis One . . . . . . . 117

Research Hypothesis Two . . . . . . 125

Research Hypothesis Three . . . . . 129

Unexpected Results. . . . . . . . . 140

Limitations . . . . . . . . . . 146

Suggestions for Future Research . . . . 148

Summary and Conclusions . . . . . . 151

BIBLIOGRAPHY . . . . . . . . . . . . . . . . . 155

APRENDICES

A CROSS-CULTURAL ADAPTABILITY INVENTORY. . . . . 167

B CONTROL SUBJECTS DEMOGRAPHIC SURVEY. . . . . 170

C EXPERIMENTAL SUBJECTS DEMOGRAPHIC SURVEY • • . 171 
APPENDICES

PAGE

D SM PROGRAM SPONSOR AND CROSS-CULTURAL

MINISTRY CLASS TEACHER INTERVIEW QUESTIONS • • 173

E TABLES ASSOCIATED WITH THIS RESEARCH . . . . 175 
II Ethnic Background. . . . . . . . . . . . . . . 97

III Gender . . . . . . . . . . . . . . 98

IV Church Affiliation . . . . . . . . . . 98

V Dietary Practices. . . . . . . . . . . . 98

VI Years Abroad . . . . . . . . . . . . . 99

VII Linguistic Background. . . . . . . . . . . 99

VIII ANOVAs of the CCAI Dimensions and the Treatment Variable . . . . . . . . . 102

IX Mann-Whitney U Test of the CCAI Dimensions and the Treatment Variable . . . . . . . 103

$\mathrm{X} \quad$ ANOVA of the Treatment Subjects and FO Repeated Measure. . . . . . . . 106

XI ANOVA of the Treatment Subjects and PAC Repeated Measure . . . . . . . 107

XII ANOVA of the Treatment Subjects and the Total CCAI Repeated Measure. . . . . 108

XIII Wilcoxon Signed Rank Test for Repeated CCAI Dimensions. . . . . . . . . . . . . 109

XIV Pearson Product Moment Correlation Coefficients $\left(r^{\prime} s\right)$ among the CCAI Dimensions And Demographic Variables . . . . . 114 
XV Spearman Rank-Order Correlation

Coefficients ( $r^{\prime} s$ ) among the CCAI

Dimensions And Demographic Variables . . . . 115

XVI ANOVA of the Treatment Subjects

and ER Repeated Measure. . . . . . . . . 175

XVII ANOVA of the Treatment Subjects

and the Total CCAI Repeated Measure. . . . . 176

XVIII Mann-Whitney Information for

Research Subjects and the CCAI . . . . . . . 177

XIX Incidence Table of Repeated CCAI Dimensions. . 178

XX Pearson Product Moment Correlation

Coefficients ( $r^{\prime} s$ ) among

the CCAI Dimensions. . . . . . . . . . . 179

XXI Spearman Rank-Order Correlation

Coefficients ( $\mathrm{R}^{\prime} \mathrm{s}$ ) among

the CCAI Dimensions. . . . . . . . . . . 180 
CHAPTER I

INTRODUCTION

\section{BACKGROUND}

Cross-cultural communication was something I became aware of soon after arriving in Japan as a Seventh-day Adventist (SDA) church-sponsored student missionary (SM). Eor two months I had gone through my own difficulties of homesickness and adjusting to a new environment. I had also become somewhat acquainted with some Japanese customs of appropriate behavior while in public. As a sojourner who was living in another culture on a short-term basis, I felt fairly well equipped although still nervous about my place in Japanese society. I thought I was no different from other sojourners, i.e., businesspeople, exchange students, or even other missionaries who thought they understood and appreciated other cultures.

For some time I had planned a small picture-taking trip to one of the scenic spots in Japan. At the last minute, I was asked to take an American (not an SM) who was in Japan to 
renew his korean visa. This was no problem until we got on the train. Half way through the trip, he pulled out this mixture of wheat germ, peanut butter, and granola. He went on eat the mixture, talking as he ate with some of the mixture pouring out of his mouth.

According to my Japanese wife, eating in public and talking while eating is not totally inappropriate. She points out that there are many sidewalk noodle shops where many patrons stand and noisily eat ramen, udon, and soba and talk at the same time, albeit normally behind a curtain. However, what he did next was something I have not seen many Japanese do and something wife tells me is inappropriate behavior in Japanese culture.

After eating this "food", he took a whitish-brown handkerchief (in desperate need of cleaning) out of his pocket, and blew his nose heartily, loudly, and long. As I watched him eat and blow his nose, I also looked at some of the faces of the Japanese passengers on the train. From their expressions (grimacing and turning their heads) at the sight, it seemed that many of the Japanese on the train were uncomfortable with what he was doing. From this episode, I learned two things. 
First, this man possibly did not know that blowing his nose so loudly with such a dirty handkerchief and eating as he did made some people react the way they did. Second, this incident helped me realize that I too might be misunderstood verbally and non-verbally at any given time. I started to question my understanding of Japanese culture and I knew from that point that coming to Japan was more than teaching Conversational English. As I later learned, going to a foreign culture also included my ability to adapt via attitudinal changes toward the host culture, to adjust to the problems of culture shock that I felt of being in a culture other than my own, and to be effective (i.e., reach a sense of competence) in that new culture.

According to Lustig and Koester, intercultural communication is "a symbolic, interpretive, transactional, contextual process in which people from different cultures create shared meanings" (1993, p. 51). However, as illustrated above, the process of creating shared meanings between individuals from two different cultures can be filled with obstacles. These obstacles are created by cultural differences of perceptions, beliefs, values, norms, and behavior and how these differences are communicated verbally 
and non-verbally.

Because of the obstacles individuals face when encountering a person from another culture, research has focused on developing sojourners' adaptation, adjustment, and effectiveness in another culture. Researchers generally believe the issues of intercultural adaptation, adjustment, and effectiveness, are closely related to intercultural communication competence (ICC) (Abe \& Wiseman, 1983; Dodd, 1991; Hannigan, 1990; Lustig \& Koester, 1993; Ruben \& Kealey, 1979). However, researchers have often disagreed on the definitions, components, measurements, and approaches best suited for research in ICC. According to Lustig and Koester (1993) the different approaches used in ICC research when taken together, suggest that ICC is a very complex phenomenon. . (and that) to achieve interpersonal competence in interactions with people from different cultures a variety of personal and interpersonal components should be considered. ( $p$. 66)

Despite the disagreements, intercultural researchers agree that people from all cultures should improve their ICC (Collier, 1989; Lustig \& Koester, 1993; Martin \& Hammer, 1989; Ruben, 1989). Lustig and Koester point out that competent intercultural communication has become a necessity both internationally and domestically. Martin \& Hammer also 
add that ICC is integral to an individual's successful adaptation in an overseas environment.

Because of the importance of ICC, training programs have been developed to successfully prepare individuals for living in a culture other than their own. Research in the past ten years has focused on training program design and the effectiveness of participants' cross-cultural training (Gudykunst, Hammer, \& Wiseman, 1977; Gudykunst \& Hammer, 1983; Blake \& Heslin, 1983; Bhawuk, 1990; Brislin, Landis, \& Brandt, 1983; Hammer, 1984; Hammer \& Martin, 1992; Albert, 1983; Hannigan, 1990).

Most of this research has been developed through the use of various inventories that focus on the diverse approaches that training programs offer (e.g., behavioral, trait, and perceptual approaches). These approaches will be discussed in the next chapter. Many of these approaches are generalizable to this research population. However, there are no recent research studies which detail the relationship of a pre-departure training program at a seventh-day Adventist church SM program and its participants' ICC.

In order to understand more fully the pre-departure program at Walla Walla College, a more detailed description 
of the program at Walla Walla College will be provided in chapter three. However, it is important to briefly describe the program at Walla Walla College at this point.

\section{WALLA WALLA COLLEGE'S PRE-DEPARTURE PROGRAM}

The Seventh-day Adventist (SDA) church has been sending undergraduate college students as SMs to foreign cultures for over 20 years. As an SDA educational institution, walla Walla College sponsors an SM program that sends an average of 30-60 SMs to foreign cultures each year. SMs then have the opportunity to associate interculturally with individuals from a culture different from their own for approximately one year. Research addressing pre-departure training issues and their relation to ICC principles will add to ICC knowledge and help Walla Walla College assess its pre-departure training program. In the next section, the purpose for this research will be discussed.

\section{PURPOSE OF THIS RESEARCH}

The purpose of this research is to assess the effectiveness of the SM pre-departure training program at Walla Walla College in current ICC principles. This research 
involves the use of an inventory and a demographic survey. The inventory, called the cross-Cultural Adaptability Inventory (CCAI), developed by Kelley and Meyers (1992) is a self-reporting behavioral measure. The demographic survey will help to determine differences between the experimental group and the control group, as well as within both groups. Both the inventory and the demographic survey are more fully discussed in the methodology chapter.

The experimental subjects will take the CCAI twice and the control subjects will take the CCAI once. The experimental subjects' post-treatment results will be considered when comparing them with the control subjects' CCAI results. Based on the following research hypotheses, the relationships among intercultural communication competence (ICC) and experimental subjects who take the pre-departure course and control subjects that do not take the pre-departure course will be addressed:

1. The experimental subjects will demonstrate higher levels of ICC than control group subjects.

2. The experimental subjects will demonstrate enhanced levels (comparing pre- and post-inventory results) of ICC after they take the pre-departure class at walla Walla College.

3. There will be relationships among subjects' ICC and the demographic variables involved in this research. 
In order to more fully understand the terminology presented in the CCAI, operational definitions of the CCAI behavioral/attitudinal categories are pertinent to the two proposed research hypotheses and proposed research question and will be discussed next. The terms to be defined are: emotional resilience, flexibility/openness, personal autonomy, and perceptual acuity.

\section{OPERATIONAL DEEINITIONS}

Emotional Resilience

Kelley and Meyers suggest that emotional resilience is the ability to effectively modulate, and deal constructively with, negative emotional reactions when confronted with other cultures. As a component of cross-cultural adaptability measured on the CCAI, SMs' self-assessment of their emotional resilience when dealing with other cultures is important.

Because living in another culture is filled with possible negative experiences, it is vital that SMs living in another culture effectively modulate and deal constructively with negative emotional reactions when encountering another culture. SMs who have lived in a culture other than their own, and perhaps those who have lived longer than others in 
another culture, would possibly be more resilient to changes. In addition, age and gender might lead to more emotional resiliency in an unfamiliar environment.

\section{Flexibility/Openness}

Kelley and Meyers suggest that a nonjudgmental attitude and flexibility toward other cultures are major components of cross-cultural effectiveness. As a component of cross-cultural adaptability measured on the CCAI, SMs' flexibility/openness is the ability to be "broad-minded" or have an interpersonal orientation that consists of a curiosity or natural respect toward others (Hawes and Kealey, 1981). SMS who respect another culture and host culture individuals could be more nonjudgmental and tolerant of the ways others express themselves. Not only this, SMs could view themselves as more willing to associate with host culture individuals. Furthermore, the willingness to be flexible and open could contribute to SMS' ability to be more sociable, as well as the desire to dispel many feelings of loneliness in an unfamiliar environment.

Similar to those who are emotionally resilient, SMs who have lived in another culture for any length of time might be more flexible/open toward another culture. In addition, age, 
gender, and ethnic background might also have something to do with flexibility/openness toward other cultures.

\section{Perceptual Acuity}

Kelley and Meyers state that perceptual acuity is the ability to perceive and evaluate accurately the feelings and values of a culturally different person. However, perceptual acuity is not limited to this. It also is related to valuing other cultures and identifying or empathizing with host culture individuals. SMs who are willing to empathize with host culture individuals change their cultural frame of reference to include the host culture frame of reference.

This frame of reference is established via verbal and nonverbal cues within a social relationship. SMs who are perceptually aware are sensitive to the subtleties and nuances of verbal and nonverbal cues within the host culture. Without perceptual acuity, intercultural communication competence (ICC) is difficult to attain.

As a component of cross-cultural adaptability measured on the CCAI, SMS' perceptual acuity will possibly be related to previous experiences in another culture or even the host culture that they are going to as SMs. It also might have something to do with age, gender, and ethnic background as 
well as the ability to speak foreign languages. It would definitely affect those SMs who fluently speak the language of the culture to which they are going.

\section{Personal Autonomy}

Kelley and Meyers state that someone who is able to maintain personal autonomy in a cross-cultural situation has a strong sense of self and a personal value system that does not depend on the surrounding environment to dictate behavior. As a component of cross-cultural adaptability measured on the CCAI, SMS who are personally autonomous do not overly depend on their environment for their identity. They know who they are, where they come from, and the values and beliefs in which they feel comfortable.

Because of a strong sense of identity, SMs who are personally autonomous generally feel in control of their environment, yet do not use their power to manipulate it. Because personally autonomous SMs respect others and their value systems, these SMs do not use their strong sense of identity to manipulate their environment.

It is important next to review the plan for this thesis: Chapter II is a review of ICC literature, definitions, approaches to ICC, and intercultural training models. 
Chapter III gives a more complete description of the pre-departure program at Walla walla College, the experimental and control group populations, the inventories used in this research, and research methodology. Chapter IV addresses the quantitative results of the data. In the final chapter, the relationship between the results from the inventory, the literature review, and the demographic survey will be discussed. The limitations of this research, unexpected results, and suggestions for future research will also be discussed. 
CHAPTER II

\section{LITERATURE REVIEW}

\section{INTRODUCTION}

This chapter will discuss previous research done in the area of intercultural communication competence, pre-departure training, and the effects of culture on communication. This chapter will also provide an overall understanding of the role intercultural communication competence (ICC) plays in intercultural adjustment and adaptability, and how ICC affects training program methodology.

For these reasons this chapter is divided into four sections: first, definitions of sojourner, communication, culture, and intercultural communication; second, a description and definitions of intercultural adjustment and adaptability processes; third, definitions of intercultural communication competence and an overview of the different approaches to ICC studies; and finally, an overview of different pre-departure training programs and their methods. In this section, the methods Walla Walla College's SM program 
uses to train SMs will be discussed.

INTERCULTURAL COMMUNICATION AND THE INELUENCE

OF CULTURE ON COMMUNICATION

\section{DEEINITIONS}

An understanding of who a sojourner is, what culture and communication entails, and the influence of culture on communication is necessary in order to better understand intercultural communication and the influence culture has on communication. For these reasons, it is important to define the terms sojourner, culture, and communication. A basic understanding of these terms will provide a basis for an understanding of ICC and various programs' training methodology

\section{Sojourner}

Furnham (1988) suggests that a definition of a sojourner should be based on two dimensions: length of time in another culture and purpose of living in another culture. According to Furnham, a definition based on those two dimensions help to differentiate between three other groups of people who are often designated as sojourners: tourists, migrants, and refugees. Tourists are individuals who are travelling 
temporarily in another culture. Migrants and refugees are individuals who spend a long period of time in another culture not necessarily intending to return "home." Sojourners, on the other hand, often spend six months to five years at a place, usually intending to return "home."

In addition to a temporal dimension, Eurnham distinguishes between sojourners' purposes or motives and those of tourists. He states that tourists travel for a variety of nonspecific reasons (e.g., relaxation, self-enlightenment). Sojourners' motives, on the other hand, are more specific and goal-oriented. Sojourners' motives usually change when sojourners spend more time in the new culture.

As a part of adjustment to new cultures, sojourners also must learn to communicate when they encounter members of the host culture. Sojourners and host culture individuals deal with many facets of communication when interacting. Because of this, an understanding of communication and the many definitions of communication is necessary.

Communication

There are many definitions of communication. To recapitulate all the past or present definitions (Dance \& 
Larson (1976) found 126 for communication) would be unreasonable. However, it is not unreasonable to mention some of the concepts that are inherent in current definitions of communication. More importantly, many of these basic concepts are vital to an understanding of how culture and communication are mutual components in ICC.

Most traditional definitions of communication refer to the transmission of messages from a source or sender to a receiver. Porter and Samovar (1994) use the terms behavioral source and responder rather than source and receiver. This is an important distinction because previous definitions point out communication as a mechanical transmission of information rather than transmission of information between two behavioral interactants.

Because communication is a behavioral phenomenon, each participant attaches meaning to the messages and is affected by them (Hoopes, 1979; Porter \& Samovar, 1988, 1994; Gudykunst \& Ting-Toomey, 1988). Because those who interact endeavor to make meaningful messages, both the behavioral source and responder use communication as a tool to induce or elicit particular attitudes and behaviors from each other. Consequently, because people are always changing, 
communication is constantly changing. Further, communication is irreversible (i.e., once something is said, it cannot be retrieved), and takes place in a physical and social context (Porter \& Samovar, 1994).

A second view of communication (B. Hall, 1992; Pearce \& Cronen, 1980; Pearce \& Kang, 1988) refers to communication as action rather than the mode for action. Specifically, Pearce and Kang refer to communication "as the generic term for the processes of interpreting one's own and others' actions, and for performing actions that will be interpreted" (p. 25). Participants in the communication process co-create and co-manage social reality, i.e., what participants both believe and believe that other people believe (B. Hall, 1992).

Because participants are constantly recreating and manipulating social reality through interaction, social reality is reliant on interaction and interaction becomes an omnipotent source of everything that is social (B. Hall, 1992). Because communication is omnipotent, it can liberate as well as bind or imprison new ideas. That is why Hall mentions that the "ultimate good or function of communication is to allow for the freedom of creatively extending seminal 
ideas. . .to new ones" (p. 57).

A third view of communication, initially expressed by Hymes (1962) and later by Philipsen (1989), and Carbaugh (1990, 1994), describes how people use language situationally in various cultures. Carbaugh (1994) states that "communication is the primary and situated social process of meaning-making, which occurs in particular forms and yields multiple outcomes" (p. 48). However, Carbaugh does not equate communication with culture: "Each person presents culture, but the social process--between them--of communication. . . is not itself culture" (p. 49). However, even though communication does not equal culture, Carbaugh admits that communication, without reference to setting and positioning, is not possible. Lustig and Koester (1993) suggest another definition of communication. They state that communication "is a symbolic, interpretive, transactional, contextual process in which people create shared meanings" (p. 25). Individuals communicate using symbols (i.e. a verbal or nonverbal unit of meaning) and each symbol is interpreted through a transactional process. Communication is a transactional process of shared creation of messages and meanings and is thus a two-way process where no one person is 
exclusively the sender and the other person exclusively the receiver.

Lustig and Koester further state that communication is contextual, i.e., it includes the actual physical, social, and interpersonal circumstances that the participants are in. These circumstances change and involve a dynamic relationship between people, activities, objects, and experiences. In other words, messages between two interactants are not static and involve various interpretations in different situations. Because of this, messages between interactants can be filled with misunderstanding. Lustig and Koester point out that while misunderstandings abound, shared meanings are created by people as they participate in the communication process.

It is apparent that behavior is a common feature in all definitions of communication. Because communication is a fundamental outgrowth of behavior, it is easier to understand intercultural communication. In order to more fully understand how culture affects behavior, an explanation of culture is necessary. The following section will deal with definitions of culture.

\section{Culture}

Defining culture is as difficult as defining 
communication (Kroeber and Kluckhohn (1952) found 160 definitions for the term). However, most definitions of culture suggest that culture is at least anything shared among a group or community of people (Barnlund, 1994; Gudykunst \& Ting-Toomey, 1988; B. Hall, 1992; Hiebert, 1986, 1993; Lustig \& Koester, 1993; Pearce \& Cronen, 1980; Porter \& Samovar, 1988, 1994).

One perspective of culture focuses on culture as "a historically transmitted system of symbols, meanings, premises, routines, and rules. . ." (Philipsen, 1989, p. 260). Shared meanings within each society or group are vital to the ongoing historical and relational changes each society or group faces as each generation passes consistent social information to successive generations. We maintain society or group membership by learning about the rules, values, and expectations of conduct through the social information perpetuated by the group (Collier, 1994). This social information is observable as particular groups within a given society interact.

A second definition of culture states that "culture is a script or schema shared by a large group" (Gudykunst \& Ting-Toomey, 1988, p. 30), or "a deposit of knowledge, 
beliefs, values, attitudes,. . .acquired by a large group of people in the course of generations through individual and group striving" (Porter \& Samovar, 1988, p. 19). According to Lustig and Koester (1993), this deposit, script, or schema is in the minds of the individual communicators and must be shared (acted upon) with a large group of people. This shared deposit of ideas affects behavior and is developed by the group to assure its survival in a particular physical and human environment (Hoopes, 1979).

A third, more anthropological view of culture emphasizes the ongoing transformation of its members (Pearce \& Cronen, 1980; Cronen, Chen, \& Pearce, 1988). Culture is never static and its members continually exhibit diversity in their shared life experiences (B. Hall, 1992). Through communication a given set of beliefs have meaning (Pearce \& Kang, 1988). Furthermore, culture is closely related to the social realities within a given society and is in fact "the overriding social system or reality that encompasses all social variables" (B. Hall, 1992, p. 54). In other words, culture is not one of many variables within society, but is the prevailing force that dictates social reality.

There is a distinct similarity between the second and 
third definitions above. While the second definition focuses on the communication of symbols, etc., common to one cultural environment, it also suggests a facet of culture similar to the third definition, i.e., that culture is constantly changing (never static) as a result of the interactants in the culture.

Some important concepts can be inferred from these three definitions of culture. Because cultures change and individuals within cultures change, it is consistent to believe that all participants that are involved in culture, whether host or sojourner, change culture because of their involvement in it. Individuals and groups strive together and share life experiences. Life experiences change as participants interact and culture is never the same after host culture individuals and sojourners who come from different backgrounds share experiences from their respective native cultures.

It would seem, therefore, that culture without communication and communication without culture is impossible. Because cultural information is not simply a transmitted system of symbols, etc., but something that involves change and interaction, it is important to define 
intercultural communication and comment on the influence of culture on conmunication.

Intercultural Communication and Culture's Influence on communication

Numerous definitions of intercultural communication exist. Most definitions refer to intercultural communication as communication that occurs between people from different cultural backgrounds (Barnlund, 1994; Hiebert, 1986, 1993; Hoopes \& Pusch, 1979; Lustig \& Koester, 1993; Porter \& Samovar, 1994). However, intercultural communication has many dimensions. First, understanding culture's influence on communication or intercultural communication involves an understanding of the circumstances or context that participants are in and have grown up with. Previous studies of intercultural communication (E.T. Hall, 1988, 1989, 1989, 1990, 1990; Hofstede \& Bond, 1984; Lustig, 1988; Lustig \& Koester, 1993; Porter \& Samovar, 1994; Rokeach, 1973; Smart, 1988; Triandis, 1988, 1990; Zavalloni, 1980) have focused on one or more of the following dimensions of intercultural communication: language meaning and use, religious traditions, values, social behavior (the relative emphasis on individualism or collectivism), orientation to personal space 
and time, the means used to adapt to changes and cope with uncertainties, or all nonverbal behaviors used to emphasize the verbal message.

These dimensions vary based on the degree of difference between people from dissimilar cultures. Specifically, Lustig and Koester state that people are from dissimilar cultures

whenever the degree of difference between them is sufficiently large and important that it creates dissimilar interpretations and expectations about what are regarded as competent communication behaviors. (p. 58)

How extensive these cultural differences are, what constitutes cultural differences, and the effect exterded communication has on creating a set of common understandings in the new culture are all important factors when determining competent communication behaviors. These factors, along with Lustig and Koester's initial definition of communication (i.e., a symbolic, interpretive, transactional, contextual process in which people create shared meanings), yield the following definition of intercultural communication:

Intercultural communication is a symbolic, interpretive, transactional, contextual process in which the degree of difference between people is large enough and important enough to create dissimilar interpretations and expectations about what are regarded as competent behaviors that 
should be used to create shared meanings. (p. 58) While the degree of difference between people of dissimilar cultures can be extreme, the degree of difference between people who are members of the same dominant culture can be equally extreme as reflected in different subcultures or subgroups (Porter \& Samovar, 1988, 1994). Lustig and Koester (1993) regard this aspect of communication as intracultural, interethnic, or interracial communication and suggest these concepts are all part of the broader concept of intercultural communication.

This research is concerned with the broader concept of intercultural communication as it pertains to interpersonal communication between people from two distinct dominant cultures (e.g., Japanese and United States). Distinctions might appear between participants' intercultural communication competence who are, for example, African-American and Caucasian-American. If ethnic background is found to be a possible factor, it will be discussed in the results of this research.

In light of Lustig and Koester's definition of intercultural communication, it would follow that dissimilar interpretations and expectations play a part in sojourners' 
successful or unsuccessful adjustment and adaptation in foreign cultures. In the next section, definitions of the processes of intercultural adjustment and adaptation will be discussed.

\section{THE PROCESSES OF INTERCULTURAL ADJUSTMENT AND ADAPTATION}

There are fundamental dimensions of living and working in another culture that include the ability to adjust and adapt to that culture (Cui \& Awa, 1992; Hannigan, 1990). Because most sojourners go through a period of adjustment and seek to adapt to the culture they are in, it is important to discuss these dimensions individually.

\section{Adjustment}

Encounters with another culture are filled with uncertainties and surprises and the idea of living in a new culture can be confusing and emotionally disabling. Cross-cultural trainers often identify four different sojourner responses to culture shock: 1) fight, i.e., an extremely hostile stance toward the host nationals, 2) flight, i.e., retreating from interaction with the host culture and associating only with members of one's own 
culture group or even going home early, 3) going native, i.e., abandoning one's own native cultural identity and attempting to adopt host culture attitudes, etc., in every way, or 4) adaptation, finding ways to appropriately adjust behavior and comprehend another culture while maintaining adequate identity with one's own culture (J. Bennett, 1977; Grove \& Torbiorn, 1993; Hoopes, 1979).

While these researchers consider adapting to the host culture the most appropriate response, adjusting to a new culture can be one of the most frustrating and debilitating aspects of living in a new culture. Oberg (1960) is generally credited with introducing the term of culture shock. Oberg views culture shock as "an occupational disease of people who have been suddenly transplanted abroad" ( $p$. 177).

However, the process of this disorientation and confusion has been called many other things including cultural fatigue (Guthrie, 1975; Taft, 1977), transition shock (J. Bennett, 1977), role shock (Byrnes, 1966), and pervasive ambiguity (Ball-Rokeach, 1973). Notwithstanding these efforts to minimize negative connotations, some researchers claim that the term culture "shock" is a loaded 
term and includes negative connotations (Adler, 1987; Furnham, 1988; Grove \& Torbiorn, 1993; Stewart, 1977). Perhaps this represents the negative outlook many have of intercultural training (IT) programs that emphasize the need to overcome the negative things that might occur when in a new cultural environment.

Stewart (1977) suggests that IT programs often treat culture shock as a disease or problem. Because people consider culture shock a disease, overcoming culture shock is seen as a matter of survival, not an opportunity for inner growth and cross-cultural learning. However, as many researchers suggest, sojourners can transform the dissonant and often disruptive aspects of living in a culture different from their own into a positive cross-cultural learning experience (Adler, 1987; J. Bennett, 1977; Stewart, 1977; Weaver, 1993). Ruben and Kealey (1979) also suggest a positive definition of adjustment by saying it is

the general psychological well being, self-satisfaction, contentment, comfort with, and accommodation to, a new environment after the initial perturbations which characterized culture shock have passed. (p. 21)

In other words, rather than something negative, adjustment is a comfort level sojourners attain after dealing with the 
minor problems of culture shock. In addition, adjustment is transitory and is a natural part of intercultural adaptation (Cui \& Awa, 1992; Dodd, 1991; Grove \& Torbiorn, 1993; Hannigan, 1990; Ruben \& Kealey, 1979).

\section{Adaptation}

Researchers differ on what they consider the dimensions of cross-cultural adaptation. Ruben and Kealey (1979) suggest cross-cultural adaptation has three dimensions: psychological adjustment, culture shock, and intercultural effectiveness. Grove and Torbiorn (1993) share similar views and suggest that cross-cultural adaptation involves sojourners' motivation, both cognitively and psychologically. According to Grove and Torbiorn, adaptation includes the willingress to accept a new frame of reference, along with social changes, that results from interaction with the host culture.

Kim (1988, 1989, 1994) believes sojourners adapt through an ongoing process of stress, change, and growth. This process is cumulative-progressive and usually follows the initial shock experience. According to Kim (1988, 1989, 1994), cross-cultural adaptation is cumulative-progressive because it is an accumulation of positive and negative 
experiences that do not follow a straight path. Kim (1988) states: "Stress, adaptation, and growth, together, define the internal dynamics of strangers' cross-cultural experiences in a 'draw-back-to-leap' pattern similar to the movement of a wheel" (p. 56).

In other words, sojourners are always adjusting. Full cross-cultural adaptation is never something one fully attains because the adaptation process involves a transformation of individuals through successive degeneration and regeneration. Cui and Awa (1992), on the other hand, view cross-cultural adaptation as a multidimensional process in which functional success is assured if sojourners can overcome stress, cope with the environment sufficiently, feel at home in the new culture, and assimilate.

While it may seem pessimistic to some that sojourners will always need to adjust and that full cross-cultural adaptation is never fully attained, Kim's definition seems to more closely reflect the experience many have had living in another culture. There is a sense of feeling somewhat at home in a new culture, but there is also the sense that at any given moment you will take a step backward. While many sojourners have overcome some stress, there is a new 
experience waiting for all sojourners that will test and occasionally overwhelm them.

This is not to suggest that Kim's definition is overly pessimistic. Because many participants in this research have not been overseas and will not be able to reflect on past overseas experiences, it is possible that they will inaccurately assess their own intercultural adjustment and adaptation abilities.

\section{INTERCULTURAL COMMUNICATION COMPETENCE}

DEFINITIONS

\section{Intercultural Communication Competence}

Reviews of past intercultural communication competence (ICC) studies point out the different approaches toward ICC, the lack of clarity in which ICC has been defined, and the inappropriateness of some of the approaches used in ICC research (Collier, 1989; Dinges, 1983; Imahori \& Lanigan, 1989; Lustig \& Koester, 1993; Ruben, 1989; Spitzberg, 1989). Spitzberg (1989) makes the point that, to date, ICC research is "not very cumulative, possibly duplicative and avoidant of attempts to integrate research and theory across studies and perspectives" (p. 243). While this may be true, there are 
certain fundamental characteristics that researchers seem to agree on which have led to some basic definitions of ICC.

ICC has been most closely related to appropriateness, success, or effectiveness in the host culture (Hannigan, 1990; Imahori \& Lanigan, 1989; Ruben \& Kealey, 1979; Spitzberg \& Cupach, 1984; Triandis, 1983). Further, ICC demands sufficient knowledge, suitable motivations, and skilled actions (Lustig \& Koester, 1993). Interpersonal factors such as empathy, communicative skill, ability to cope with stress, ability to display respect of other cultures, ability to tolerate ambiguous situations in other cultures, and the ability to display nonjudgmentalness contribute to effectiveness (Hannigan, 1990; Ruben, 1987; Ruben \& Kealey, 1979). Hannigan further says that cross-cultural ineffectiveness is a result of factors such as ethnocentrism, inflexibility, task-related behavior, perfectionism, narrow-mindedness, dependent anxiety, and self-centered role behaviors.

Some researchers measure effectiveness by job performance i.e., if sojourners are performing their job functions well, then they are effective in that new culture (Harris, 1973; Hawes \& Kealey, 1981). Cui and Awa (1992) 
point out that cross-cultural adjustment and job performance are correlated. However, Cui and Awa also state that cross-cultural adaptation is a much larger process. According to cui and Awa, to be interculturally successful a person should be able to act appropriately and effectively in the host culture.

According to Kim (1988), appropriateness and effectiveness are two interrelated elements of ICC. Appropriateness refers to the interactants' perception that they understand the substance of their encounter while feeling their values or norms have not been compromised too thoroughly. Effectiveness, on the other hand, refers to the interactants' ability to remain true to specific cultural norms for specific roles or tasks in a given context.

Kim distinguishes ICC from actual intercultural communication performance (ICE). Competence is something that individuals perceive themselves as either capable or not capable of doing, while performance is based on actual behavior in particular situations. Kim believes that ICC (or host communication competence as she calls it) is the foundation for sojourners' ability to manage conditions around them correctly. ICC should be examined in detail by 
analyzing the nature of the goals of intercultural interaction and its four key empirical indicators (Kim, 1988). Kim suggests these indicators determine sojourners' performance in host cultures. These indicators are:

1) knowledge of the host communication system, i.e., the capacity of strangers to identify and understand messages in different situations of interaction with the host environment,

2) cognitive complexity in responding to the host environment,

3) affective (emotional, aesthetic) co-orientation with the host culture, i.e., motivational readiness and emotional participation in the cultural values, attitudes, and aesthetic/emotional experiences of the host culture,

4) behavioral capability to perform various interactions in the host environment, i.e., the ability to select behaviors that are effective and appropriate in various social situations. (pp. 85, 86)

According to some researchers, ICP is a perceived evaluation of sojourners' ability to act appropriately and effectively in host cultures (Hammer, 1989; Kim, 1988; Lustig \& Koester, 1993; Spitzberg \& Cupach, 1984; Spitzberg, 1989, 1994). Specifically, Spitzberg and Cupach (1984) suggest:

The perception of competence is a graduated phenomenon in which behaviors, affective responses, and cognition are enmeshed within an unfolding dynamic process of conversation. This dynamic process leads to impressions of a person or conversation as more or less appropriate and 
effective. (p. 109)

In other words, sojourners are perceived by host culture individuals as interculturally competent or incompetent through the dynamic process of interaction between sojourners and host culture individuals.

This points to some new conceptualizations regarding ICC. Because contact between two individuals from distinctly different cultures involves communicative interaction, some researchers do not distinguish between ICC and ICP (Imahori \& Lanigan, 1989; Lustig \& Koester, 1993; Spitzberg, 1989; Spitzberg \& Cupach, 1984). For them, ICC includes performance in the host culture environment. Competence is not an individual attribute and can not be separated from the relationships and situations within with communication occurs (Lustig \& Koester, 1993). Imahori and Lanigan (1989) point out that competence cannot be measured unilaterally because "to achieve competence both parties' needs must be fulfilled, . . to actively participate in the exchange" (p. 273). This emphasis points to a bilateral model of ICC competence and the following definition of ICC:

intercultural communication competence is the appropriate level of motivation, knowledge, and skills of both the sojourner and the host-national in regards to their relationship, leading to an 
effective relational outcome. (pp. 276-277)

Kim (1991), on the other hand, suggests that too much emphasis has been placed on the relational aspect of ICC. According to Kim, the conceptualization of outcome-oriented communication competence (i.e., Imahori \& Lanigan, 1989; Spitzburg \& Cupach, 1984), based on perceived appropriateness and effectiveness, does not take into account the fact that "different decoders may assess the same person's competence differently. . .by the same decoder in different situations" (p. 262). In other words, judgments of sojourner ICC can vary among host culture individuals and even with one host culture individual's experiences with the sojourner over different interactions. One host culture individual's judgment of a sojourner's ICC could be different than another host culture individual's. Additionally, one host culture individual's judgment could even change depending on the situation and the sojourner's response to the host culture environment.

Furthermore, Kim believes the relational or successful outcome view of ICC diverges from a true definition of competence in intercultural situations. Specifically, Kim states that the relational view of ICC "tends to blur the 
principle of multilateral causality in the interpersonal communication system" (p. 263). In other words, the relational view tends to overemphasize cross-cultural interaction as the basis for all interpersonal communication while at the same time suggesting that all effective interaction is a matter of perceived effectiveness, success, or appropriateness.

According to Kim, "ICC must be viewed as located within the person as his or her capability to communicate with individuals from other cultures" (p. 270). For Kim then, ICC is not just perceived on the part of the host culture individual, but is something the sojourner senses about his or her cognitive, affective, and behavioral capabilities in another culture. This is an important distinction. Because sojourners' perceived effectiveness is a judgement (perhaps clouded by host culture individual biases) about sojourners' interaction abilities, Kim believes the relational view of ICC does not place enough emphasis on the sojourners' sense of their own interaction abilities.

The differences between Kim and those espousing the relational view of ICC are significant and lead many researchers to conclude that ICC is made up of many facets. 
According to Ruben (1989), the different facets of ICC may include building and maintaining positive relationships, transmitting information with minimal loss of meaning, or reaching an appropriate level of compliance and/or cooperation through persuasion. Ruben points out that these facets may be related conceptually and empirically, while remaining distinct in theory, research selection, and training contexts.

Distinctions in theory, research, selection, and training have led many to approach ICC differently. These approaches have been essential in the creation of many cross-cultural training programs. According to Lustig and Koester (1993) there have been four major approaches used to research ICC: the trait approach, perceptual approach, behavioral approach, and culture-specific approach.

Because each approach contributes to an overall understanding of ICC, it is important to discuss each approach individually. This will also help to suggest how Walla Walla College SM program sponsors view ICC and how they select individuals as SMs. In the next section, each of these approaches (including Walla Walla College's approach to ICC) will be discussed individually. 


\section{TRAIT APPROACH}

One approach commonly used in missionary training programs to select and train missionary personnel has been the trait approach (Cleveland, Mangone, \& Adams, 1960). Those who espouse the trait approach suggest that people who are interculturally competent have the appropriate personality traits or attributes that help them succeed in an intercultural context. These traits include such aspects as cultural sensitivity, adaptability/flexibility in thinking, motivation, extroversion, interest in foreign cultures, and emotional and social stability in one's own culture (Cleveland, Mangone, \& Adams; 1960; Gardner, 1962; Guthrie and Zektick, 1967; Harris, 1973; Ivancevich, 1969; Maretzki, 1965).

Selecting personnel to fill overseas posts (e.g., businesspeople, students, etc.) becomes quite easy if generalizations regarding sojourners' individual personality traits can be made. Iists of ICC attributes would be created and the absence or presence of any of those attributes would indicate who would probably be successful or unsuccessful in another culture.

However, as Spitzberg (1989) points out, many lists "are 
derived from the a priori conceptions of the authors or those who have gone overseas rather than empirically validated components" (p. 243). In other words, using the trait approach, sojourners' ICC is based on a preformulated and generalized conception of what traits constitute ICC. Whether a person possesses or does not possess these personality and social traits determines who is more or less competent.

Lustig and Koester (1993) suggest that, while it is rather simple to generalize and to select personnel for overseas assignment based on a predetermined set of personality or social attributes, ICC is more complex than that. For example, individuals behave differently in each encounter and traits that are typical of competent behavior in some cultures (e.g., extroversion) might not be considered competent behavior in other cultures.

\section{ATTITUDINAL/PERCEPTUAL APPROACH}

Gudykunst, Wiseman, and Hammer's (1977) research focuses on attitude theory as the basis for attitudinal satisfaction in another culture (see also Abe \& Wiseman, 1983; M. Bennett, 1993; Hammer, Gudykunst, \& Wiseman, 1978; Martin, 1987; 
Wiseman, Hammer, \& Nishida, 1989). Lustig and Koester (1993) point out that the attitudinal/perceptual approach emphasizes the importance of the emotional or motivational dimension prevalent in sojourners who possess competent behaviors.

Sojourners' behavior can be related to three attitudinal dimensions associated with ICC: ability to deal with psychological stress, ability to communicate effectively, and willingness to establish interpersonal relationships. According to Gudykunst, et al. (1977), these three attitudinal dimensions of sojourners' cross-cultural attitude can be divided into three components: affective, cognitive, and conative. They further state that these three components make up a "third-culture perspective" which is fundamental to sojourners' attitude toward another culture.

The first part of sojourners' cross-cultural attitude, i.e., the affective (evaluative) component is, according to Gudykunst, et al. (1977), the psychological perspective that sojourners use to evaluate intercultural encounters. This component corresponds to the feeling or emotional aspect sojourners have towards the host culture. It includes tolerance for ambiguity, flexibility, sensitivity, and the ability to defer judgment (Martin, 1987). As a factor in 
sojourners' cross-cultural attitude, the affective component is based on sojourners' degree of ethnocentrism (Wiseman, Hammer, \& Nishida, 1989). According to Gudykunst and Kim (1984) ethnocentrism is the "tendency to identify with our ingroup and to evaluate out-groups and their members according to the ingroups' standards" (p. 92).

However, as an integral part of the cross-cultural attitude, Hoopes (1979) suggests that each person has an attitude toward another culture along a continuum that begins at ethnocentrism and ends with assimilation, adaptation, biculturalism, or multiculturalism. According to Hoopes, through training and experience people can learn to grow from being ethnocentric to being assimilative, adaptive, bicultural, and multicultural, thus changing their attitudes.

The second part of sojourners' cross-cultural attitude, i.e., the cognitive component, includes stereotypes or perceptions sojourners have of the host culture (Gudykunst, Wiseman, \& Hammer, 1977). Barna (1994) states that stereotypes are stumbling blocks to interaction and are

overgeneralized, second-hand beliefs that provide conceptual bases from which we "make sense" out of what goes on around us, whether or not they are accurate or fit the circumstance. (p. 341)

According to Martin (1987), stereotypes involve three areas: 
1) the knowledge sojourners have of the other culture, 2) self-awareness regarding one's own beliefs and values (i.e., identifying with one's own culture), and 3) knowledge of cultural differences and the impact these have on intercultural interaction.

These three areas reflect on sojourners' cultural upbringing and the dimensions of cultural variability among cultures. According to Paige (1993), the challenge of training sojourners is to help them integrate alternate cultural frames of reference into their life. By such integration, sojourners can remove harmful stereotypes.

The third part of sojourners' cross-cultural attitude, i.e., the conative component, refers to sojourner behavioral tendencies when interacting with the host culture. This includes the behaviors and actions exhibited when communicating with host culture individuals (Wiseman, Hammer, \& Nishida, 1989). Wiseman et al. refer to this component of the cross-cultural attitude as the degree of social distance sojourners feel toward the host culture and vice versa. The greater the social distance felt toward a person from another culture, the more inaccurate information will be gathered, thus increasing misunderstanding and ethnocentrism. 
Therefore, sojounners who possess a fully developed third-culture perspective will not easily accept inaccurate information based on stereotypes, prejudge the people they are interacting with, or exhibit ethnocentric behavior. They will be sensitive to the differences they might have with host culture individuals, build and maintain relationships with host culture individuals, and effectively manage cross-cultural psychological stress and strive to deal with difficulties associated with cross-cultural stress.

\section{BEHAVIORAL APPROACH}

Lustig and Koester (1993) point out that those who espouse the behavioral approach to ICC "suggest that it is necessary to go beyond what people think they do in intercultural interactions and observe what they actually do" (p. 65). Characteristics of ICC that reflect behavioral psychology have been suggested by various researchers (Abe \& Wiseman, 1983; Grove \& Torbiorn, 1993; Hammer, 1984; Hoopes, 1979; Kealey, 1989; Koester \& Olebe, 1988; Martin \& Hammer, 1989; Olebe \& Koester, 1989; Ruben, 1976; Ruben \& Kealey, 1979). The behavioral approach to ICC is in contrast to other approaches to ICC where self-reporting measures alone 
are considered adequate to measure ICC.

Because behaviors are the most appropriate criterion of measuring ICC, Koester and Olebe (1988) find that the strength of the behavioral approach is the ability to perceive and assess sojourner intercultural communication effectiveness from a variety of vantage points, including those of participants, expert observers, organizational directors, clients (or representatives of clients), and even the sojourners themselves (p. 237).

Because intercultural communication effectiveness is perceived from different vantage points, Ruben (1976) adds that behavioral competencies reflect on sojourners' abilities to exhibit behavior rather than their intentions, understanding, knowledge, attitudes, or desires. In other words, the most significant reflection of sojourners' attitudes, etc., is based on sojourners' actions not on what they merely think.

Researchers, including Ruben, have developed measures that assess behaviors that sojourners display in intercultural communication settings (Hammer, 1984; Koester \& Olebe, 1988; Ruben \& Kealey, 1979). In Ruben's measure there are nine dimensions of communication skills associated with 
behavioral competence: display of respect, interaction posture, orientation to knowledge, empathy, task related roles, relational roles, individualistic roles, interaction management, and tolerance for ambiguity. Other researchers have used Ruben's behavioral assessment measure as a means to establish their own measures, as well as a basis for their own studies in ICC.

One of these measures, developed by Koester and Olebe (1988) is a reformulation of Ruben's instrument. It is called the Behavioral Assessment Scale for Intercultural Communication (BASIC). In this instrument, Koester and Olebe rework Ruben's dimensions of intercultural communication effectiveness measures in order to make them usable by nonexpert peer observers (Koester \& Olebe, 1988; Olebe \& Koester, 1989). One of the original Ruben scales, individualistic roles, is discarded. All other general items in the BASIC are similar to Ruben's instrument.

Research closely reflecting Ruben's (1976), yet focusing on a group of technical advisors and spouses assigned to an overseas post over a two-year period, was done by Ruben and Kealey (1979). They suggest that particular communication behavioral skilis lead to greater effectiveness and ease in 
adjustment. Sojourners who were observed to possess behavioral skills such as respect, tolerance of ambiguity and non-judgmentalness appeared to be more effective in their assignments than sojourners who lacked those qualities.

Kealey (1989), building on earlier research (Ruben \& Kealey, 1979; Hawes \& Kealey, 1981), points out that there is "empirical support for the validity of a behavioral as opposed to a self-report measure of personality related characteristics" (p. 390). In addition, Kealey states that

Personality variables have clearly been shown to influence how individuals interpret situations and certain personality variables, and in turn, were found to be predictive of these different interpretations. (p. 423)

In other words, because personality variables are instrumental in interpreting situations, Kealey believes that personality traits are inseparable from effective cross-cultural interaction.

However, whereas other behaviorists claim that training can change one's skill level or knowledge, Kealey claims that sojourner must first possess certain personality traits. Otherwise, no amount of training will ever enable them to effectively transfer skills and knowledge when dealing with people of another culture. 
This research relies solely on behaviorally-based self-reporting measures, a demographic survey, observations of an audiotaped pre-departure class session, and interviews with SM program sponsors; there are no host culture participant observations of sojourners. Further behavioral research, involving host culture participants' observations of SMs, along with interviews of sponsors and host culture participants, would be necessary to more fully evaluate walla Walla College's SM program.

CULTURE SPECIFIC APPROACH

Lustig and Koester (1993) point to Triandis' work, among others, as the best representation of the culture-specific approach (Albert, 1983; Fiedler, Mitchell, \& Triandis, 1971; Triandis, 1983). As a basis for the culture specific approach, Triandis (1983) claims that some methods of measuring cultural appropriateness are culture specific. In other words, some methods of measuring cultural appropriateness deal with concepts, stimuli, and actions that are common in a particular culture. When sojourners go into another culture they learn culture-specific communication rules, rituals, and skills of verbal and nonverbal expression 
that are practiced by host culture individuals (Hammer, 1989; Lustig \& Koester, 1993).

Because values and norms change within cultures, then values and norms across cultures also will change and will not be universal, i.e., generalizable across cultures (Albert, 1983; Triandis, 1983). Interpretation of norms and values are also critical. Eor example, what is considered a compliment in one culture can be seen in another culture as an attempt to manipulate, and a gift can be seen as a bribe (Albert, 1983). Because all people are subjective in relation to their own culture, the "major goal of intercultural training is to help individuals understand. . . and to teach them about the other's subjective culture" (Albert, 1983, p. 188).

In other research, Abe and Wiseman (1983), in an attempt to generalize Hammer, Gudykunst, and Wiseman's (1978) research on intercultural effectiveness, suggest that there is evidence for both culture-general and culture-specific components. While Hammer et al. suggest that there are three components of intercultural effectiveness, i.e., the abilities to deal with psychological stress, to communicate effectively, and to establish interpersonal relationships, 
Abe and Wiseman maintain that the Japanese sample they studied reveals that there are five dimensions of intercultural effectiveness: the ability to communicate interpersonally, the ability to adjust to different cultures, the ability to deal with different societal systems, the ability to establish interpersonal relationships, and the ability to understand another. Abe and Wiseman do see some correlation with some of their dimensions and those of Hammer et al., but point to any differences with Hammer et al. as evidence for a culture-specific approach as well as a culture-general approach.

Lustig and Koester (1993) agree that there is evidence for both a culture-general and a culture-specific interpretation for intercultural communication competence (ICC). First, ICC is culture-specific (contextual) i.e., made in respect to specific relational and situational contexts. Second, ICC is culture-general in that it requires culture-general behaviors that are both appropriate and effective. Third, while sojourners require knowledge about the people and appropriate behaviors associated with a particular culture, the culture-general approach provides important valuable "insights into the intercultural 
communication process abstractly and can be a very powerful tool in making sense of cultural practices, regardless of the cultures involved" (Lustig \& Koester, p. 69). Furthermore, it is important to assume that generic skills associated with ICC will apply. In other words, there are behaviors, attitudes, and traits that are universal, i.e., applicable to all cultures.

This research will focus on a culture-general interpretation. First, the inventory used is culture-general and focuses on generic behaviors universally applicable. Second, the pre-departure training that the SMs receive is culture-general. Future research will need to be done in order to assess SMS' culture-specific ICC.

\section{WALLA WALLA COLLEGE'S APPROACH}

In this section, I will discuss the approach Walla Walla College uses to assess SMs' ICC. Because the SM program at Walla Walla College does ask SMs to go through an evaluation process to deem their appropriateness for service overseas, an understanding of Walla Walla College's approach in assessing SMS' ICC is important.

Walla Walla College's student missionary 
pre-departure program sponsors use the trait approach to assess participants' ICC. Program sponsors' evaluation involves administration of an individual, personality trait, self-assessment inventory. Prospective SMs are then asked to discuss with the college chaplain (who is also the SM program director) the results of the inventory. It is his assessment, the assessments of a screening committee (made up of the school chaplain, dormitory deans, the ESL program director, the SM director, as well as others involved in the SM program), and the assessments of people who know prospective SMs personally, that helps determine whether or not prospective SMs possess the appropriate traits needed for being an SM.

The people who know prospective SMs personally are asked to assess SM personality traits and fill out a recommendation form based on a five-point scale: excellent, above average, average, below average, or poor. This scale grades prospective SMS' personalities in the following thirteen general areas: their spiritual influence; spiritual commitment; attitude toward church structure, doctrines, and standards; judgement; dependability; leadership potential; cooperation; initiative and resourcefulness; intellect; 
personality; adaptability; appearance; and emotional stability

Those who assess SMs are also asked to underline specific qualities that prospective SMs demonstrate. These include whether or not prospective SMs possess a positive Christian influence, are extroverted, stable, well-groomed, flexible, quick, confident, natural born leaders, mature, active supporters of the church, and dedicated spiritual individuals.

INTERCULTURAL TRAINING AND INTERCULTURAL TRAINING APPROACHES

In order to better understand Walla Walla College's pre-departure training program for student missionaries (SMs), it is important to define intercultural training (IT) and plot the different intercultural training methods used in most IT programs. After defining and discussing the various training processes prevalent in most IT programs, the type of training Walla Walla College uses in training SMs before they begin their assignments overseas will be discussed.

DEFINITIONS

IT has been classified in different ways depending on 
the goals and objectives intercultural specialists emphasize. The controversy centers around not only the goals (cognitive, affective, and behavioral) and content (culture-general or culture specific), but also the process (experiential or intellectual), of IT (J. Bennett, 1986; Brislin, Landis, \& Brandt, 1983; Gudykunst \& Hammer, 1983; Paige, 1993).

The goals of IT are, according to Brislin, Landis, and Brandt (1983), to effect changes in people's thinking (cognitions), their affective reactions (feelings), and their behavior. These changes are achieved by the content of IT programs (either culture-general, culture-specific, or both), as well as the process trainers use (experiential, intellectual, or both) (J. Bennett, 1986). IT programs stress different processes to achieve effective training goals.

There are many definitions of IT. Some researchers make a distinction between IT and intercultural education (IE) (Harrison \& Hopkins, 1967; Kohls, 1980; Nadler, 1970). They point out that IT contains value/emotive and social interaction components and is experiential, while IE is didactic and contains cognitive educational components about the customs, institutions, and norms of a culture. 
However, Gudykunst and Hammer (1983) note that many researchers do not distinguish between IE and IT sufficiently and for this reason many definitions of IE and IT are very similar. Therefore, Gudykunst and Hammer use the term "training" broadly to include some activities that have typically been considered educational, i.e., didactic. In order to distinguish between various training schemata, Gudykunst and Hammer propose a classification scheme for training techniques. The scheme involves four quadrants that are created by cross-classifying two axes. These four quadrants are: 1) Culture General-Experiential, 2) Culture Specific-Experiential, 3) Culture General-Didactic, and 4) Culture Specific-Didactic.

To understand Gudykunst and Hammer's classification of training programs is important when classifying the kinds of training programs available, as well as classifying Walla Walla College's training program. There are several distinct approaches to IT that trainers currently use. These include: 1) the intellectual approach, 2) the area training approach, 3) the self-awareness approach, 4) the cultural awareness approach, and 5) the integrated or multidimensional approach. Gudykunst and Hammer's four quadrants help to distinguish 
between each of these approaches.

Janet Bennett (1986) extends Gudykunst and Hammer's quadrants and more fully distinguishes between three widely used models of IT: orientation, training, and education. According to Bennett, those who view IT as orientation emphasize intellectual goals and use the intellectual method of conveying culture-specific content to prospective sojourners. Those who view IT as training are interested in affective goals, and use experiential methods to train sojourners in "how" to survive in another culture. Finally, those who view IT as education blend the previous two approaches, emphasizing both cognitive and affective goals, employing experiential and didactic methods, and using culture-specific and culture-general contexts. Because Bennett believes that IT as education most adequately fulfills the functions of IT, she claims that the most appropriate approaches to IT are educationally-based.

Based on Bennett's evaluation of different IT methods and Gudykunst and Hammer's classification of these methods, it is important to examine, evaluate, and classify the different approaches to IT. An examination of various IT approaches will help to differentiate current IT approaches 
with the approach Walla Walla College uses to train SMs. In the next section, current approaches to IT (including the approach to IT Walla Walla College uses in their program) will be categorized (using Gudykunst and Hammer's quadrants) and evaluated (using Bennett's criteria).

\section{INTELLECTUAL APPROACH}

The intellectual approach to IT has been popular for many years. Proponents of this approach assume that sojourners can obtain a cognitive understanding of another culture through traditional courses about the culture to which they are assigned. This approach corresponds with Gudykunst and Hammer's (1983) culture-general didactic and culture-specific didactic quadrants.

According to Brislin, Landis, and Brandt (1983), in a cognitively-based approach to IT trainees are introduced to various facts about the country through lectures, group discussions, video tapes, and reading materials. These facts can include, for example, information about the country's economy, climate, quality of life issues, differences in host behavior from that of the sojourner, decision-making styles, and typical experiences and problems sojourners face 
overseas.

A culture-specific didactic approach that is an outgrowth of the intellectual approach is Albert's (1983) culture assimilator. The assimilator has sojourners select among four responses to "critical incidents" or episodes, three of which are from the sojourners' point of view and one that represents the response of the host culture individual. These episodes describe interactions between people from two cultures followed by alternative attributions (or inferences) to their behaviors. It is from these attributes that trainees interpret both their own and host culture individuals' behavior, and thus expand trainees' conceptions of possible attributions in any given situation (Albert \& Triandis, 1994).

The advantages of the intellectual approach to IT have made them very popular over the years. According to Bennett (1986), the methods involved are very accessible; i.e., they can be directed by anyone, they meet sojourners where they are, and they satisfy the need to know more cultural information (see also Brislin \& Pederson, 1976).

However, the limitations of the intellectual approach are clear. According to Bennett, there is "the lack of 
congruence between an individual's living experience abroad and the classroom environment" (p. 123). The classroom environment fails to deal adequately with the emotional issues and the problems associated with actually dealing with the host culture. Further, while those using the intellectual approach to IT convey knowledge about the culture, they usually do so in generalizations about the culture, failing to deal with actual overseas situations.

\section{AREA TRAINING APPROACH}

The area training approach to IT incorporates simulation training, experiential learning, and bicultural intercultural communication at either an in-country site or a simulation of it (Brislin, Landis, \& Brandt, 1983; Gudykunst, Hammer, \& Wiseman, 1977; Gudykunst \& Hammer, 1983). The area training approach corresponds with Gudykunst and Hammer's culture-specific experiential quadrant and, unlike the intellectual approach, accentuates affective goals, culture specific content and experiential processes (J. Bennett, 1986). In addition, Bennett states, "the trainees are active participants in the learning, which is derived from experiences in the here-and-now in which the trainees are 
involved" (p. 124).

There are several advantages to using area training. Area training is trainee-centered rather than trainer-centered; i.e., trainees must reflect on their own experiences and draw conclusions based on those experiences. Second, area training requires trainee responsibility for the learning process and is based on problem solving skills rather than information transmission (trainers are facilitators and trainees have to discover and solve problems for themselves when they occur). Third, area training helps trainees learn how to learn (trainees test themselves during training and learn to handle problems independently from trainers) (Bhawuk, 1990; McCaffery, 1993; Trifonovitch, 1973). Finally, area training is readily observable; i.e., aspects of the host culture are readily accessible and the host culture individuals involved in the training enable trainees to experience cross-cultural interaction first hand (Brislin, Landis, \& Brandt, 1983).

Criticisms of simulation and in-country training are similar and result mainly from financial considerations. Because organizations wishing to train their employees for overseas assignments can not readily afford to send trainees 
to host culture training sites around the world, trainees have little opportunity to participate in an intensive host culture residential training program (J. Bennett, 1986; Brislin, Landis, \& Brandt, 1983). Similarly, these organizations can not readily afford to bring host culture individuals to reenact host culture behaviors in simulations of the host culture.

There are further criticisms of the area training or experiential approach to IT (e.g., J. Bennett, 1986; Bhawuk, 1990; MCCaffery, 1993). First, McCaffery points out that while the experiential approach has been very effective, those trainees who have a high educational level, e.g., those with college degrees, going directly into graduate school, are less likely to appreciate experiential learning. Second, some researchers suggest that it is not possible to simulate the host culture, that some cross-cultural skills are very complex, and these skills must not only be experienced but also taught. This leads some researchers to note that there is a lack of cognitive learning in the experiential training approach and that this approach ignores aspects of culture such as political, social, and interpersonal factors ( $J$. Bennett, 1986; Bhawuk, 1990). 
SELF-AWARENESS APPROACH

The self-awareness or human relations approach to intercultural training (IT) is an approach that presupposes that trainees' understanding of themselves will lead to greater ability to adjust in another culture and therefore be more effective in that culture (J. Bennett, 1986; Gudykunst, Hammer, \& Wiseman, 1977). According to Bennett, the self-awareness approach "uses experiential processes, has affective goals, and is so culturally general in its content that 'culture' learning must be an extrapolated outcome" ( $\mathrm{J}$. Bennett, 1986, p. 125). In other words, any culture learning that trainees may gain from this approach of IT must be inferred. Because this approach to IT focuses on experiential processes and is culture general in its content, it corresponds with Gudykunst and Hammer's (1983) culture general-experiential quadrant.

The emphasis of self-awareness training is on role play. According to Janet Bennett (1986), the goal of this kind of training is to "bring into consciousness for the participants their own feeling, emotions. . .designed to encourage change in the individual's. . .behaviors" (p. 125). In other words, if trainees understand their own feelings in relationship to 
their own culture, then they can better understand other cultures.

However, researchers point out limitations of the self-awareness approach to IT (J. Bennett, 1986; Gudykunst \& Hammer, 1983). First, that which trainees learn is based on American values. In other words, this type of IT is culture-bound. According to Bennett, it "is built on the American values of openness, equality, individuality, directness, etc." (p. 126). Second, the self-awareness approach does not provide trainees a framework in which to analyze future situations. Trainees have no basic concept of behavioral and attitudinal differences between their own culture and the host culture.

\section{CULTURAL AWARENESS APPROACH}

The cultural awareness approach to IT educates individuals to recognize their own values and contrast these values with those of other cultures while applying insights gained from their training to improve cross-cultural interaction (J. Bennett, 1986; Brislin, Landis, \& Brandt, 1983; Bhawuk, 1990; Gudykunst \& Hammer, 1983; Gudykunst, Hammer, \& Wiseman, 1977). The training techniques used 
indicate that cultural awareness training corresponds with Gudykunst and Hammer's (1983) culture general-experiential quadrant.

The goal of this approach is for trainees to: 1) understand their own values, 2) to examine contrasts with other cultures, and 3) to apply insights they have gained to enhancing the effectiveness of interaction with host culture individuals (J. Bennett, 1986). The form this approach takes is varied, ranging, for example, from the Contrast American approach (Stewart, 1966), the Cultural Self-Awareness approach (Kraemer, 1975), and the Intercultural Communication Workshop (ICW) (Hoopes, 1975).

The strengths of the culture awareness approach are many. First, by contrasting cultural values, participants call into question their behavioral, affective, and cognitive responses to another culture. Second, because program sponsors encourage participant learning through interaction between international and U.S. participants, this approach approximates real situations in other cultures and can be used with sojourners going to different assignments ( $J$. Bennett, 1986; Brislin, Landis, \& Brandt, 1983). Third, because the cultural awareness approach seeks to educate 
individuals, it goes beyond mere intellectualizing correct behaviors and emphasizes the reality of interaction in another culture.

The limitations of this approach have to do with the large amount of time involved for most training situations, the extent of training the teacher-trainers must undergo (especially in Contrast-American and ICW), and how accurately training reflects cultural norms (J. Bennett, 1986; Gudykunst \& Hammer, 1983). If only a small amount of time is available for training, then it is time consuming both for trainers to be trained and for trainees to go through the extensive training the culture awareness approach entails. Further, once in the host culture, trainees might find much of what they learned irrelevant.

\section{INTEGRATED APPROACH}

There is consensus among many researchers that anyone planning to build an IT program should carefully integrate different aspects of cross-cultural learning ( $J$. Bennett, 1986; Gudykunst \& Hammer, 1983; Martin, 1989; Paige, 1993). First, an IT program should incorporate culture-general information and experiences with culture-specific information 
and experiences and as such include all of Gudykunst and Hammer's (1983) quadrants. Second, an IT program should be highly personalized and address cognitive, behavioral, and affective learning. Third, an IT program should encourage trainees to "learn-how-to-learn", i.e., a pedagogy that replaces learning mere cultural facts with learning how to live in another culture and respect alternate ways of knowing the meaning of truth and reality (Paige, 1993).

Various researchers propose integrated IT programs that reflect these three aspects of cross-cultural learning ( $\mathrm{J}$. Bennett, 1986; Gudykunst \& Hammer, 1983; McCaffery, 1993). For example, Gudykunst and Hammer (1983) point to a three-stage approach that incorporates perspective training, interaction training, and context-specific training. McCaffery (1993) suggests that trainees need a culture-general ability to manage transitions, a culture-specific ability of gaining fluency (both communicatively and in everyday-life skills), and a developing knowledge of the culture.

The various approaches to IT have been discussed in order to contrast them with the type of IT Walla Walla College offers to its SMs. This also makes it easier to 
classify and evaluate Walla Walla College's approach to IT.

\section{WALLA WALLA COLLEGE'S APPROACH}

An evaluation of Walla Walla College's pre-departure program should include a brief discussion of the type of training trainees receive before going on their overseas assignment. After looking at the materials I received from the student missionary (SM) sponsors at Walla Walla College and the syllabus of the course in cross-cultural ministry, it is evident that the SMs at Walla Walla participate in an intellectual training program that highlights cognitive learning.

SM program training techniques fall under Gudykunst and Hammer's (1983) culture general-didactic and culture specific-didactic quadrants and involve culture-general and culture-specific assignments. Culture-general lectures are given about cross-cultural adaptation and SMs must write a culture-specific paper about the country to which they are going. If they do not know their overseas assignments, they still must write a paper about a particular country. They are also required to interview two former SMs, one faculty member who has lived overseas, and three screening committee 
members.

\section{CONCLUSION}

There are significant things to consider as a result of the literature review. In the review of the literature I clarified specific terms for this research. This included definitions of sojourner, communication, culture, and intercultural communication. An understanding of what a sojourner is, what culture and communication entails, and the influence of culture on communication, is necessary in order to better understand intercultural communication and the influence culture has on communication. Furthermore, a basic understanding of these terms provides a basis for understanding intercultural communication competence (ICC) as well as various programs' training methodology.

In the second section I reviewed definitions of intercultural adjustment and adaptability processes. In this section, I suggested that these two fundamental processes occur when sojourners go overseas and that it is important to continually adjust and adapt when living in another culture. Because most sojourners go through a period of adjustment and seek to adapt to the culture they are in, it is important to 
discuss these dimensions individually.

In the third section, I examined the current definitions of ICC as well as the four different approaches to ICC studies: trait approaches, attitudinal/perceptual approaches, behavioral approaches, and culture-specific approaches. These different approaches to ICC influence this research in the following ways: 1) there is evidence for a culture-general and culture-specific interpretation for ICC, 2) ICC is not only something that sojourners feel about themselves, but is also something perceived about them.

First, ICC is culture-specific (contextual), i.e., made in respect to specific relational and situational contexts, and culture-general; i.e., it requires culture-general behaviors that are both appropriate and effective in all cultures. This research will focus on culture-general behaviors. While culture-specific research could be important to future research of the SM program at Walla Walla College and other Seventh-day Adventist (SDA) colleges as well, the inventory used, the Cross-Cultural Adaptability Inventory (CCAI), is a culture-general instrument. Furthermore, the teacher of the course lectures and gives exams covering culture-general material. The one exception 
to this is that SMs are required to write a culture-specific paper about the country they will be going to.

Second, ICC is not only something that sojourners feel about themselves, but is also something perceived about them. Perceived ICC is an important part of ICC research. However, the CCAI is a self-reporting measure that measures SMs' perceptions of themselves at the time of administering the inventory. Furzher research, involving host culture participants' observations, along with interviews of sponsors and host culture participants, would be necessary to more fully evaluate SMs' ICC.

In the fourth section of the literature review I described the different approaches to intercultural training (IT) currently used in pre-departure training programs. After differences between the approaches were discussed, it is clear that most intercultural communication specialists believe an approach to IT should incorporate three aspects of training. These include a combination of culture-specific with culture-general information, experiential and intellectual educational activities, and activities that enhance trainees' cognitive, behavioral, and affective processes. Also included in this section was a discussion of 
Walla Walla College's pre-departure training program.

Walla Walla College's pre-departure program is didactic, mostly culture-general, and tends to deal with SMs' cognitive processes. Because chapter five deals with answering the research question and analyzing the research hypotheses, SMs' inventory results from the CCAI administered before and after the course in cross-cultural ministry are important. The results from the CCAI and demographic survey will help to evaluate the effectiveness of Walla Walla College's pre-departure program and provide suggestions for future research. The results will also be used to suggest ways to improve the pre-departure training program at Walla Walla College. 


\section{CHAPTER III}

\section{METHODS}

\section{INTRODUCTION}

This chapter describes the methodology of this research. It includes a more complete description of the pre-departure program at Walla Walla College, the experimental and control group populations, the inventories used, and research methodology.

A DESCRIPTION OF THE STUDENT MISSIONARY PROGRAM AND THE PARTICIPANT SUBJECTS

Because of increased exposure to another culture, student missionaries (SMS) have many opportunities to communicate interculturally with host culture nationals. Because program sponsors at Walla Walla College want SMs to make the most of their experience overseas and to represent the Seventh-day Adventist (SDA) church most effectively, program sponsors take the training of SMs seriously. According to program sponsors, SMs who encounter extreme intercultural difficulties are sent home before completing 
their term of service.

Classification of these intercultural difficulties are based on the practices of at least one host culture SM program (i.e., in Japan) when disciplining SMs. These difficulties consist mostly of insensitivity to verbal and nonverbal cues within the host culture (perceptual acuity) and ignoring SDA church standards. They include, for example, extreme homesickness, conflicts between SMs and program administrators in the host culture, and failing to live up to program regulations (e.g., dating nationals or other SMs, drinking, or using drugs).

When SMs are sent home, it adversely affects the church-sponsored host culture program. Specifically, these programs suffer financially when SMs have to return home (e.g., in Japan, paying language students are sent away when classes that the SMs teach are canceled). Also, because these programs rely on SMs to proselytize, prospective converts might also become disillusioned and quit attending Bible classes that SMs are conducting if SMs are sent back to their native countries. Thus, successfully adapting to another culture is significant not only for SMs, but also for the host culture programs they work for. 
In order to help SMs successfully adapt to the culture they are sent to, Walla walla College requires that all SMS go through a screening process to determine their suitability as SMs. The screening committee has established the following eight basic criteria for those seeking to become SMS (see 1993-1994 Walla Walla College SM application packet):

1. You must be a baptized member of the Seventh-day Adventist Church.

2. You must have a high school and college minimum GPA of 2.1 to apply.

3. You must have your WWC account (not loans) cleared before your departure as a SM. Experiential credit may defer loans for one undergraduate year only.

4. You must agree to abide by all WWC, General Conference, and local field guidelines for SMs. one of those stipulations is that two people who are dating or engaged may not be assigned to the same location of service. Dating of peers and/or nationals is not permissible during your term of service.

5. You must complete each step of the application process in a timely manner.

6. It is your responsibility to raise necessary funds to cover travel and related expenses.

7. You are required to take RELM 223-Introduction to Cross Cultural Ministry which meets Tuesday and Thursday evenings during Spring Quarter. This is a three credit course which may meet part of your general education requirements in the area of electives in Religion or Theology. Individuals who are unable to take this class may apply for an alternative education experience. Make an appointment with the Chaplain to discuss alternatives.

8. In order to apply for Korea you must have 
completed your associate or bachelor's requirements before you plan to leave for Korea. Exceptions may be made by KEL Institute on a need basis. (p. 1)

The first basic requirement is important because all SMs must be baptized Seventh-day Adventists in order to participate in the program. The first and fourth basic requirements are important because sMs represent not only Walla Walla College, but the General Conference of Seventh-day Adventists and the local (i.e., host culture) church. SMs are considered missionaries and have the responsibility to introduce host culture non-SDAs to the SDA church through Bible studies, English Bible classes, and social contact.

The seventh basic requirement is the basis for this research. In order to help SMs successfully adapt to a new culture and to introduce concepts of culture and mission to them, Walla Walla College has developed a pre-departure training course (RELM 233, Cross-Cultural Ministry) for SMs that all SMs are requested to take. While some do not (and are told to do alternative assignments), most SMs take this course before going on their overseas assignments.

According to the syllabus outline, the cross-cultural ministry course is split into five sections: 1) history of 
missions, 2) the theological basis for missions, 3) cultural understanding and missions, 4) practical considerations in missions, and 5) spiritual preparation for missions. It is obvious by the course section titles that there is a theological, historical, cultural and spiritual focus as it relates primarily to mission. Because SMs are missionaries, the motivation behind training SMs is to represent the church appropriately in whatever culture SMs are sent to and to help them adapt to the cultural differences they will encounter. SM program sponsors and the teacher of the cross-cultural ministry course also hope that SMs will be a positive influence toward bringing non-SDA, host culture individuals to Christ.

Because this is a missionary program the teacher spends a large amount of time covering the theological and historical background of mission work from a Seventh-day Adventist (SDA) and non-SDA perspective. Other facets of missionary work, such as practical concerns (traveling and health, dating with other SMs and host culture nationals) are also covered. Because SMs are strongly urged to rely upon God as their source of strength during their year in another culture, SMs also participate in dedicatory services, 
dedicating their mind, spirit, and body to the advancement of the gospel.

The cultural understanding section of the course is covered in a two-week span. According to the teacher, his lectures are based on personal experiences while living in other cultures, as well as on the textbook required for the course. According to the syllabus and the textbook he uses, the teacher covers four areas dealing with cultural understanding and mission. These four areas are entitled: 1) cultural differences and the missionary, 2) cultural assumptions of western missionaries, 3) missions and anthropology, gospel, and culture, and 4) the incarnational missionary.

EXPERIMENTAL AND CONTROL POPULATIONS

In order to determine if there are differences between subjects who received treatment (i.e., pre-departure training) and those who did not receive treatment, it is necessary for groups to be matched in as many ways as possible. The experimental group, who took pre-departure training consisted of twenty three (23) $18-25$ year old male and female Seventh-day Adventist church members, most of whom 
were going overseas for approximately one year to work in Seventh-day Adventist (SDA) institutions as SMs. As SDA church members they would probably have a basic understanding of SDA church world mission through other religion classes taken at Walla Walla College and through membership in the church. All experimental subjects were undergraduate college students at Walla Walla College and had been SDA church members for 0-10+ years. All experimental subjects took a pre-departure training course.

The control population consisted of thirty four (34) 18$30+$ year old male and female college undergraduate students at Walla Walla College. Thirty one (91\%) control subjects were SDA church members and had been church members for $0-10+$ years, while 3 (9\%) expressed that they were not SDA church members. Similar to experimental subjects, control subjects also would also likely have a basic understanding of SDA church world mission through other religion classes taken at Walla Walla College and through membership in the church. The differences between the experimental subjects and the control subjects were based on the following: none of the control subjects had taken previous pre-departure training, nor were they planning to live overseas as SMs in the next 
year.

INVENTORY USED

As mentioned in chapter two, intercultural communication competence (ICC) principles of adaptability, adjustability, and effectiveness in another culture have led cross-cultural specialists to develop instruments that measure sojourners' ICC. This research included administration of an inventory, called the Cross-Cultural Adaptability Inventory (CCAI) (Kelley and Meyers, 1992), that reflects these principles. The research also included a demographic survey. Both the CCAI and the demographic survey are reprinted in the appendix.

The CCAI measures a person's interpersonal skills that reflect behavioral tendencies, i.e., the ability to adapt, adjust, and be effective in another culture. The inventory is split into four behavioral/attitudinal scales that are aspects of an individual's ability to adapt cross-culturally. These are: emotional resilience (ER), flexibility/openness $(F O)$, personal autonomy (PAC), and perceptual acuity (PA). Respondents are asked to circle 1 of 6 responses (DT--Definitely true about me right now; T--True; TT--Tends 
to be true; TNT--Tends to be not true; NT--Not true; DNT--Definitely not true about me right now) to 50 statements, distributed among the four CCAI dimensions. The responses reflect the respondents' feelings about themselves at the time of inventory administration and have a value of 1-6 points. The points from each of the responses correspond with one of the four CCAI scales. These points are added together to amass a total score for each of the CCAI scales. Finally, an aggregate score of all four CCAI dimensions is computed.

According to the CCAI manual, there are nine negatively worded items distributed throughout the entire instrument to reduce a response bias to rate all items similarly. Emotional resilience is the largest CCAI scale with 18 items. These items correspond to the following groupings:

Coping, especially with stress and ambiguity Items $1,4,34,36,39,48$;

Rebounding from, and acceptance of, imperfections and mistakes

Items $7,26,31$, and 45 ;

Trying new things and experiences

Items 13, 23, and 29;

Interacting with people in new or unfamiliar situations

Items 16, 21, and 42 . (p. A-2) 
The flexibility/openness scale contains 15 items. These items are grouped in the following manner:

Liking for, openness toward, interest in, and desire to learn from, people and ideas different from oneself

Items $5,8,11,22,40,43,46$, and 49;

Tolerance, nonjudgmentalness, and understanding toward others different from oneself Items 19, 27, 32, and 37;

Elexibility with regard to experiences Items 2, 14, and 30. (p. A-5)

The perceptual acuity (PAC) scale contains 10 items (3, $9,15,20,24,28,33,38,44$, and 50). According to the CCAI manual, these items assess the extent to which people pay attention to, and accurately perceive, various communication cues and skills (both verbal and nonverbal) across cultures. Most of the PAC items describe useful behaviors in another culture and items 9 and 20 not only focus on communication behaviors, but also how competent the person is in the behavior.

The personal autonomy (PA) scale contains 7 items (6, 12, 17, 25, 35, 41, and 47). According to the CCAI manual, these items assess the extent to which people have developed a personal value system which they feel comfortable with and the confidence to act on these values in the midst of 
diversity. At the same time, the scale examines the extent to which people respect others and their values. Finally, the FA scale examines the extent to which people feel motivated to change their values in a cross-cultural environment while remaining non-defensive and open to such change.

It is important that an inventory be both valid and reliable. According to results from the 1987 CCAI, following the collection of 653 responses to the CCAI, Kelley and Meyers determined that one CCAI scale was found to be too closely correlated with the Flexibility/openness scale. For the 1992 inventory, Kelley and Meyers determined that this scale was too weak to form a distinct scale and collapsed it into the FO scale. All items were then divided among the four dimensions. One of the original items had weak correlation with any CCAI scale and was dropped. Another item (\#46) was found to have high factor loading in two dimensions and was included on both the FO and the PAC dimensions.

Coefficient alphas were computed for internal consistency reliability on each of the four dimensions and the total score. Overall reliability (standardized alpha) 
for the CCAI was determined on the basis of 49 (of 50) items retained. Listed below are individual scale reliability (standardized alpha) estimates for the 1987 CCAI:

$\begin{array}{lrl}\text { Total Score } & 49 \text { items } & .90 \\ \text { Emotional Resilience } & 18 \text { items } & .82 \\ \text { Flexibility/Openness } & 15 \text { items } & .80 \\ \text { Perceptual Acuity } & 10 \text { items } & .78 \\ \text { Personal Autonomy } & 7 \text { items } & .68\end{array}$

These estimates show a high overall reliability. However, individual reliability scores for each section of the inventory are not as high. The Personal Autonomy scale shows low individual scale reliability (.68). Nevertheless, the close scores between the other three scores show a reasonable internal consistency reliability.

The CCAI also has high validity. It has content validity, since it has been determined through previous research to cover the subject comprehensively and efficiently. Previous research includes the initial development of the CCAI and the ongoing refinement of the instrument, as well as research studies completed and in progress using the CCAI. Therefore, it is a useful survey of what is known so far about cross-cultural adaptability within the CCAI parameters.

The CCAI claims to have construct validity, since 
attempts have been made to cover all of the relevant content areas. Other items not directly linked to cross-cultural adaptability have been left out (e.g., general personality items) of the CCAI. Furthermore, the method used in developing the CCAI, based on an evaluation of research results and methodical polling of cross-cultural communication experts, reinforces the assertion of construct validity.

\section{DEMOGRAPHIC SURVEY}

The demographic survey that I developed requested information pertaining to four areas: 1) age, gender, and ethnic background, 2) religious background, 3) living in other cultures and time spent living in other cultures, 4) pre-departure cross-cultural coursework taken, and 5) nonnative languages spoken. The questions asked were important for a broader understanding of the individuals involved in this research and to answer research question three.

The first and second set of demographic questions dealt with age, gender, ethnic, and religious background. The first set of questions specifically helped to determine 
whether ICC was related to age, gender, or ethnic background. Religious background information (i.e., whether they are Seventh-day Adventist and if so how long they have been Seventh-day Adventist) helped to determine if ICC was related to religious background.

A further demographic question pertaining to diet (Are you a vegetarian?) helped to determine whether the individuals participating in this research would tend to eat or not eat foods that were meat-based. Ptak, Cooper, and Brislin (1995) point out that a person's willingness to eat food from other cultures can be a sign of cultural sensitivity or the willingness to experience new things. Because many cultures have a meat-based diet and many SDA church members are vegetarian, I thought this might contribute to some cross-cultural misunderstanding. In other words, if sMs are adamantly vegetarian it is significant whether or not they would be able to handle sensitive issues of diet and to diplomatically refuse certain native food.

The third set of demographic questions dealt with time spent in another culture. Because of previous experience and in talking with other returned SMs, I assumed that if SMs had lived in another culture they would possibly be more 
interculturally competent than those who had never lived in another culture. A further question of how long they had lived in other cultures helped to determine if length of time in other cultures had anything to do with ICC.

The fourth set of demographic questions was intended to determine whether any of the subjects had prior cross-cultural training. This set of questions helped to eliminate control subjects who had previous pre-departure training from the research and helped to determine the philosophy of subjects regarding relationships with host culture individuals.

Finally, the last set of demographic questions dealt with other languages spoken and how fluent participants were in those languages. While this had more to do with linguistic competency, previous research (Acton \& Walker de Felix, 1986) suggests that linguistic competency is related to ICC. According to Action and Walker de Felix, the person who is able to converse, i.e., reaches the 'citizen' stage, with host culture individuals in the host culture only rarely has problems with the subtleties of language and culture. 


\section{DATA ANALYSIS}

Data analysis in the present research was similar to that used by Kelley and Meyers and other researchers who employ Likert scales. Specifically, I used two parametric statistical tests i.e., a one-way analysis of variance (ANOVA) to test for the difference of means and Pearson Product-Moment Correlations to test for significant correlations among the CCAI dimensions and the independent variables.

However, in this research I also ran statistical tests that Kelley and Meyers did not use in their research. Because parametric tests are not meant to be used with ordinal data, the assumption is that Kelley and Meyers treated their Likert scale data as interval level data. In other words, Kelley and Meyers assigned absolute values to the six choices that respondents had (i.e., Definitely True..., True..., Tends to Be True..., Tends Not to Be True..., Not True..., and Definitely Not True About Me Right Now) and treated these choices as equidistant to each other. It is my belief that it is not possible to claim equidistance in Likert scale response choices. Therefore, I also treated the CCAI data obtained in my research as ordinal level data 
and used nonparametric statistical tests to analyze the data. This was done to compare the results of the ANOVA and the Pearson Product-Moment Correlations with the results of the nonparametric versions of these tests.

Nonparametric statistics test hypotheses about data for which the underlying distribution of the data is not assumed (Statview Manual, 1994). Instead of just estimating the parameters of a hypothesized distribution, and running a computation on these estimates (as Kelley and Meyers did), I also employed the alternative of ranking the observations of each of the groups and performing a statistical computation on the rank scores using nonparametric statistical tests.

The Wilcoxon signed rank test is an appropriate nonparametric version of a paired t-test. It was used to compare the results of the experimental subjects' pre- and post-treatment inventory results. The Mann-Whitney U-test is an appropriate nonparametric version of an unpaired t-test. It was used to compute the post-treatment rank scores of the experimental subjects with the rank scores of the control subjects

In order to statistically test the relationships among the independent variables and the CCAI dimensions (gender, 
age, vegetarianism, ethnic background, years abroad, language fluency, treatment, ER, FO, PAC, and PA), and for comparative purposes, this research ran two correlation tests: Spearman's correlation coefficient and Pearson's correlation coefficient. Spearman's correlation coefficient test is a statistical analysis of rank scores. It calculates a correlation coefficient based on the ranks of the values of two variables (Statview Manual, 1994). All tests in this research were run at the .05 level of statistical level of significance.

Also, according to Kelley and Meyers, missing values were assigned item means rounded to the nearest integer. In the current research, missing values were treated as invalid observations and not included as part of the study.

\section{RESEARCH METHOD}

The research method utilized in this research consisted of administering the Cross-Cultural Adaptability Inventory (CCAI) and demographic surveys to two groups of Walla Walla college students: 23 experimental subjects and 34 control subjects. The experimental subjects took a class in cross-cultural ministry during spring quarter 1994 (10 weeks) 
offered by the Theology department at Walla Walla College and completed the inventory twice: once before taking the class and once after finishing the class. When comparing the results of the experimental group with those of the control group, the post-treatment scores were taken into consideration.

The control group was somewhat difficult to establish. At first, I planned to involve only Walla Walla College students who planned to go as SMs and had not taken the predeparture training. These individuals would have been tested twice: at the time they decided to participate in the program and just before leaving on their SM assignment. However, because of time and location constraints, I was unable to access those SMs who were going overseas in a timely manner. Many students who decided to be SMs made their plans only 2-3 weeks before leaving for their assignments. I could not adequately administer the inventory within the same time constraints as the experimental subjects (i.e., 10 weeks).

Because of this problem, I asked the teacher of the cross-cultural ministry class to involve students from other classes that he taught at Walla Walla College. Therefore, the control group consisted of 34 students from two other 
classes taught in the theology department at Walla Walla College. However, these students took the CCAI only once during Fall quarter 1994. The control subjects did not take any pre-departure training and had no vested interest in becoming SMs. They did not go through the application process to become SMs, nor did they participate in cross-cultural ministry class activities.

However, control subjects did share some common traits with experimental subjects. As the results of the demographic survey reveal, 54 of the 57 subjects (95\%) indicated that they were Seventh-day Adventist (SDA) church members. SDA church membership is mandatory for SMs serving overseas. Because most of the subjects in this research were SDA church members and Walla Walla College students, it is reasonable to assume that most of the subjects were made aware of the SDA church's mission programs. When looking at the Walla Walla College campus, posters and advertisements are posted highlighting the SM program. Furthermore, all students take religion courses at the college and attend college religious functions. This would indicate that all 57 subjects were at least made aware of the church's religious tenets and mission emphasis. 
Observation of the experimental groups' cross-cultural ministry class was not possible. Because of these difficulties, observations were supplemented by the following methods: 1) obtaining the 1993-1994 SM application packet, 2) audiotaped interviews with program sponsors during fall and winter 1993-1994, 3) one observation of a SM screening committee meeting during winter 1994, 4) an audiotaped interview with the teacher of the cross-cultural ministry class, 5) an audiotape of one class session, and 6) obtaining the class syllabus and required classroom textbooks. The interview questions posed toward SM program sponsors and the teacher of the cross-cultural ministry class are reprinted in the appendix.

Evaluation of the cross-cultural ministry class curriculum was based on the class syllabus, the textbooks used in class, the interview with the teacher of the class, and the audiotaped class session. Evaluation of the SM program included analysis of the interviews with program sponsors, the interview with the class teacher, and the 1993-94 SM application packet. I analyzed the information from the class session and the interviews with the teacher of the class and the SM program sponsors by listening to the 
tape-recorded interviews, class session, and SM screening comittee meeting repeatedly during the course of this research.

When evaluating the cross-cultural ministry class I looked for several factors which determined the focus of predeparture training. First, I was interested in the extent to which the teacher of the class was aware of intercultural communication competence (ICC) principles. Second, it was important to see how he presented his knowledge of ICC to those in class. Third, I was interested in how the textbooks represented current ICC theory. Fourth, I was concerned with the dynamics of the class, i.e., how open the teacher was to student ideas of culture and cross-cultural communication. Finally, I was interested in how much time in class the teacher spent discussing culture and dealing with people from another culture. Subsequently, in connection with this final analysis, I was interested in the assignments and tests students were required to take as a result of discussions in class and readings from the textbook. Each of the these factors were analyzed throughout the course of the research by: 1) listening to the audiotape of the class session, 2) listening to the interview with the teacher, and 3) reading 
the class syllabus.

The information I obtained directed my thinking in a number of ways. First, I was able to determine the program sponsors' and class teacher's knowledge of intercultural communication by analyzing literature collected for this research and applying it to the comments they made during the interviews. Second, I was able to ascertain the content and focus of the SM program by reading the 1993-94 SM application packet prior to and during the course of this research. Finally, the information I obtained from the class syllabus, the class textbooks, and the audiotape of the cross-cultural ministries class helped me to discern the focus of Walla Walla College's pre-departure training program. Information regarding class tests and assignments helped me to determine whether the teacher focused on a culture-general and/or culture-specific interpretation of ICC. In addition, I was able to compare the information I obtained from the class to the literature regarding different kinds of intercultural training (IT) programs (e.g., didactic or experiential) found in the literature review. 


\section{CHAPTER IV}

\section{RESULTS}

The purpose of this research was to assess the effectiveness of the SM pre-departure training program at Walla Walla College in developing an understanding of intercultural communication competence (ICC) principles among students planning to do missionary work abroad. This chapter will be devoted to reporting the results of the demographic survey and the Cross-Cultural Adaptability Inventory (CCAI), developed by Kelley and Meyers (1993), for this research. First, the results of the demographic data concerning the subjects involved in this research will be described. Then the results of the CCAI subject to data analysis will be described in three sections according to the research hypotheses posed in Chapter I. Demographic data are listed in TABLES I-VII.

TABLES I-VII reveal numerous important demographic factors. However, some demographic factors contained in the demographic survey are not fully represented in TABLES I-VII. This includes the years abroad, age, ethnic background, 
church affiliation, and previous classes taken in cross-cultural learning, parameters. In the cases of age, ethnic background, years of Seventh-day Adventist (SDA) church affiliation, and years abroad parameters, it was found that when analysis was initially done on the data these parameters revealed empty cells and had to be reduced from 5 and 6 point scales to 2 point scales. In other words, there was often no representation in the demographic categories mentioned (e.g., no participants listed themselves as SDA for 3-4 years).

A demographic parameter not represented in TABLES I-VII is previous courses taken in cross-cultural learning. All 57 subjects (100\%) participating in this research indicated that they had not taken any previous classes in cross-cultural learning.

Eurthermore, the years of SDA church affiliation parameter initially was considered important for this research. However, there were not enough non-SDA subjects involved in the research. Fifty four (95\%) research subjects reported that they were SDA church members. Fifty one (90\%) of these subjects indicated that they were SDA church members 10+ years, 1 (1.5\%) had been an SDA church member $0-2$ years 
and 2 (3.5\%) had been SDA church members 5-7 years. Therefore, because of such a high number of SDA church members and the length of time most of them indicated SDA church affiliation, it was determined that SDA church membership was not a statistically significant variable to include in this research.

TABLE I

AGE

\begin{tabular}{||c|c|c|c||}
\hline AGE & $\begin{array}{c}\text { CONTROI } \\
\text { SUBJECTS }\end{array}$ & $\begin{array}{c}\text { EXP } \\
\text { SUBJECTS }\end{array}$ & OVERALI \\
\hline $18-20$ & $21(62 \%)$ & $12(52 \%)$ & $33(58 \%)$ \\
\hline $21+$ & $13(38 \%)$ & $11(48 \%)$ & $24(42 \%)$ \\
\hline TOTAL & $34(60 \%)$ & $23(40 \%)$ & $57(100 \%)$ \\
\hline
\end{tabular}

TABLE II

ETHNIC BACKGROUND

\begin{tabular}{|c|c|c|c||}
\hline $\begin{array}{c}\text { ETHNIC } \\
\text { BCKGRND }\end{array}$ & $\begin{array}{c}\text { CONTROL } \\
\text { SUBJECTS }\end{array}$ & $\begin{array}{c}\text { EXP } \\
\text { SUBJECTS }\end{array}$ & OVERAII \\
\hline $\begin{array}{c}\text { CAUCAS- } \\
\text { AMERICAN }\end{array}$ & $28(82 \%)$ & $18(78 \%)$ & $46(81 \%)$ \\
\hline $\begin{array}{c}\text { OTHER- } \\
\text { AMERICAN }\end{array}$ & $6(18 \%)$ & $5(22 \%)$ & $11(19 \%)$ \\
\hline TOTAL & $34(60 \%)$ & $23(40 \%)$ & $57(100 \%)$ \\
\hline
\end{tabular}




\section{TABLE III}

GENDER

\begin{tabular}{||c|c|c|c||}
\hline \hline GENDER & $\begin{array}{c}\text { CONTROL } \\
\text { SUBJECTS }\end{array}$ & $\begin{array}{c}\text { EXP } \\
\text { SUBJECTS }\end{array}$ & OVERALL \\
\hline FEMALE & $20(59 \circ)$ & $16(70 \%)$ & $36(63 \%)$ \\
\hline MALE & $14(41 \%)$ & $7(30 \%)$ & $21(37 \%)$ \\
\hline TOTAL & $34(60 \%)$ & $23(40 \%)$ & $57(100 \%)$ \\
\hline
\end{tabular}

TABLE IV

CHURCH AFEILIATION

\begin{tabular}{|c|c|c|c||}
\hline \hline SDA & $\begin{array}{c}\text { CONTROL } \\
\text { SUBJECTS }\end{array}$ & $\begin{array}{c}\text { EXP } \\
\text { SUBJECTS }\end{array}$ & OVERALI \\
\hline YES & $31(91 \%)$ & $23(100 \%)$ & $54(95 \%)$ \\
\hline NO & $3(9 \%)$ & $0(0 \%)$ & $3(5 \%)$ \\
\hline TOTAL & $34(60 \%)$ & $23(40 \%)$ & $57(100 \%)$ \\
\hline
\end{tabular}

TABLE V

DIETARY PRACTICES

\begin{tabular}{||c|c|c|c||}
\hline VEG & $\begin{array}{c}\text { CONTROI } \\
\text { SUBJECTS }\end{array}$ & $\begin{array}{c}\text { EXXP } \\
\text { SUBJECTS }\end{array}$ & OVERALI \\
\hline YES & $18(53 \%)$ & $15(65 \%)$ & $33(58 \%)$ \\
\hline NO & $16(47 \%)$ & $8(35 \%)$ & $24(42 \%)$ \\
\hline TOTAL & $34(60 \%)$ & $23(40 \%)$ & $57(100 \%)$ \\
\hline
\end{tabular}


TABLE VI

YEARS ABROAD

\begin{tabular}{|c|c|c|c||}
\hline $\begin{array}{c}\text { YEARS } \\
\text { ABROAD }\end{array}$ & $\begin{array}{c}\text { CONTROI } \\
\text { SUBJECTS }\end{array}$ & $\begin{array}{c}\text { EXPP } \\
\text { SUBJECTS }\end{array}$ & OVERALI \\
\hline YES & $11(32 \%)$ & $10(43 \%)$ & $21(37 \%)$ \\
\hline NO & $23(68 \%)$ & $13(57 \%)$ & $36(63 \%)$ \\
\hline TOTAL & $34(60 \%)$ & $23(40 \%)$ & $57(100 \%)$ \\
\hline
\end{tabular}

TABLE VII

LINGUISTIC BACKGROUND

\begin{tabular}{|c|c|c|c||}
\hline $\begin{array}{c}\text { I.ANGUAGE } \\
\text { FLUENCY }\end{array}$ & $\begin{array}{c}\text { CONTROL } \\
\text { SUBJECTS }\end{array}$ & $\begin{array}{c}\text { EXPP } \\
\text { SUBJECTS }\end{array}$ & OVERALI \\
\hline YES & $8(24 \%)$ & $4(17 \%)$ & $12(21 \%)$ \\
\hline NO & $26(76 \%)$ & $19(83 \%)$ & $45(79 \circ)$ \\
\hline TOTAL & $34(60 \%)$ & $23(40 \%)$ & $57(100 \%)$ \\
\hline
\end{tabular}

RESEARCH HYPOTHESIS ONE

The experimental subjects will demonstrate higher levels of ICC than control subjects.

In order to address this hypothesis, first the posttreatment raw scores of the experimental subjects and the raw scores of the control subjects were taken into consideration. Analysis of variance (ANOVA) was performed on each of the four dimensions in the CCAI as well as the total CCAI scores. Cases missing on either the grouping variable or the analysis 
variable were excluded. Statistical significance was set at $\mathrm{p}<.05$. The results from the ANOVAs involving the 4 CCAI dimensions, as well as the overall CCAI score, are listed in TABLE VIII. Total possible points accumulated for each of the CCAI dimensions are: ER (108), FO (90), PAC (60), PA (42), and total CCAI (300). The means for the experimental subjects and the control subjects (see TABLE VIII) reflect aggregate inventory results for each of the CCAI dimensions and the total CCAI.

After this, the post-treatment rank scores of the experimental subjects and the rank scores of the control subjects were considered. This was done to see if there were any differences between the results of the ANOVAs done on the raw scores of both groups and nonparametric analyses of the rank scores.

As mentioned in the third chapter of this research, the Mann-Whitney U-test is an appropriate nonparametric version of a two group unpaired t-test. It was used to compute the post-treatment rank scores of the experimental subjects with the rank scores of the control subjects in the four CCAI dimensions and the overall CCAI. Similar to the ANOVAs computed for the raw scores, missing values on either the 
grouping variable or the analysis variable were omitted. Statistical significance was set at $p<.05$. The results of the Mann-Whitney U-test are listed in TABLE XVIII (see Appendix) and in TABLE IX.

The ANOVAs for the treatment and control groups reveal statistical significance in three dimensions of the CCAI (ER, FO, and $P A C)$, and the total CCAI score. In the ER dimension statistical significance was high $(\mathrm{p}=.0018, \mathrm{n}=56, \mathrm{p}<$ .05), while statistical significance was also high in the FO $(\mathrm{p}=.0338, \mathrm{n}=56, \mathrm{p}<.05)$ and $\operatorname{PAC}(\mathrm{p}=.0121, \mathrm{n}=57, \mathrm{p}<$ .05) dimensions. The total CCAI ANOVA results also reveal high statistical significance $(\mathrm{p}=.0036, \mathrm{n}=49, \mathrm{p}<.05)$.

The results for the Mann-Whitney $U$ test of the rank scores reveal statistical significance in the same CCAI dimensions (ER, $\mathrm{p}=.0035, \mathrm{n}=56, \mathrm{p}<.05 ; \mathrm{PAC}, \mathrm{p}=.0137, \mathrm{n}$ $=57, \mathrm{p}<.05 ; \operatorname{CCAI}, \mathrm{n}=49 ; \mathrm{p}=.0050)$. The results fall below statistical significance only in $F O$ and in that dimension the results are strongly leading to statistical significance (FO, $\mathrm{p}=.0513, \mathrm{n}=56, \mathrm{p}<.05)$. Also, while the results from the Mann-Whitney nonparametric test reveal lower statistical significance than in the ANOVAs of these dimensions, statistical significance still remains high. 
TABLE VIII

ANOVAS OF THE CCAI DIMENSIONS AND THE TREATMENT VARIABIE

\begin{tabular}{||c||c|c|c|c|c||}
\hline SCALES & TRTMENT & CASES & MEAN & F VALUE & PROB $>\boldsymbol{F}$ \\
\hline \hline ER & EXP & 22 & 86.636 & 10.75 & $.0018^{\star}$ \\
& CONTROL & 34 & 79.765 & & \\
\hline \multirow{2}{*}{ FO } & EXP & 23 & 74.609 & 4.743 & $.0338^{\star}$ \\
& CONTROL & 33 & 70.212 & & \\
\hline \multirow{2}{*}{ PAC } & EXP & 23 & 50.174 & 6.824 & $.0121^{\star}$ \\
& CONTROL & 34 & 47.118 & & \\
\hline \multirow{2}{*}{ PA } & EXP & 18 & 35.167 & 2.055 & .2438 \\
& CONTROL & 31 & 34.065 & & \\
\hline CCAI & EXP & 18 & 247.000 & 9.366 & $.0036^{\star}$ \\
& CONTROI & 31 & 231.613 & & \\
\hline
\end{tabular}

Note: Trtment means the course in cross-cultural ministry offered at Walla Walla College.

EXP refers to the experimental subjects.

Statistical significance * $: p<.05$

$\mathrm{ER}=$ emotional resilience

FO=flexibility/openness

PAC=perceptual acuity

$\mathrm{PA}=$ personal autonomy

CCAI = total CCAI score 
TABLE IX

MANN-WHITNEY U TEST OF THE CCAI DIMENSIONS

AND THE TREATMENT VARIABLE

\begin{tabular}{||c||c|c|c|c|c|c|c||}
\hline SCALE & U & $\begin{array}{c}\mathrm{U} \\
\text { PRIME }\end{array}$ & $\begin{array}{c}\mathbf{Z} \\
\text { VALUE }\end{array}$ & $\begin{array}{c}\text { P } \\
\text { VALUE }\end{array}$ & $\begin{array}{c}\text { TIED Z } \\
\text { VALUE }\end{array}$ & $\begin{array}{c}\text { TIED P } \\
\text { VALUE }\end{array}$ & \# TIES \\
\hline \hline$E R$ & 200.0 & 548.0 & -2.919 & $.0035^{\star}$ & -2.927 & $.0034 *$ & 13 \\
\hline FO & 262.5 & 496.5 & -1.949 & .0513 & -1.952 & .0509 & 15 \\
\hline PAC & 239.5 & 542.5 & -2.464 & $.0137 \star$ & -2.472 & $.0135 \star$ & 15 \\
\hline PA & 216.0 & 342.0 & -1.307 & .1914 & -1.318 & .1875 & 8 \\
\hline CCAI & 143.5 & 414.5 & -2.810 & $.0050 \star$ & -2.812 & $.0049 \star$ & 10 \\
\hline
\end{tabular}

Note: In ER and FO, 1 case was omitted due to missing values. In $\mathrm{PA}$ and the CCAI results, 8 cases were omitted due to missing values.

Statistical significance ${ }^{*}: \mathrm{p}<.05$

RESEARCH HYPOTHESIS TWO

The experimental subjects will demonstrate enhanced levels (comparing pre- and post-inventory results) of ICC after they take the pre-departure class at walla Walla College.

The experimental subjects' pre- and post-treatment inventory results were the basis for testing the statistical significance of repeated measures. Some subjects did not complete all the answers to the questions on the CCAI. In all tests on the data cases missing on either the grouping variable or the analysis variable were omitted from the 
statistical analyses and statistical significance was set at $p<.05$

In order to test for statistical significance and address this hypothesis, a one factor repeated measures analysis of variance (ANOVA) was performed on each of the four dimensions in the CCAI, i.e., emotional resilience (ER), flexibility/openness (FO), perceptual acuity ( $P A C$ ), personal autonomy (PA), as well as the total CCAI score. The results from the ANOVAs are listed in TABLES XVI-XVII (see Appendix) and in TABLES $\mathrm{X}-\mathrm{XII}$.

The experimental subjects' pre- and post-treatment inventory rank scores were also considered. This was done to see if there were any differences between the results of the ANOVAs done on the raw pre- and post-test scores and the rank pre- and post-treatment inventory scores. As mentioned in the third chapter of this research, the Wilcoxson Signed Rank test is an appropriate nonparametric version of a two group paired t-test. In this research, it was used to compute the pre- and post-treatment rank scores of the experimental subjects. The results of the Wilcoxon Signed Rank test are listed in TABLE XIII.

TABLE XVII (see Appendix) and TABLES X-XII reveal 
noteworthy differences in the pre- and post-treatment ANOVA results in FO $(\mathrm{p}=.0117, \mathrm{n}=23, \mathrm{p}<.05)$ and the total CCAI score $(\mathrm{p}=.0172, \mathrm{n}=15, \mathrm{p}<.05)$, with results leading to statistical significance in $\operatorname{PAC}(\mathrm{p}=.0508, \mathrm{n}=23, \mathrm{p}<.05)$ and $\mathrm{PA}(\mathrm{p}=.0824, \mathrm{n}=15, \mathrm{p}<.05)$. TABLE XIII reveals statistical significance in the pre- and post-treatment Wilcoxon ranked results in 2 of the CCAI dimensions (FO, $\mathrm{p}=$ $.0251, \mathrm{n}=23, \mathrm{p}<.05 ; \mathrm{PAC}, \mathrm{p}=.0264, \mathrm{n}=23, \mathrm{p}<.05)$ and the total CCAI score $(\mathrm{p}=.0231, \mathrm{n}=15, \mathrm{p}<.05)$, with results leading to statistical significance in $\mathrm{PA}$ ( $\mathrm{p}=.0692$, $\mathrm{n}=15, \mathrm{p}<.05)$. TABLE VI (see appendix) and TABLE XIII do not suggest statistical significance for the repeated ER measure.

The Wilcoxon test on rank scores also reveals higher statistical significance in the perceptual acuity (PAC) dimension than the ANOVA repeated measure results for PAC (Wilcoxon, $\mathrm{p}=.0264, \mathrm{n}=23, \mathrm{p}<.05$; ANOVA, $\mathrm{p}=.0508, \mathrm{n}=$ 23, $\mathrm{p}<.05)$. In addition, when comparing the ANOVA results with those of the wilcoxon ranked results, it is clear, with the exception of PAC, that statistical significance is lower in the wilcoxon ranked tests on the data. 
TABLE X

ANOVA OF THE TREATMENT SUBJECTS AND FO REPEATED MEASURE

\begin{tabular}{|c|c|c|c|c|c|}
\hline SOURCE & DF & $\begin{array}{l}\text { SUM OF } \\
\text { SQUARES }\end{array}$ & $\begin{array}{l}\text { MEAN } \\
\text { SQUARE }\end{array}$ & F-VAIUE & P-VALUE \\
\hline $\begin{array}{c}\text { Treatment } \\
\text { (A) }\end{array}$ & 0 & 0.000 & & & \\
\hline $\begin{array}{l}\text { Subjects } \\
\text { with } \\
\text { groups }\end{array}$ & 22 & 1557.304 & 70.787 & & \\
\hline $\begin{array}{c}\text { EO } \\
\text { Reptd } \\
\text { Msr } \\
\text { (B) }\end{array}$ & 1 & 50.087 & 50.087 & 7.552 & $.0117^{\star}$ \\
\hline$A B$ & 0 & 0.000 & & & \\
\hline $\begin{array}{c}\text { B x } \\
\text { sbjcts } \\
\text { w. } \\
\text { groups }\end{array}$ & 22 & 145.913 & 6.632 & & \\
\hline
\end{tabular}

Note: Statistical Significance * : $p<.05$ 
TABLE XI

ANOVA OF THE TREATMENT SUBJECTS AND PAC REPEATED MEASURE

\begin{tabular}{|c|c|c|c|c|c|}
\hline SOURCE & DF & $\begin{array}{l}\text { SUM OF } \\
\text { SQUARES }\end{array}$ & $\begin{array}{l}\text { MFAN } \\
\text { SQUARE }\end{array}$ & F-VALUE & P-VAIUE \\
\hline $\begin{array}{c}\text { Treatment } \\
\text { (A) }\end{array}$ & 0 & & & & \\
\hline $\begin{array}{l}\text { Subjects } \\
\text { with } \\
\text { groups }\end{array}$ & 22 & 342.870 & 15.585 & & \\
\hline $\begin{array}{c}\text { PAC } \\
\text { Reptd } \\
\text { Msr } \\
\text { (B) }\end{array}$ & 1 & 38.348 & 38.348 & 4.268 & .0508 \\
\hline $\mathrm{AB}$ & 0 & -7.105 & & & \\
\hline $\begin{array}{c}\text { B } x \\
\text { sbjcts } \\
\text { w. } \\
\text { groups }\end{array}$ & 22 & 197.652 & 8.984 & & \\
\hline
\end{tabular}


TABLE XII

ANOVA OF THE TREATMENT SUBJECTS AND THE TOTAL CCAI REPEATED MEASURE

\begin{tabular}{|c|c|c|c|c|c|}
\hline SOURCE & $\mathrm{DF}$ & $\begin{array}{l}\text { SUM OF } \\
\text { SQUARES }\end{array}$ & $\begin{array}{c}\text { MEAN } \\
\text { SQUARE }\end{array}$ & F-VALUE & P-VALUE \\
\hline $\begin{array}{c}\text { Treatment } \\
\text { (A) }\end{array}$ & 0 & 0.000 & & & \\
\hline $\begin{array}{l}\text { Subjects } \\
\text { with } \\
\text { groups }\end{array}$ & 14 & 6300.667 & 450.048 & & \\
\hline $\begin{array}{l}\text { CCAI } \\
\text { Reptd } \\
\text { Msr } \\
\text { (B) }\end{array}$ & 1 & 616.533 & 616.533 & 7.293 & $.0172^{\star}$ \\
\hline$A B$ & 0 & 0.000 & & & \\
\hline $\begin{array}{c}\text { B x } \\
\text { sbjets } \\
\text { w. } \\
\text { groups }\end{array}$ & 14 & 1183.467 & 84.533 & & \\
\hline
\end{tabular}

Note: 8 cases were omitted due to missing values. Statistical significance * $: p<.05$ 
TABLE XIII

WILCOXON SIGNED RANK TEST FOR REPEATED CCAI DIMENSIONS

\begin{tabular}{|c||c|c|c|c|c|c||}
\hline \hline SCALES & \# O DIF & \# TIES & z-VALUE & P-VALUE & $\begin{array}{c}\text { TIED } \\
\text { z-VALUE }\end{array}$ & $\begin{array}{c}\text { TIED } \\
\text { P-VALUE }\end{array}$ \\
\hline \hline ER & 1 & 5 & -1.356 & .1752 & -1.358 & .1744 \\
\hline FO & 3 & 5 & -2.240 & $.0251^{\star}$ & -2.252 & $.0243^{\star}$ \\
\hline PAC & 0 & 5 & -2.220 & $.0264^{\star}$ & -2.244 & $.0249^{\star}$ \\
\hline PA & 2 & 4 & -1.817 & .0692 & -1.826 & .0679 \\
\hline $\begin{array}{c}\text { TOTAL } \\
\text { CCAI }\end{array}$ & 0 & 0 & -2.272 & $.0231^{\star}$ & -2.272 & $.0231^{\star}$ \\
\hline
\end{tabular}

Note: In ER, 1 case was omitted due to missing values. In $\mathrm{PA}$ and the CCAI, 8 cases were omitted due to missing values.

Statistical Significance ${ }^{*}: p<.05$

\section{RESEARCH HYPOTHESIS THREE}

There will be relationships among subjects' ICC and the demographic variables involved in this research.

In order to address this hypothesis, the experimental subjects' post-treatment results and the control subjects' results were considered. Pearson Product-Moment correlations were run to test for significant correlations among the CCAI dimensions and the demographic variables found in the demographic survey. Correlation matrices for the variables in the CCAI and the demographic variables were created (see 
TABLES XIV and XX).

For comparative purposes, Spearman's correlation coefficient was also run on the rank scores of the CCAI dimensions and the independent variables. Spearman's correlation coefficient is a nonparametric statistical analysis of rank scores. It calculates a correlation coefficient based on the ranks of the values of two variables. Results of Spearman's correlation coefficient are found in TABLES XV and XXI. Both correlation tests in this research were run at the .05 level of statistical significance and missing values from the CCAI dimensions were omitted from consideration.

The Pearson correlation coefficients of the demographic variables and the CCAI dimensions (see TABLE XIV) reveal statistically significant negative correlation between gender and vegetarianism $(r=-.301, n=57 p<.05)$. Thirty three (58\%) of the 57 subjects participating in this research are vegetarian. Twenty five of those 33 subjects who are vegetarian are female, while 8 are male.

There are statistically significant positive correlations among gender and FO $(r=.527, \mathrm{n}=56, \mathrm{p}<.01)$ and gender and $\operatorname{PAC}(\mathrm{r}=.377, \mathrm{n}=57, \mathrm{p}<.01)$. There are 
also statistically significant positive correlations between gender and the total CCAI results $(r=.318, \mathrm{n}=49, \mathrm{p}<$ .05). In addition to the statistically significant correlations among gender and other variables in this research, there are statistically significant negative correlations among treatment and the following CCAI dimensions: $\mathrm{ER}(\mathrm{r}=-.443, \mathrm{n}=56, \mathrm{p}<.01), \operatorname{PAC}(\mathrm{r}=-.337$, $\mathrm{n}=57, \mathrm{p}<.01), \mathrm{FO}(\mathrm{r}=-.250, \mathrm{n}=56, \mathrm{p}<.05)$, and the total $\operatorname{CCAI}(\mathrm{r}=-.408, \mathrm{n}=49, \mathrm{p}<.01)$. This would mean that those who receive treatment (i.e., the experimental subjects) are more likely to report more ER, PAC, FO, and total CCAI.

The Pearson correlation coefficients of the CCAI dimensions (see TABLE $X X$ ) also reveal high statistical correlation among the following CCAI dimensions: ER and FO ( $r$ $=.566, \mathrm{n}=56, \mathrm{p}<.01) ; \mathrm{ER}$ and $\mathrm{PAC}(\mathrm{r}=.560, \mathrm{n}=57, \mathrm{p}<$ $.01) ; \mathrm{ER}$ and $\mathrm{PA}(\mathrm{r}=.443, \mathrm{n}=49, \mathrm{p}<.01) ; \mathrm{FO}$ and $\mathrm{PAC}(\mathrm{r}=$ .703, $\mathrm{n}=56, \mathrm{p}<.01) ; \mathrm{ER}$ and the total $\operatorname{CCAI}(\mathrm{r}=.875, \mathrm{n}=$ 49, $\mathrm{p}<.01) ; \mathrm{FO}$ and the total $\operatorname{CCAI}(\mathrm{r}=.855, \mathrm{n}=49, \mathrm{p}<$ $.01) ; \mathrm{PAC}$ and the total CCAI ( $\mathrm{r}=.807, \mathrm{n}=49, \mathrm{p}<.01)$; and $P A$ and the total CCAI $(r=.463, \mathrm{n}=49, \mathrm{p}<.01)$.

The Spearman rank-order correlation coefficients of the 
demographic variables and the CCAI dimensions (see TABLES XV and XXI) reveal high statistical correlation among the same demographic variables and CCAI dimensions as in the Pearson correlation table. In fact, in most cases the Spearman correlations are very similar to the Pearson correlations. This is true with the correlations among gender and vegetarianism (Pearson, $\mathrm{r}=-.301, \mathrm{n}=57, \mathrm{p}<.05$; Spearman, $\mathrm{r}=-.306, \mathrm{n}=57, \mathrm{p}<.05$ ); gender and FO (Pearson, $\mathrm{r}=$ .527, $\mathrm{n}=56, \mathrm{p}<.01 ;$ Spearman, $\underline{r}=.511, \mathrm{n}=56, \mathrm{p}<.01) ;$ gender and PAC (Pearson, $\mathrm{r}=.318, \mathrm{n}=57, \mathrm{p}<.01$; Spearman, $\mathrm{r}=.400, \mathrm{n}=57, \mathrm{p}<.01) ;$ and gender and the total CCAI (Pearson, $\mathrm{r}=.318, \mathrm{n}=49, \mathrm{p}<.05$; Spearman, $\mathrm{r}=.310, \mathrm{n}=$ $49, \mathrm{p}<.05)$

Similar results are also found between spearman's correlation and Pearson's correlation among the correlations of treatment and $\mathrm{ER}$ (Pearson, $\mathrm{r}=-.441, \mathrm{n}=56, \mathrm{p}<.01$; Spearman, $\mathrm{r}=-.395, \mathrm{n}=56, \mathrm{p}<.01)$; treatment and $\mathrm{FO}$ (Pearson, $\mathrm{r}=-.250, \mathrm{n}=56, \mathrm{p}<.05 ;$ Spearman, $\mathrm{r}=-.263, \mathrm{n}$ $=56, \mathrm{p}<.05$ ); treatment and PAC (Pearson, $\mathrm{r}=-.337, \mathrm{n}=$ 56, $\mathrm{p}<.01)$; Spearman, $\mathrm{r}=-.330, \mathrm{n}=56, \mathrm{p}<.01$ ); and treatment and the total CCAI (Pearson, $r=-.408, \mathrm{n}=49, \mathrm{p}<$ .01 ; Spearman, $\mathrm{r}=-.406, \mathrm{n}=49, \mathrm{p}<.01)$. 
Finally, similar results between spearman's correlation and Pearson's correlation are found among the following CCAI dimensions: $E R$ and FO (Pearson, $r=.566, \mathrm{n}=56, \mathrm{p}<.01$; Spearman, $\mathrm{r}=.595, \mathrm{n}=56, \mathrm{p}<.01$ ); ER and $\mathrm{PAC}$ (Pearson, $\mathrm{r}$ $=.560, \mathrm{n}=56, \mathrm{p}<.01 ;$ Spearman, $\mathrm{r}=.595, \mathrm{n}=56, \mathrm{p}<$ $.01) ; \mathrm{ER}$ and $\mathrm{PA}$ (Pearson, $\mathrm{r}=.443, \mathrm{n}=49, \mathrm{p}<.01$; Spearman, $\mathrm{r}=.472, \mathrm{n}=49, \mathrm{p}<.01) ; \mathrm{ER}$ and the total CCAI (Pearson, $\mathrm{r}=.875, \mathrm{n}=49, \mathrm{p}<.01$; Spearman, $\mathrm{r}=.848, \mathrm{n}=$ 49, $\mathrm{p}<.01$ ); $\mathrm{FO}$ and PAC (Pearson, $\mathrm{r}=.703, \mathrm{n}=56, \mathrm{p}<.01$; Spearman, $\mathrm{r}=.654, \mathrm{n}=56, \mathrm{p}<.01) ;$ FO and the total CCAI (Pearson, $\mathrm{r}=.855, \mathrm{n}=49, \mathrm{p}<.01 ;$ Spearman, $\mathrm{r}=.855, \mathrm{n}=$ 49, $\mathrm{p}<.01$ ); $\mathrm{PAC}$ and the total CCAI (Pearson, $\mathrm{r}=.807, \mathrm{n}=$ 49, $\mathrm{p}<.01 ;$ Spearman, $\mathrm{r}=.805, \mathrm{n}=49, \mathrm{p}<.01) ;$ and $\mathrm{PA}$ and the total CCAI (Pearson, $r=.463, \mathrm{n}=49, \mathrm{p}<.01$; Spearman, $\mathrm{r}=.452, \mathrm{n}=49, \mathrm{p}<.01)$. 
TABLE XIV

PEARSON PRODUCT MOMENT CORRELATION COEFFICIENTS ( $r^{\prime} s$ ) AMONG THE CCAI DIMENSIONS AND DEMOGRAPHIC VARIABLES

\begin{tabular}{||c||c|c|c|c|c|c|c||}
\hline VRBLS & GENDER & VEG & ETHNIC & $\begin{array}{c}\text { IANG } \\
\text { FL }\end{array}$ & TRTMNT & AGE & YAB \\
\hline \hline GENDER & 1 & & & & & & \\
\hline VEG & $-.301^{\star}$ & 1 & & & & & \\
\hline ETHNIC & -.136 & .083 & 1 & & & & \\
\hline $\begin{array}{c}\text { LANG } \\
\text { FL }\end{array}$ & .142 & -.082 & -.108 & 1 & & & \\
\hline TRTMNT & -.116 & .038 & .069 & -.143 & 1 & & \\
\hline AGE & -.240 & .051 & .136 & -.142 & .030 & 1 & \\
\hline YAB & -.130 & .043 & -.036 & -.232 & -.011 & .219 & 1 \\
\hline ER & -.025 & .152 & .029 & -.132 & $-.441 *$ & .132 & .237 \\
\hline FO & $.527 \star$ & .032 & -.109 & -.025 & $-.250^{\star}$ & .046 & .045 \\
\hline PAC & $.377^{\star}$ & .136 & -.155 & -.180 & $-.337 \star$ & -.113 & .142 \\
\hline PA & .166 & -.013 & -.209 & .025 & -.205 & -.134 & .176 \\
\hline CCAI & $.318^{\star}$ & .112 & -.099 & -.109 & $-.408 \star$ & .031 & .184 \\
\hline \hline
\end{tabular}

Note: 57 observations were used in this computation. 8 cases were omitted in correlations involving PA and CCAI due to missing values in PA, ER, and FO.

One case was omitted in correlations involving ER and FO due to missing values in ER and FO.

VRBLS refers to variables.

YAB means years abroad living in other cultures.

LANG FL means the ability to speak fluently in a language other than the native language of the individual.

TRTMNT refers to treatment.

Italicized statistical significance $*: p<.01$ and other $*$ : $p$ $<.05$ 
TABLE XV

SPEARMAN RANK-ORDER CORRELATION COEFFICIENTS ( $\left.r^{\prime} s\right)$ AMONG THE CCAI DIMENSIONS AND DEMOGRAPHIC VARIABLES

\begin{tabular}{||c||c|c|c|c|c|c|c||}
\hline \hline VRBLS & GENDER & VEG & ETHNIC & $\begin{array}{c}\text { LANG } \\
\text { FL }\end{array}$ & TRTMNT & AGE & YAB \\
\hline \hline GENDER & & & & & & & \\
\hline VEG & $-.306^{\star}$ & & & & & & \\
\hline ETHNIC & -.087 & .033 & & & & & \\
\hline $\begin{array}{c}\text { LANG } \\
\text { FL }\end{array}$ & .141 & -.083 & -.184 & & & & \\
\hline TRTMNT & -.109 & .122 & -.051 & -.074 & & & \\
\hline AGE & -.233 & -.008 & .123 & -.170 & -.095 & & \\
\hline YAB & -.095 & -.062 & .087 & -.230 & -.113 & .233 & \\
\hline ER & -.016 & .201 & -.104 & -.045 & $-.395 *$ & .132 & .127 \\
\hline FO & $.511 *$ & .018 & -.071 & -.010 & $-.263 *$ & .076 & .085 \\
\hline PAC & $.400 *$ & .065 & -.091 & -.010 & $-.330^{\star}$ & -.112 & .108 \\
\hline PA & .127 & .051 & -.168 & .056 & -.190 & -.102 & .127 \\
\hline CCAI & $.310^{\star}$ & .140 & -.103 & -.088 & $-.406 *$ & .000 & .189 \\
\hline \hline
\end{tabular}

57 observations were used in this computation.

8 cases were omitted in correlations involving PA and CCAI. One case was omitted in correlations involving ER and FO due to missing values in $\mathrm{ER}$ and $\mathrm{FO}$.

Italicized statistical significance *: $p<.01$ and other * $: p$ $<.05$

\section{CONCLUSIONS}

The ANOVAs performed on the post-treatment inventory results of the experimental group and the inventory results 
of the control group reveal many statistically significant differences between the two groups, especially in ER, FO, PAC, and the total CCAI. The Mann-Whitney U-tests performed on the ranked scores of the experimental and control groups also reveal statistically significant differences between the two groups, especially in ER, PAC, and the total CCAI, with results leading to statistical significance in FO.

The repeated measures ANOVAs reveal statistically significant differences between pre- and post treatment results, especially in FO, PAC, and the total CCAI, with results leading to statistical significance in PA. The Wilcoxon signed rank tests performed on the rank scores of the pre- and post-treatment results also reveal statistically significant differences, especially in FO, PAC, and the total CCAI, with results leading to statistical significance in PA. The results of the ANOVAs and the wilcoxon tests bring up the issue of whether one could subsequently predict actual experiences in diverse cultural contexts. It is possible that the results from the tests that point to heightened intercultural communication competence (ICC) after predeparture training will help SMs successfully deal with host culture individuals. Further research would need to be done 
to ascertain how successful experimental subjects were in adapting in other cultures. Experimental subjects would need to be observed subsequent to their entrance into the host culture.

The Pearson correlation coefficients of the demographic variables and the CCAI dimensions reveal many statistically significant positive and negative correlations, chiefly among gender and the CCAI dimensions and treatment and the CCAI dimensions. In addition, the Pearsons correlation coefficients of the CCAI dimensions reveal statistically significant positive correlations. Furthermore, the Spearman correlation coefficients of the demographic variables and the CCAI dimensions reveal statistically significant results similar to those found in the Pearson correlation coefficients. Possible reasons for the results from the parametric and nonparametric tests performed on the experimental and control groups will be discussed in the following chapter. 


\title{
CHAPTER V
}

\author{
DISCUSSION, LIMITATIONS, AND \\ SUGGESTIONS FOR FUTURE RESEARCH
}

\section{RESEARCH HYPOTHESIS ONE}

Research hypothesis one investigated the experimental and control subjects' intercultural communication competence (ICC) by means of the Cross-Cultural Adaptability Inventory (CCAI). The experimental subjects took a cross-cultural ministry class (a pre-departure training course) offered at Walla Walla College and the control subjects did not take the class. There are some statistically significant differences in the two groups especially associated with treatment and the CCAI dimensions (see TABLES VIII and IX). These statistically significant differences will be discussed in the next few sections. Other CCAI dimensions approaching statistical significance will also be discussed.

\section{Statistical Significance Associated With Treatment}

The ANOVAs of treatment and the CCAI dimensions suggest statistical significance in three CCAI dimensions and the 
total CCAI: emotional resilience $(E R)(p=.0018, n=56, p<$ .05; flexibility/openness (FO) $(\mathrm{p}=.0338, \mathrm{n}=56, \mathrm{p}<.05)$; perceptual acuity $(\mathrm{PAC})(\mathrm{p}=.0121, \mathrm{n}=57, \mathrm{p}<.05)$; total $\operatorname{CCAI}(\mathrm{p}=.0036, \mathrm{n}=49, \mathrm{p}<.05) . \quad \mathrm{ER}$ and total CCAI statistical significance was extremely high even at $p<.01$, while in $P A C$ and $F O$ statistical significance was also high and approaching $\mathrm{p}<.01$.

The Mann-Whitney $U$ test of CCAI dimensions and the treatment variables reveal statistically significant differences in the same dimensions $(E R, p=.0035, n=56, p$ $<.05 ; \mathrm{PAC}, \mathrm{p}=.0137, \mathrm{n}=57, \mathrm{p}<.05 ; \operatorname{CCAI}, \mathrm{p}=.0050, \mathrm{n}=$ 49, $\mathrm{p}<.05)$, with results leading to statistical significance in $\mathrm{EO}(\mathrm{p}=.0513, \mathrm{n}=56, \mathrm{p}<.05)$. Statistically significant differences in these self-reported CCAI dimensions and the total CCAI could stem from a number of factors. These consist of the following, some of which do not include the cross-cultural ministry class at Walla Walla College: 1) the motivation of experimental subjects to become student missionaries (SMs), 2) the interview process SMs go through to become SMs, 3) the screening process SMs must go through (which includes the screening committees' perceived opinion of the ability of 
perspective SMS to be good SMS), 4) the cross-cultural ministry class itself, and 5) the desire to appear emotionally resilient, flexible and open, perceptually acute, and interculturally competent to the administrator of the inventory, themselves, or SM program coordinators.

The first three factors (motivation, the interview process, and the screening process) are noteworthy when considering the ER mean of the control subjects (79.765), the ER means of the experimental subjects pre- and posttreatment $(84.227 ; 86.636)$, the ER mean rank of the control subjects (23.382), and the ER mean rank of the experimental subjects (36.409). The ANOVA of ER reveals high statistical significance among all subjects $(\mathrm{p}=.0018, \mathrm{n}=56, \mathrm{p}<.05)$. The Mann-Whitney $U$ test of ER also reveals high statistical significance among all subjects $(p=.0035, \mathrm{n}=56, \mathrm{p}<.05)$. However, ER is not considered statistically significant in the ANOVA of repeated ER $(\mathrm{p}=.1269, \mathrm{n}=22, \mathrm{p}<.05)$ or the Wilcoxon signed rank test of repeated $E R(p=.1752, n=22$, $p<.05)$. These results suggest that something other than the cross-cultural ministry class is generating enhanced ER. Motivation, the interview and screening processes (three factors not associated with the cross-cultural ministry 
class) may have played a part in determining the inventory results of the experimental group. Motivation is an important part of becoming an SM. Gardner and Lambert (1972) suggest that there are two kinds of motivation when learning a second language, integrative and instrumental. Prospective SMs are perhaps motivated similarly as they contemplate going as SMs.

First, there is the possibility that motivation to actively integrate and minister to members of another culture (integrative motivation) led experimental subjects to self-report high levels of ER, EO, PAC, and total CCAI. When interviewing, the screening committee looks for integrational motivation.

However, it is equally possible that the motivation to become SMs in order to further their career after walla walla College or improve social status (instrumental motivation) led experimental subjects to self-report high levels of ER, EO, PAC, and total intercultural communication competence (ICC). From personal experience and listening to the experience of former and present SMs, I believe going as SMs helps to enhance future employment and educational opportunities. I was told that going as an SM would 
definitely improve my chances when being considered for ministry. In addition, one SM not a member of either the experimental or control groups) mentioned that going as an SM would improve her chances of being accepted into a particular graduate school she wanted to attend.

The interview process is also an important part of becoming an SM. The process from application in the program to final approval can be long, taking days or weeks depending on the prospective SM. The process usually includes interviews with a faculty member who has been overseas, three screening committee members (i.e., SM program coordinators), and two former sMs. The interview process can help prospective SMs learn what SM program coordinators know about necessary behavioral, value, and cultural differences. Understanding these differences can then help prospective SMs review their own ICC needs and make changes accordingly.

The screening process that SM program applicants must go through is a vital part of becoming SMs. Specifically, screening committee members consider the applications of many prospective SMs and the qualities they consider necessary for SM service through the screening process. When I interviewed the screening committee and perused the 1994-1995 SM 
application packet, the importance of these qualities became apparent.

Some of the qualities the screening committee members consider when approving or denying applications for SM service include many factors that are determinants in the CCAI. These include the following: motivation, personality, leadership, emotional stability, adaptability, personal growth potential, physical limitations, judgement, attitude toward the church, spiritual experience, ability to financially afford going as SMs, and witnessing experience. As a result, the committee members look for those people who will work well as SMs and fit a typical SM pattern. When prospective SMs lack certain qualities deemed necessary to be good SMs, the screening committee denies the application.

Because of this high standard, it is possible that SMs who are accepted into the program already possess high ER, FO, PAC, and total ICC. In other words, SMs who pass the screening process not only possess the qualities screening committee members deem essential to be good SMs (qualities which correlate with many of the CCAI dimensions), but also evaluate themselves highly in those areas which are also determinants in the CCAI dimensions. 
The fourth factor that could have made a statistically significant difference in the ER, FO, PAC, and total CCAI results is the cross-cultural ministry class at Walla walla College. Specifically, the cross-cultural ministry class at Walla Walla College can address issues related to ER and PAC by the following methods: 1) reading the books required for the class, 2) listening to the lectures in the training class, and, 3) discussions in class involving ER, FO, PAC, and overall ICC between the prospective SMs and the teacher in the class. Considering the teacher's methods, it is possible that the cross-cultural ministry class contains aspects of ER, FO, PAC, and overall ICC training.

An additional reason to believe SMs may already possess enhanced ER, FO, PAC, and ICC has nothing to do with the class, motivation, the interview and screening process, or that they actually possess enhanced ER, FO, PAC, and ICC. Specifically, the SMS' desire to appear emotionally resilient, flexible, open, perceptually acute, and interculturally competent to themselves, the SM program coordinators, or the administrator of the inventory, may lead experimental subjects to self-report enhanced levels in these areas. 
RESEARCH HYPOTHESIS TWO

Research hypothesis two investigated the experimental group's ICC before and after they took the pre-departure class at Walla Walla College. From the CCAI repeated measures ANOVAs, there is statistical significance in repeated $\mathrm{FO}(\mathrm{p}=.0117, \mathrm{n}=23, \mathrm{p}<.05)$ and repeated total $\operatorname{CCAI}(\mathrm{p}=.0172, \mathrm{n}=15, \mathrm{p}<.05)$, with results leading to statistical significance in repeated $\mathrm{PAC}(\mathrm{p}=.0508, \mathrm{n}=23$, $\mathrm{p}<.05)$ and PA $(\mathrm{p}=.0824, \mathrm{n}=15, \mathrm{p}<.05)$ (see TABLES XII$X V$ ). The Wilcoxon signed rank test (see TABLE XVII) reveals statistical significance in the following repeated CCAI dimensions: FO $(\mathrm{p}=.0251, \mathrm{n}=23, \mathrm{p}<.05), \mathrm{PAC}(\mathrm{p}=.0264$, $\mathrm{n}=23, \mathrm{p}<.05)$, and total $\operatorname{CCAI}(\mathrm{p}=.0231, \mathrm{n}=15, \mathrm{p}<$ .05), with results leading to statistical significance in PA $(\mathrm{p}=.0692, \mathrm{n}=15, \mathrm{p}<.05)$. In the next few sections the statistical significance of these repeated CCAI dimensions will be discussed.

Repeated CCAI Dimensions

The parametric and nonparametric tests of FO, PAC, and total CCAI suggest that the post-treatment inventory results, when contrasted with the pre-treatment inventory scores in 
FO, PAC, and total CCAI, are statistically significant. This could be the result of a number of factors which are a part of the syllabus for the class: 1) the books used in the class dealing with cultural issues, 2) the class lectures, 3) discussions in class among the students and teacher of the class, and 4) class assignments and tests dealing with cultural issues.

One factor which could have influenced the pre- and post-treatment inventory results of SMs taking the CCAI is the books used in the class that deal with cultural issues, Case Studies in Missions by Paul and Francis Hiebert and Anthropological Insights for Missionaries by Paul Hiebert. The Hieberts (1987, 1993) cover many aspects of cross-cultural adaptation and differences in cultural norms in their books. For example, Hiebert (1993) mentions various aspects of culture shock (described as "psychological unrest" (p. 65)), ethnocentricism, as well as various value differences (e.g., religious, symbol, time, and space) between cultures.

A second factor which could have influenced the pre- and post-treatment inventory results of SMs taking the CCAI is class lectures (which closely followed the textbooks used in 
the class) that deal with cultural issues. The professor who teaches the class at Walla Walla College, while not being familiar with the content of the CCAI, stressed in our interview the importance of introducing dimensions associated with the CCAI (e.g., the importance of SM flexibility/openness and adaptability across cultures). The class syllabus and the audiotape of the class discussing different aspects of culture awareness indicate that discussions in class include constructs found in the FO and PAC dimensions of the CCAI, as well as the total CCAI. It is not surprising, therefore, that students have enhanced inventory results in FO, PAC, and total CCAI after taking the CCAI .

A third factor which could have influenced the pre- and post-treatment inventory results of SMs taking the CCAI is the discussions among the students and the teacher of the cross-cultural ministry class at Walla Walla College. In the audiotape recording used as a basis for this research, the teacher of the class discusses the concept of culture, along with the dimensions of culture (cognitive, affective, and evaluative) and the manifestations of culture (behavior and products, i.e., material objects). 
Students in the taped discussion do not seem to question the role culture plays in understanding the values and behavior of the host culture. In addition, there does not seem to be any comment by students on the audiotape that would indicate an ethnocentric attitude or disrespect for cultural beliefs or values. However, whether the lack of student comments is due to a mutual understanding of culture between the teacher and students or because they do not question the teacher's understanding of culture, can not be ascertained.

A fourth factor which could have influenced the pre- and post-treatment inventory results of prospective SMs taking the CCAI is the classroom assignments and tests that cover cultural issues. Classroom assignments and tests could have helped prospective SMs more fully understand the dynamics of intercultural interaction. Classroom assignments and tests cover the case studies from Case Studies in Missions as well as the material covered in lecture and discussion on cultural issues. Furthermore, a project paper is written on the country SMs are going to or are interested in. This paper covers the history, culture, and religion of the country as they relate to mission service and is 6 pages in length. 


\section{RESEARCH HYPOTHESIS THREE}

The third research hypothesis investigates the relationships among subjects' intercultural communication competence (ICC) (as measured by the CCAI), their age, gender, ethnic background, dietary standard (i.e., vegetarian or non-vegetarian), if they have lived in another culture, and if they speak a language fluently other than their native language. Pearson correlation coefficients and Spearman correlation coefficients were developed considering the demographic variables as well as the CCAI dimensions (see TABLES XVIII-XXI). The correlation matrices reveal some statistically significant correlations among the variables, as well as correlations approaching statistical significance.

Gender and the CCAI Dimensions

The Pearson correlation coefficients table (see TABLE XVIII) reveals statistically significant positive correlation of gender with the total CCAI ( $r=.318, \mathrm{n}=49, \mathrm{p}<.05$ ) and two of the CCAI dimensions, FO $(r=.527, \mathrm{n}=56, \mathrm{p}<.05)$ and $\operatorname{PAC}(\mathrm{r}=.377, \mathrm{n}=57, \mathrm{p}<.05)$. Gender negatively correlates with vegetarianism $(r=-.301, \mathrm{n}=57, \mathrm{p}<.05)$. The Spearman correlation coefficients table (see TABLE XX) 
also reveals statistically significant correlation among the same variables (CCAI, $r=.310, \mathrm{n}=49, \mathrm{p}<.05 ; \mathrm{FO}, \mathrm{r}=$ $.511, \mathrm{n}=56, \mathrm{p}<.05 ; \mathrm{PAC}, \mathrm{r}=.400, \mathrm{n}=57, \mathrm{p}<.05 ;$ vegetarianism, $\mathrm{r}=-.306, \mathrm{n}=57, \mathrm{p}<.05)$.

The correlations among gender and the CCAI dimensions FO and $\mathrm{PAC}$ and gender and the total CCAI might be explained by various gender-related factors. One possible explanation for the correlations is that females in this study were greatly influenced by the wording of the CCAI and especially in the FO and PAC dimensions. A second explanation may be that females tend to focus on the relational aspects of interaction, are sensitive to cultural differences in verbal and nonverbal behaviors, and are flexible, open, tolerant, and non-judgmental of different ways of thinking. Finally, females might have had previous satisfactory cross-cultural relationships with members of another culture, both at home and abroad. This supports research done by Tannen (1986) and Wood (1994) in the area of feminine and masculine interactional patterns.

First, the test used to assess the CCAI itself reveals statistical significance relating to gender and $F O(p=.00$, $\mathrm{n}=653, \mathrm{p}<.05)$, as well as gender and $\operatorname{PAC}(\mathrm{p}=.04, \mathrm{n}=$ 
653, $p<.05)$. This would suggest that, when the CCAI is used with other groups, gender could be a statistically significant variant. Because of this, it is possible to assume that gender in this research could also be a statistically significant variable and that CCAI wording does influence responses according to gender. In other words, a statistically significant number of females in this research would produce similar results as in previous research and demonstrate high levels of FO and PAC when taking the CCAI.

The correlations among gender and FO and PAC also indicates that the interaction patterns of females and males are different in relation to FO and PAC. Specifically, females revealed a high level of those elements inherent in FO and PAC: flexibility, openness, tolerance, and comfort when interacting with people from different cultural backgrounds who think differently from themselves (FO), as well as sensitivity to the verbal and nonverbal behaviors that are inherent in the values, assumptions, and customs of the host culture (PAC).

According to Wood (1994), females are socialized to be adept at giving and receiving numerous response cues, i.e., verbal and nonverbal behaviors that signify concern and 
interest in interaction. Because verbal and nonverbal cues are part of using interaction to build and maintain relationships with others, females are also generally comfortable building intimate relationships and disclosing. Further, as a part of feminine culture, talking is perhaps the primary method to disclose and develop closeness within relationships, as well as express interest, attention, and communication (Wood, 1994).

Tannen (1986) also mentions that feminine interaction is fundamental to building relationships. Specifically, she suggests that females are socialized to be attuned to metamessages: those messages that are not a part of the actual verbal message, but are the nonverbal message behind the verbal message. In other words, metamessages are those things communicated about relationships, the attitudes we have toward each other, the situation, and what we are saying (Tannen, 1986).

Males, on the other hand, are not socialized to be attuned to metamessages. In addition, the importance of interaction is different for them (Tannen, 1986). According to Wood, within masculine culture, relationships are not central and communication is something to do as a way to 
solve problems rather than to build and maintain relationships. In addition, males maintain a great degree of distance when interacting with others, reserved when disclosing themselves or involving themselves in interaction.

Based on Tannen's and Wood's research into masculine and feminine cultures, it is not surprising that females in this research could self-report enhanced FO and PAC as a product of their socialization process. Furthermore, when dealing with members of another culture, females who are socialized to welcome close relationships when interacting with others, might also welcome close relationships with members of another culture. Therefore, when responding to the total CCAI, females could consider themselves as interculturally competent. When responding to the FO and PAC dimensions, they could consider themselves as perceptually acute, flexible, and open when interacting with members of another culture.

The third factor which could account for differences in the total CCAI, FO, and PAC inventory results relating to gender is a consequence of the second factor mentioned above (i.e., the differences in socialization patterns of males and females). Specifically, the differences in the total CCAI, 
FO, and $\mathrm{PAC}$ inventory results relating to gender suggest that it is possible that previous cross-cultural relationships female and male subjects from Walla walla College have with members of another culture, both at home and abroad, could be satisfactory or unsatisfactory based on gender. Some of the female SMs that I have observed over the years have revealed a high level of involvement in social activities with host culture individuals. This could lead to satisfactory impressions of intercultural relationships.

Previous intercultural effectiveness research reveals that one factor of sojourner satisfaction with stays abroad is related to relationships sojourners make with host culture individuals (Kealey, 1989; Rohrlich \& Martin, 1991). Specifically, sojourners who are more satisfied with their cross-cultural experience also have more contact with host culture individuals. Eurthermore, satisfaction of relationships with members of another culture is related to enhanced psychological adjustment (Searle \& Ward, 1990).

While previous intercultural effectiveness research was conducted with people who have actually lived overseas, it is possible that subjects in this research were reflecting on past cross-cultural relationships, both at home and abroad, 
when responding to the total CCAI and the FO and PAC dimensions. Tannen (1986) and Wood (1994) point out the tendency in feminine culture to enhance and develop relationships and connections with other people.

Reflecting on Tannen's and Wood's research, it is possible that the female subjects in this research are thinking of past cross-cultural interaction with members of another culture, both at home and abroad, as a means to enhance and build relationships. The female SMs (not associated with this research) that I am observing at this time often are involved in social activities with their Japanese English students. These activities could lead to improving relationships with the Japanese students. These activities include such things as having students come into their home, aerobics classes, baking classes, and trips to Japanese cultural sites.

Males, on the other hand, might hesitate to be involved in such close personal interaction or deem it necessary to fulfill a requirement for mission outreach. This would follow Tannen's and Wood's research that suggests that males tend to see personal relationships as a means to solve problems or fulfill a requirement. Males in this research 
could be reflecting on past interaction with members of another culture, both at home and abroad, with instrumental motivation when answering the CCAI. Perhaps some of the social activities mentioned above (i.e., trips to cultural sites and having students in their home) are times when males would be anxious to do things with their hosts only as a means to fulfill a requirement.

\section{Gender and Vegetarianism}

Gender negatively correlating with vegetarianism ( $r=$ $-.301, \mathrm{n}=57, \mathrm{p}<.05)$ suggests that as the number of subjects reported themselves to be male it was less likely that they were vegetarian. This supports the data. Of all the subjects, 33 (58\%) said they were vegetarians and 24 (42\%) said they were not vegetarians. Of the 21 males participating in this research, 8 (38\%) reported that they were vegetarian and 13 (62\%) reported that they were not vegetarian. Of the 36 females participating in this research, 25 (69\%) reported that they were vegetarian and 11 (31\%) reported that they were not vegetarian.

Treatment and the CCAI Dimensions

Pearson's correlation coefficients reveal negative 
correlations between treatment and ER $(r=-.441, \mathrm{n}=56, \mathrm{p}<$ $.01)$, treatment and FO ( $\mathrm{r}=-.250, \mathrm{n}=56, \mathrm{p}<.05)$, treatment and $\operatorname{PAC}(\mathrm{r}=-.337, \mathrm{n}=57, \mathrm{p}<.01)$, and total $\operatorname{CCAI}(\mathrm{r}=-.408, \mathrm{n}=49, \mathrm{p}<.01)$. Spearman's correlation coefficients reveal negative correlations between treatment and $\operatorname{ER}(\mathrm{r}=-.395, \mathrm{n}=56, \mathrm{p}<.01)$, treatment and FO $(\mathrm{r}=$ $-.263, \mathrm{n}=56, \mathrm{p}<.05)$, treatment and $\mathrm{PAC}(\mathrm{r}=-.330, \mathrm{n}=$ 57, $\mathrm{p}<.01)$, and treatment and total CCAI $(\mathrm{r}=-.406, \mathrm{n}=$ 49, $\mathrm{p}<.01$.

These correlations support the results of the ANOVAs and Mann-Whitney U tests between treatment and ER, treatment and FO, treatment and PAC, and treatment and the total CCAI. Specifically, the ANOVAs on each of these three CCAI dimensions and treatment report that treatment is statistically significant in the results of 3 dimensions and the total $\operatorname{CCAI}(\mathrm{ER}, \mathrm{p}=.0018, \mathrm{n}=56, \mathrm{p}<.05 ; \mathrm{FO}, \mathrm{p}=$ $.0338, \mathrm{n}=56, \mathrm{p}<.05 ; \mathrm{PAC}, \mathrm{p}=.0121, \mathrm{n}=57, \mathrm{p}<.05 ;$ CCAI, $p=.0036, n=49, p<.05)$. The Mann-Whitney U tests reveal similar statistical significance among 2 of the CCAI dimensions and the total CCAI (ER, $\mathrm{r}=.0035, \mathrm{n}=56, \mathrm{p}<$ $.05 ; \mathrm{PAC}, \mathrm{p}=.0137, \mathrm{n}=57, \mathrm{p}<.05 ; \operatorname{CCAI}, \mathrm{p}=.0050, \mathrm{n}=$ 49, $\mathrm{p}<.05)$, with results leading to statistical 
significance in $\mathrm{FO}(\mathrm{p}=.0513, \mathrm{n}=56, \mathrm{p}<.05)$.

These correlations suggest that because control subjects did not participate in the treatment (i.e., the cross-cultural ministry class at Walla walla College) they are reporting lower ER, FO, PAC, and total CCAI. Those subjects who are members of the experimental group have statistically higher results in ER, FO, PAC, and total CCAI due to their participation in the treatment.

In other words, the negative correlations among treatment and the CCAI dimensions could be the result of not participating in experimental group functions, i.e., those factors associated with participation in the SM program. These include the following previously discussed factors: 1) the motivation of experimental subjects to become SMs (whether instrumental or integrative) 2) their motivation to get something out of the cross-cultural ministry class, 3) the interview process SMs go through to become SMs, 4) the screening process SMs must go through (which includes the screening committees' perceived opinion of the ability of perspective SMS to be good SMs), and 5) the cross-cultural ministry class itself.

However, while correlations among treatment and the CCAI 
dimensions reveal statistically significant negative correlation (see TABLES XVIII and XX) and statistically significant probability in the results of the treatment and control groups (see TABLE VIII), it is important to note that statistical tests on the repeated $E R$ dimension reveal that treatment was not statistically significant. This suggests that other factors (i.e., factors 1-4 above) could have had a greater influence than the cross-cultural ministry class itself.

Finally, Pearson's correlation coefficients among the CCAI dimensions (see TABLES XIX and XXI), revealed statistically significant positive correlations among the following dimensions: $\mathrm{ER}$ and $\mathrm{FO}(\mathrm{r}=.566, \mathrm{n}=56, \mathrm{p}<.01)$; $\mathrm{ER}$ and $\mathrm{PAC}(\mathrm{r}=.560, \mathrm{n}=56, \mathrm{p}<.01) ; \mathrm{ER}$ and $\mathrm{PA}(\mathrm{r}=.443$, $\mathrm{n}=49, \mathrm{p}<.01) ; \mathrm{ER}$ and the total $\operatorname{CCAI}(\mathrm{r}=.875, \mathrm{n}=49, \mathrm{p}$ $<.01) ; \mathrm{FO}$ and $\operatorname{PAC}(\mathrm{r}=.703, \mathrm{n}=56, \mathrm{p}<.01) ; \mathrm{FO}$ and the total $\operatorname{CCAI}(\mathrm{r}=.855, \mathrm{n}=49, \mathrm{p}<.01) ; \mathrm{PAC}$ and the total $\operatorname{CCAI}(\mathrm{p}=.807, \mathrm{n}=49, \mathrm{p}<.01) ; \operatorname{PA}$ and the total $\operatorname{CCAI}(\mathrm{p}=$ $.452, \mathrm{n}=49, \mathrm{p}<.01)$.

Spearman's correlation coefficients among the CCAI dimensions revealed similar statistically significant results among the following dimensions: $E R$ and FO $(r=.595, n=56$, 
$\mathrm{p}<.01) ; \mathrm{ER}$ and $\operatorname{PAC}(\mathrm{r}=.477, \mathrm{n}=56, \mathrm{p}<.01) ; \mathrm{ER}$ and $\mathrm{PA}$ $(\mathrm{r}=.472, \mathrm{n}=49, \mathrm{p}<.01) ; \mathrm{ER}$ and total $\operatorname{CCAI}(\mathrm{r}=.848, \mathrm{n}=$ 49, $\mathrm{p}<.01) ; \mathrm{FO}$ and $\operatorname{PAC}(\mathrm{r}=.654, \mathrm{n}=56, \mathrm{p}<.01) ;$ FO and total CCAI $(r=.854, \mathrm{n}=49, \mathrm{p}<.01) ; \mathrm{PAC}$ and total CCAI ( $r$ $=.805, \mathrm{n}=49, \mathrm{p}<.01) ; \mathrm{PA}$ and total $\operatorname{CCAI}(\mathrm{r}=.452, \mathrm{n}=$ $49, \mathrm{p}<.011$.

High correlation among all the CCAI dimensions suggests that the CCAI dimensions are strongly related to one another and that the dimensions support each other within the scope of ICC studies.

\section{UNEXPECTED RESULTS}

Many unexpected results emerged from the data. First, there are no statistically significant correlations between years spent abroad (YAB) and any of the CCAI dimensions. It was expected that having lived abroad would be statistically significant in this research. Pearson's correlation coefficient reveals that $Y A B$ and ER are approaching statistical significance $(r=.237, \mathrm{n}=56, \mathrm{p}<.05)$. However, Spearman's correlation coefficient reveals that YAB and ER are not closely related $(\mathrm{r}=.127, \mathrm{n}=56, \mathrm{p}<.05)$. In order for clear statistical significance to emerge, 
further research must be done with those who have lived overseas. In addition, further research must be done with how living overseas affects SMs' ER.

A limitation found in the demographic survey could also explain why YAB did not emerge as statistically significant. The demographic survey originally split YAB into 6 different responses (see Appendix B and C). Because too many empty cells emerged when attempting to do ANOVA with the original data, YAB had to be narrowed considerably to a two-factor response, i.e., whether the individual had lived abroad or not.

A second unexpected result is that there are no statistically significant correlations among language fluency in another language and the CCAI dimensions. It was expected that language fluency would significantly affect the statistical results in some dimensions of the CCAI. Many second language researchers suggest there is a relationship between greater language fluency (including the ability to understand the rule systems in verbal codes, i.e., phonology, morphology, semantics, syntax, and pragmatics, of each language) and ICC (Acton \& Walker de Felix, 1986; Byram, 1988; Lustig \& Koester, 1993). 
Acton and walker de Felix refer to it as the "acculturation threshold" that sojourners attain when going beyond the tourist and survivor stages to reach the stages of immigrant and citizen. Byram refers to the relationship between cultural meanings and language in its social and psychological settings as the link between cultural and language awareness. Lustig and Koester mention that ICC requires appreciation, knowledge, motivation, and associated actions that help sojourners recognize the critical role of $\mathrm{v}$ verbal codes within cultures.

A more thorough recognition of verbal codes would therefore seem to further ICC and be statistically significant in the relationship among the language fluency variable and the CCAI dimensions (especially perceptual acuity, i.e., PAC). However, there were not enough subjects to (see TABLE VII) conclusively suggest relationships among language fluency and the CCAI dimensions.

A third unexpected result is the statistically significant correlations among gender and the CCAI dimensions. While treatment was expected to show statistical significance, the statistical significance among gender and FO (Pearson, $\mathrm{r}=.527, \mathrm{n}=56, \mathrm{p}<.01$; Spearman, $\mathrm{r}=.511, \mathrm{n}$ 
$=56, \mathrm{p}<.01$ ), gender and PAC (Pearson, $\mathrm{r}=.377, \mathrm{n}=57, \mathrm{p}$ $<.01$; Spearman, $\mathrm{r}=.400, \mathrm{n}=57, \mathrm{p}<.01$ ) and gender and total CCAI (Pearson, $\mathrm{r}=.318, \mathrm{n}=49, \mathrm{p}<.05$; Spearman, $\mathrm{r}=$ .310, $\mathrm{n}=49, \mathrm{p}<.05)$ was interesting. However, as mentioned in the discussion of research hypothesis three, it is possible that female responses are a result of feminine interactional patterns. These patterns fit those CCAI dimensions which are most interrelationly dependent (FO and $\mathrm{PAC})$.

A fourth unexpected result is the high correlation among most of the CCAI dimensions (see TABLES XIX AND XXI). I expected that there would be high correlation among all the items (the CCAI manual reveals high correlation among all the items) to reflect the interrelatedness of all the CCAI dimensions and their importance in assessing the ICC of subjects who take the inventory.

However, the level of interrelatedness among all CCAI items suggests that, for the subjects in this research taking the CCAI, some dimensions may be too similar in wording or content, i.e., have high and equal loading on, and correlation with, many of the items in the two dimensions. This does not lessen the impact of the research results. 
However, it would be important to see if the tendency for very high correlation would continue in further research.

Finally, I expected that the parametric and nonparametric tests on the data would reveal different statistically significant results. However, with the exception of a couple of cases, results were statistically significant at $\mathrm{p}<.05$ across the same dimensions using either nonparametric or parametric tests. For example, the ANOVA (the parametric test) of the FO dimension and the treatment variable $(\mathrm{p}=.0338, \mathrm{n}=56, \mathrm{p}<.05)$ was different from the Mann-Whitney $U$ test (the nonparametric test) of the same variables $(\mathrm{p}=.0513, \mathrm{n}=56, \mathrm{p}<.05)$. While the MannWhitney $U$ test reveals results leading to statistical significance and not clear statistical significance, the results are very close to statistical significance.

In another example, the ANOVA (the parametric test) of the repeated PAC dimension revealed results leading to statistical significance $(\mathrm{p}=.0508, \mathrm{n}=57, \mathrm{p}<.05)$, while the Wilcoxon signed rank test (the nonparametric test) for repeated $P A C$ revealed statistical significance $(p=.0264, n$ $=57, \mathrm{p}<.05)$. Again, the results in both tests are very close. This would indicate that there are very few 
differences (at least of statistically significant results) between the parametric and nonparametric tests on the data of this research.

Nevertheless, this leads to some problems I found in the design of Kelley and Meyers' inventory. First, the CCAI manual reveals that Kelley and Meyers used ANOVA to calculate non-interval data. In other words, they used Likert scales (values from 1-6) assuming that each of the inventory items could be calculated and that all of the inventory items had equal weighting. However, the CCAI manual reveals that inventory items are not equal. $E R$, the largest dimension contains 18 items, FO contains 15 items, PAC contains 10 items, and PA contains 7 items. Furthermore, they assumed population normality (i.e., that the raw score distributions would be distributed normally around the sample means). However, simply calculating raw scores risks including outliers (observations so far away from the rest of the sample that they should be discarded) as valid observations (Wonnacott \& Wonnacott, 1977). The nonparametric tests used in this research did not look at the observations but instead considered their ranks.

Second, Kelley and Meyers substituted CCAI item missing 
response values with the item mean, rounded to the nearest integer. This would seem to compromise the data. In other words, by replacing missing values with item means the researcher risks data validity, especially with score distributions that are not normally distributed.

\section{LIMITATIONS}

There were several limitations associated with this research. First, because of work requirements that took the researcher to Japan, much of the research was dependent on audiotapes of the cross-cultural ministry class and the teacher of the class to administer the CCAI. There was $100 \%$ response from experimental subjects. However, because many SMs who did not take the pre-departure training offered at Walla Walla College left before I could administer the CCAI to them, I had difficulty obtaining an adequate control group.

It was initially determined that the control subjects would come from SMs who would be going overseas, but had not taken the cross-cultural ministry class. However, because accessing these people became impossible, I decided that other students attending Walla Walla College would need to 
constitute the control group. This was not a major problem, but did require asking the teacher of the cross-cultural ministry class to provide subjects for the control group. Fortunately, he found a number of students in his and an associate's other classes at Walla Walla College that had not taken any previous pre-departure training. While none of the control subjects intended or wanted to go overseas as SMs, their involvement in this research did help to clarify the possible role of other variables not initially considered when planning this research (e.g., the motivation to go as SMs and the screening process to become SMs).

However, while sharing many similar characteristics with the experimental group (e.g., many were Seventh-day Adventist Church members, had taken or were taking courses acquainting them with SDA church mission), the fact that the new control group did not intend to go overseas as SMs could have made a difference in the results. A group of students who had not taken pre-departure training, but intended to go as SMs might have reported different results.

Second, the number of subjects, i.e., 23 in the experimental group and 34 in the control group, was not enough to acquire a variety of responses that would reveal 
differences in the demographic variables. Many empty cells resulted when loading the data, especially in regard to YAB, age, and ethnic background. However, to have a larger number of subjects, another group of experimental and control subjects would have to be approached to take the inventory. This would have meant waiting another year for a new group of experimental subjects.

Third, because the teacher of the cross-cultural ministry class had to administer the CCAI and the demographic inventories and record the audiotape of actual classes, some subjects did not complete some of the CCAI dimensions and only one recording of an actual cross-cultural ministry class session was obtained. To have subjects complete the CCAI dimensions and to obtain more accurate observations of class sessions, administration of the inventories and observations would have to be done in person. Unfortunately, being there in person was impossible because of work commitments out of the country.

SUGGESTIONS FOR FUTURE RESEARCH

This research examined and evaluated the relationship between a pre-departure training program and its 
participants' intercultural communication competence (ICC). For a more complete evaluation of the SM program and for future ICC research, other areas of ICC research should be considered.

First, this research is based on self-reported ICC, i.e., the feelings that subjects have regarding their own ICC. The literature review has suggested that ICC is both outcome-oriented, i.e., based on perceived appropriateness and effectiveness (Imahori \& Lanigan, 1989; Spitzburg \& Cupach, 1984), and located within the person as his or her self-reported capability to communicate with individuals from other cultures. Future ICC research should also focus on host culture individuals' perceived ICC of SMs.

Second, this research focused on the cross-cultural ministry class as the basis for the difference in the ICC of prospective SMs participating in the cross-cultural ministry class at Walla Walla College and Walla Walla College students who did not participate in the class. However, according to SM program coordinators at Walla Walla College, a number of prospective SMs are cleared for overseas service without having to go through intercultural training (IT).

Future ICC research should focus on the self-reported 
ICC of SMs who do not take part in IT. In addition, future ICC research should focus on the self-reported role the screening and interviewing process has on the SMs' ICC. Finally, future ICC research should focus on what influence other approaches to IT might have on SMs' ICC. This would require the introduction of other types of approaches to IT. However, to best understand, evaluate, and recommend changes to Walla Walla College's SM program, other approaches to IT (e.g., experiential/culture general, experiential/culture specific) should be considered to see the effect these approaches might have on the self-reported ICC of SMS participating in the SM program at Walla Walla College.

Third, this research focused on the cross-cultural ministry class as the basis for the difference in the self-reported ICC of prospective SMs participating in the cross-cultural ministry class at Walla Walla college. Future ICC research should focus on the SM IT programs at other Seventh-day Adventist colleges that have IT programs.

Fourth, this research revealed statistically significant relationship among gender and some of the CCAI dimensions. Future ICC research of the SM program in the Seventh-day Adventist church should further study the influence gender 
has on ICC.

Fifth, this research relied largely on an inventory for analysis of the SM program at Walla Walla College. Future ICC research of SM programs should involve more observations of the cross-cultural ministry class, interviews with SMs who take the class and with those who do not.

Finally, this research focused on the self-reported ICC of SMs before they left on their overseas assignments. In order to understand the influence SM IT has on SMS, as well as the influence living overseas has on SMS' ICC, future ICC research should also include SMS' self-reported return ICC, i.e., the self-reported ICC of SMs after they return from overseas. This might reveal how effective living overseas is for SMS' ICC.

\section{SUMMARY AND CONCLUSIONS}

This research revealed important differences between subjects involved with this research in three areas: 1) with those subjects who took the pre-departure training course at Walla Walla College and those who did not and 2) with male and female subjects. The differences that emerged suggest a number of important issues regarding the IT program at Walla 
Walla College.

First, because the results of the inventory suggest that the IT program at Walla Walla College enhances the ICC of program participants, it is important that some form of training is mandatory for all prospective SMs planning to go overseas. The SM program director indicated there are a number of prospective SMs who do not go through the cross-cultural ministry course that Walla Walla College offers. The 1993-94 SM application packet mentions that SMs who do not take the IT course may apply for an alternative education experience. However, SM program coordinators, in need of people to fill SM positions overseas, indicated that people who wanted to become SMs who had not taken the class are often quickly screened just prior to leaving overseas and do not benefit from IT.

Second, while the academic approach to IT that walla Walla College uses to train SMs seems to enhance the ICC of program participants, it is possible that SM program participants would benefit from a pre-departure training program that would include other forms of IT (e.g., experiential/culture specific or experiential/culture general). An IT program that consists of other forms of IT 
could include training methods that help to address the different socialization needs of male and female SMs involved in the SM program. This could enhance the ICC of all SMs (males and females) going overseas.

To address the different socialization needs of male and females SMs, appreciation of differences between specific cultures should continue to be a part of SMS' IT. This is especially important in the area of understanding another culture's standards. From previous experience, SMs have been known to openly offend host culture individuals due to cultural misunderstandings. Because SMs need to clearly ascertain how specific cultures deal with interrelational issues and the role males and females have within that culture, it would be important for prospective SMs to spend time interacting with host culture individuals before they are sent to that culture.

One issue that did not emerge as a result of subjects' involvement in this research is the appropriateness of using an instrument like the CCAI to assess the ICC of SMs. The methods of screening potential participants in the SM program at Walla Walla College focus on the participants' various personality traits. The CCAI is a self-reporting behavioral 
instrument. It would not be appropriate to use the CCAI as a means to select individuals for the SM program.

However, as an instrument to assess SMs' ICC, the CCAI could help SMs more fully understand their ICC tendencies. Used in this way, the CCAI can be used as a tool to help SMs understand their capability to interact with individuals from other cultures in an appropriate and effective manner. Furthermore, the CCAI can help SMs recognize the areas in which personal ICC growth can take place.

It is hoped that this research will inspire intercultural communication researchers to further investigate the influence of $I T$ in church-oriented mission programs as well as further investigate the ICC of prospective sojourners that church-oriented mission programs send overseas. Future research and implementation of different training techniques could help to enhance the ICC of SMs going overseas. 


\section{BIBLIOGRAPHY}

Abe, H. \& Wiseman, R.L. (1983). A cross-cultural confirmation of the dimensions of intercultural effectiveness. International Journal of Intercultural Relations, 7, 53-67.

Acton, W.R. \& Walker de Felix J. (1986). Acculturation and mind. In Valdes, J.M. (Ed.), Culture bound: Bridging the cultural gap in language teaching (pp. 20-32). Cambridge: Cambridge University Press.

Adler, P.S. (1987). Culture shock and the cross-cultural learning experience. In L.F. Luce \& E.C. Smith (Eds.), Toward internationalism: Readings in cross-cultural communication (pp. 24-35). Cambridge, MA: Newbury House.

Albert, R.D. (1983). The intercultural sensitizer or culture assimilator: A cognitive approach. In D. Landis \& R.W. Brislin (Eds.) Handbook of intercultural training, Vol. 1, (pp. 186-217). New York: Pergamon Press.

Albert, R.D. \& Triandis, H.C. (1994). Intercultural education for multicultural societies: Critical issues. In L.A. Samovar \& R.E. Porter (Eds.), Intercultural communication: A reader (pp. 425-435). Belmont, CA: Wadsworth.

Ball-Rokeach, S.J. (1973). From pervasive ambiguity to a definition of the situation. Sociometry, 36, 378-389.

Barna, L.M. (1988). The stress factor in intercultural relations. In L.A. Samovar \& R.E. Porter (Eds.), Intercultural communication: A reader (pp. 19-49). Belmont, CA: Wadsworth.

Barna, L.M. (1994). Stumbling blocks in intercultural communication. In L.A. Samovar \& R.E. Porter (Eds.) Intercultural communication: A reader (pp. 337-346). Belmont, CA: Wadsworth. 
Barnlund, D.C. (1994). Communication in a global village. In R.E. Porter and L.A. Samovar (Eds.), Intercultural communication: A reader (pp. 26-36). Belmont, CA: Wadsworth.

Bennett, J.M. (1977). Transition shock: Putting culture shock in perspective. International and Intercultural Communication Annual, 4, 45-52.

Bennett, J.M. (1986). Modes of cross-cultural training: Conceptualizing cross-cultural training as education. International Journal of Intercultural Relations, 10, 117-134.

Bennett, M.J. (1993). Towards ethnorelativism: A developmental model of intercultural sensitivity. In R.M. Paige (Ed.) Education for the intercultural experience (pp. 21-71). Yarmouth, ME: Intercultural Press.

Bhawuk, D.F.S. (1990). Cross-cultural orientation programs. In R.W. Brislin (Ed.), Applied cross-cultural psychology (pp. 325-346). Newbury Park, CA: Sage.

Blake, B.F. \& Heslin, R. (1983). Evaluating cross-cultural training. In D. Landis \& R.W. Brislin (Eds.), Handbook of intercultural training, 1 (pp. 203-223). New York: Pergamon Press.

Brislin, R.W. (1981). Cross-cultural encounters, face-to-face interaction. Elmsford, NY: Pergamon.

Brislin, R.W., Landis, D., \& Brandt, M.E. (1983). Conceptualizations of intercultural behavior and training. In D. Landis \& R.W. Brislin (Eds.), Handbook of intercultural training, 1 (pp. 1-35). New York: Pergamon Press.

Brislin, R.w. \& Pederson, P. (1976). Cross-cultural orientation programs. New York: Gardner Press.

Byram, M. (1988). Foreign language education and cultural studies. Language, Culture, and Curriculum, 1, $15-31$. 
Byrnes, F. (1966). Role shock: An occupational hazard of American technical assistants abroad. Annals of the American academy of political and social science, 368, 95-108.

Carbaugh, D. (1990). Toward a perspective on cultural communication and intercultural contact. Semiotica, 80 , $15-35$.

Carbaugh, D. (1994). Toward a perspective on cultural communication and intercultural contact. In L.A. Samovar \& R.E. Porter (Eds.) Intercultural communication: A reader (pp. 45-59). Belmont, CA: Wadsworth.

Cleveland, H., Mangone, G.J., \& Adams, J.C. (1960). The overseas Americans: A report on Americans abroad. New York: McGraw-Hill.

Collier, M.J. (1989). Cultural and intercultural communication competence: Current approaches and directions for future research. International Journal of Intercultural Relations, 13, 287-302.

Collier, M.J. (1994). Cultural identity and intercultural communication. In L.A. Samovar \& R.E. Porter (Eds.) Intercultural communication: A reader (pp. 36-45). Belmont, CA: Wadsworth.

Cronen, V.E., Chen, V., \& Pearce, W.B. (1988). Coordinated management of meaning: A critical theory. In Y.Y. Kim \& W.B. Gudykunst (Eds.), Theories in intercultural communication (pp. 66-98). Newbury Park: Sage.

Cui, G. \& Awa, N.E. (1992). Measuring intercultural effectiveness: An integrative approach. International Journal of Intercultural Relations, 16, 311-328.

Dance, F.E.X. \& Larson, C. (1976). The functions of human communication: A theoretical approach. New York: Holt, Rinehart, and Winston.

Dinges, N. (1983). Intercultural competence. In D. Landis \& R.W. Brislin (Eds.), Handbook of intercultural training, 1 (pp. 176-202). New York: Pergamon Press. 
Dodd, C.H. (1991). Dynamics of intercultural communication. Dubuque, IA: Wm C. Brown.

Fielder, F.E., Mitchell, T., \& Triandis, H.C. (1971). The culture assimilator: An approach to cross-cultural training. Journal of Applied Psychology, 55(2), 95-102.

Furnham, A. (1988). The adjustment of sojourners. International and Intercultural Communication Annual, 11, $42-61$.

Gardner, G.H. (1962). Cross-cultural communication. Journal of Social Psychology, 58, 241-256.

Gardner, R \& Lambert, W. (1972). Attitudes and motivation in second language learning. Rowley, MA: Newbury House.

Grove, C.L. \& Torbiorn, I. (1993). A new conceptualization of intercultural adjustment and the goals of training. In R.M. Paige (Ed.), Education for the intercultural experience (pp. 73-108). Yarmouth, ME: Intercultural press.

Gudykunst, W.B. \& Hammer, M.R. (1983). Basic training design: Approaches to intercultural training. In In D. Landis \& R.W. Brislin (Eds.), Handbook of intercultural training, 1 (pp. 118-153). New York: Pergamon Press.

Gudykunst, W.B., Hammer, M.R., \& Wiseman, R.L. (1977). An analysis of an integrated approach to cross-cultural training. International Journal of Intercultural Relations, 1, 99-110.

Gudykunst, W.B. \& Kim, Y.Y. (1984). Communicating with strangers: An approach to intercultural communication. New York: Random House.

Gudykunst, W.B. \& Ting-Toomey, S. (1988). Culture and interpersonal communication. Newbury Park, CA: Sage. 
Gudykunst, W.B., Wiseman, R.L., \& Hammer, M.R. (1977). Determinants of a sojourner's attitudinal satisfaction: A path model. In B. Rubin (Ed.), Communication yearbook, 1 (pp. 415-425). New Brunswick: Transaction, Inc.

Guthrie, G.M. (1975). A behavioral analysis of culture learning. In R.W. Brislin, S. Bochner, \& W. Lonner (Eds.), Cross-cultural perspectives on learning. New York: Wiley.

Guthrie, G.M. \& Zektick, I. (1967). Predicting performance in the Peace Corps. Journal of Social Psychology, $71,11-21$.

Hall, B.J. (1992). Theories of culture and communication. Communication Theory, 2(1), 50-70.

Hall, E.T. (1988). Context and meaning. In L.A. Samovar and R.E. Porter (Eds.), Intercultural communication: A reader (pp. 44-54). Belmont, CA: Wadsworth.

Hall, E.T. (1989). Beyond culture. New York: Doubleday.

Hall, E.T. (1989). The dance of life: The other dimension of time. New York: Doubleday.

Hall, E.T. (1990). The silent language. New York: Doubleday.

Hall, E.T. (1990). The hidden dimension. New York: Doubleday.

Hammer, M.R. (1984). The effects of an intercultural communication workshop on participants' intercultural communication competence: An exploratory study. Communication Quarterly, 32, 252-262.

Hammer, M.R. (1989). Intercultural communication competence. In M.K. Asante \& W.B. Gudykunst (Eds.) Handbook of international and intercultural communication ( $p p$. 247-260). Newbury Park, CA: Sage. 
Hammer, M.R., Gudykunst, W.B., \& Wiseman, R. (1978). Dimensions of intercultural effectiveness: An exploratory study. International Journal of Intercultural Relations, 2, 383-393.

Hannigan, T.P. (1990). Traits, attitudes, and skills that are related to intercultural effectiveness and their implications for cross-cultural training: A review of the literature. International Journal of Intercultural Relations, $14,89-111$.

Harris, J.G., Jr. (1973). A science of the south Pacific: Analysis of the character structure of the Peace Corps volunteer. American Psychologist, 28, 232-247.

Harrison, R. \& Hopkins, R (1967). The design of cross-cultural training. Journal of Applied Behavioral Science, 3, 431-460.

Hawes, F. \& Kealey, D.J. (1981). An empirical study of Canadian technical assistance: Adaptation and effectiveness on overseas assignment. International Journal of Intercultural Relations, 4, 239-258.

Hiebert, P.G. (1986). Cultural anthropology. Grand Rapids, MI: Baker Book House.

Hiebert, P.G. (1993). Anthropological insights for missionaries. Grand Rapids, MI: Baker Book House.

Hiebert, P.G. \& Hiebert, F. (1987). Case studies in missions. Grand Rapids, MI: Baker Book House.

Hofstede, G. \& Bond, M.H. (1984). Hofstede's culture dimensions: An independent validation using Rokeach's value survey. Journal of Cross-Cultural Psychology, 15, 417-433.

Hoopes, D.S. (1975). Readings in intercultural communication, Vol. 1. Pittsburgh: Intercultural Communication Nework. 
Hoopes, D.S. (1979). Intercultural communication concepts and the psychology of intercultural experience. In M.D. Pusch (Ed.), Multicultural education: A cross cultural training approach (pp. 10-38). Yarmouth, ME: Intercultural Press.

Hoopes, D.S. \& Pusch, M.D. (1979). Definition of terms. In M.D. Pusch (Ed.) Multicultural education: A cross-cultural training approach (pp. 2-8). Yarmouth, ME: Intercultural Press.

Hymes, D.H. (1962). The ethnography of speaking. In T. Gladwin \& W. Sturtevant (Eds.), Anthropology and human behavior (pp. 13-53). Washington, D.C.: Anthropological Society of Washington.

Hymes, D.H. (1972). On communicative competence. In J.B. Pride \& J. Holmes (Eds.), Sociolinguistics. Harmondsworth, England: Penguin.

Imahori, T.T. \& Lanigan, M.L. (1989). Relational model of intercultural communication competence. International Journal of Intercultural Relations, 13, 269-286.

Ivancevich, J.M. (1969). Perceived need satisfaction of domestic versus overseas managers. Journal of Applied Psychology, 53, 274-278.

Kealey, D.J. (1989). A study of cross-cultural effectiveness: Theoretical issues, practical applications. International Journal of Intercultural Relations, 13, $383-428$.

Kelley, C. \& Meyers, J.E. (1993). The cross-cultural adaptability inventory manual. La Jolla, CA.

Kim, Y.Y. (1988). Communication and cross-cultural adaptation: An integrative theory, Philadelphia: Multilingual Matters.

Kim, Y.Y. (1989). Intercultural adaptation. In M.K. Asante \& W.B. Gudykunst (Eds.) Handbook of international and intercultural communication (pp. 275-294). Newbury Park, CA: Sage. 
Kim, Y.Y. (1991). Intercultural communication competence: A systems-theoretical view. In S. Ting-Toomey \& F. Korzenny (Eds.) Cross-cultural interpersonal communication (pp. 259-275). Newbury Park, CA: Sage.

Kim, Y.Y. (1994). Adapting to a new culture. In L.A. Samovar and R.E. Porter (Eds.), Intercultural communication: $A$ reader (pp. 392-404). Belmont, CA: Wadsworth.

Koester, J. \& Olebe, M. (1988). The behavioral assessment scale for intecultural communication effectiveness. International Journal of Intercultural Relations, 12, 233-246.

KohIs, $\mathrm{R}$ (1980). Issues in cross-cultural training. In N. Asuncion-Lande (Ed.), Ethical perspectives and critical issues in intercultural communication. Falls Church, VA: SCA, 1980 .

Kraemer, A.J. (1975). Cultural self-awareness and communication. International Education and Cultural Exchange, $10(3), 13-16$.

Kroeber, A., \& Kluckholn, C. (1952). Culture: A critical review of concepts and definitions. Cambridge, MA: Peabody Museum.

Lustig, M.W. (1988). Value differences in intercultural communication. In L.A. Samovar \& R.E. Porter (Eds.), Intercultural communication: $A$ reader (pp. 55-61). Belmont, CA: Wadsworth.

Lustig, M.W. \& Koester, J. (1993). Intercultural competence: Interpersonal communication across cultures. New York: HarperCollins.

Maretzki, T.W. (1965). Transition training: A Theoretical approach. Human Organization, 24(2), 128-134.

Martin, J.N. (1987). The relationship between student sojourner perceptions of intercultural competencies and previous sojourn experience. International Journal of Intercultural Relations, 11, 337-355. 
Martin, J.N. (1989). Predeparture orientation: Preparing college sojourners for intercultural interaction. Communication Education, 38, 249-258.

Martin, J.N. \& Hammer, M.R. (1989). Behavioral categories of intercultural communication competence: Everyday communicators' perceptions. International Journal of Intercultural Relations, 13, 303-332.

McCaffery, J.A. (1993). Independent effectiveness and unintended outcomes of cross-cultural orientation and training. In R.M. Paige (Ed.), Education for the intercultural experience (pp. 219-240). Yarmouth, ME: Intercultural Press.

Nadler, L. (1970). Developing human resources. Houston: Gulf.

Oberg, K. (1972). Culture shock and the problem of adjustment in new cultural environments. In D.S. Hoopes (Ed.), Intercultural communication. Washington, D.C.: Society for Intercultural Education, Training, and Research.

Olebe, M. \& Koester, J. (1989). Exploring the cross-cultural equivalence of the behavioral assessment scale for intercultural communication. International Journal of Intercultural Relations, 13, 333-347.

Paige, R.M. (1993). On the nature of intercultural experiences and intercultural education. In R.M. Paige (Ed.) Education for the Intercultural Experience (pp. 1-19). Yarmouth, ME: Intercultural Press.

Pearce, W.B. \& Cronen, V.E. (1980). Communication, action, and meaning: The creation of social realities. New York: Praeger.

Pearce, W.B. \& Kang, K. (1988). Conceptual migrations: Understanding "travelers' tales" for cross-cultural adaptation. In Y.Y. Kim \& W.B. Gudykunst (Eds.), Cross-cultural adaptation (pp. 20-41). Newbury Park, CA: Sage. 
Philipsen, G. (1989). An ethnographic approach to communication studies. In B. Dervin, L. Grossberg, B.J. O'Keefe, \& E. Wartella (Eds.), Rethinking communication (pp. 258-268). Newbury Park, CA: Sage.

Porter, R.E. \& Samovar, I.A. (1988). An introduction to intercultural communication. In R.E. Porter \& I.A. Samovar (Eds.), Intercultural communication: A reader (pp. 15-30). Belmont, CA: Wadsworth.

Porter, R.E. \& Samovar, L.A. (1994). An introduction to intercultural communication. In R.E. Porter \& L.A. Samovar (Eds.), Intercultural communication: A reader (pp. 4-25). Belmont, CA: Wadsworth.

Ptak, C.L., Cooper, J., \& Brislin, R.W. (1995). Cross cultural training programs: Advice and insights from experienced trainers. International Journal of Intercultural Relations, 19(3), 425-453.

Rohrlich, B.F. \& Martin, J.N. (1991). Host country and reentry adjustment of student sojourners. International Journal of Intercultural Relations, 15, 163-182.

Rokeach, M. (1973). The nature of human values, New York: Free Press.

Ruben, B.D. (1976). Assessing communication competency for intercultural adaptation. Group and Organization Studies, $1,334-354$.

Ruben, B.D. (1985). Human communication and cross-cultural effectiveness. In L.A. Samovar and R.E. Porter (Eds.), Intercultural communication: A reader (pp. 95-105). Belmont, CA: Wadsworth.

Ruben, B.D. (1987). Guidelines for cross-cultural communication effectivess. In I.F. Luce \& Smith, E.C. (Eds.), Toward Internationalism: Readings in cross-cultural communication (pp. 36-46) Cambridge, MA: Newbury House.

Ruben, B.D. (1989). The study of cross-cultural competence: Traditions and contemporary issues. International Journal of Intercultural Relations, 13, 229-240. 
Ruben, B.D. \& Kealey, D.J. (1979). Behavioral assessment of communication competency and the prediction of cross-cultural adaptation. International Journal of Intercultural Relations, 3, 15-47.

Sager, S. (1994). Statview. Berkley, CA: Abacus Concepts.

Smart, R. (1988). Religion-caused complications in intercultural communication. In L.A. Samovar \& R.E. Porter (Eds.), Intercultural communication: A reader (pp. 62-76). Belmont, CA: Wadsworth.

Spitzberg, B.H. (1989). Issues in the development of a theory of interpersonal competence in the intercultural context. International Journal of Intercultural Relations, $13,241-268$.

Spitzberg, B.H. (1994). A model of intercultural communication competence. In L.A. Samovar \& R.E. Porter (Eds.) Intercultural communication: A reader (pp. 347-359). Belmont, CA: Wadsworth.

Spitzberg, B.H. \& Cupach, W.R. (1984). Interpersonal communication competence. Beverly Hills, CA: Sage.

Stewart, E.C. (1966). The simulation of cultural difference. Journal of Communication, 16, 291-304.

Stewart, E.C. (1977). The survival stage of intercultural communication. International and Intercultural Communication Annual, 4, 17-31.

Taft, R. (1977). Coping with unfamiliar cultures. In $N$. Warren (Ed.), Studies in cross-cultural psychology, 1 (pp. 121-153). London: Academic Press.

Tannen, D. (1986). That's not what I meant!: How conversational style makes or breaks relationships. Random House: New York.

Triandis, H.C. (1983). Essentials of studying cultures. In D. Landis \& R.W. Brislin (Eds.) Handbook of intercultural training, 1 (pp. 82-117). New York: Pergamon Press. 
Triandis, H.C. (1988). Collectivism v. individualism: A reconceptualisation of a basic concept in cross-cultural social psychology. In G.K. Verma \& C. Bagley (Eds.), Cross-cultural studies of personality, attitudes, and cognition (pp. 60-95). New York: St. Martins Press.

Triandis, H.C. (1990). Theoretical concepts that are applicable to the analysis of ethnocentrism In R.W. Brislin (Ed.), Applied cross-cultural psychology (pp. 34-55). Newbury Park, CA: Sage.

Trifonovitch, G. (1973). On cross-cultural orientation techniques. Topics in Culture Learning, 1, 38-47.

Weaver, G.R. (1993). Understanding and coping with cross-cultural adjustment stress. In R.M. Paige (Ed.) Education for the Intercultural Experience (pp. 137-167). Yarmouth, ME: Intercultural Press.

Wiseman, R.I., Hammer, M.R., \& Nishida, H. (1989). Predictors of intercultural communication competence. International Journal of Intercultural Relations, 13, 349-370.

Wonnacott, T.H. \& Wonnacott, R.J. (1977). Introductory Statistics. New York: John Wiley \& Sons.

Wood, J.T. (1994). Gender, communication, and culture. In L.A. Samovar \& R.E. Porter (Eds.), Intercultural communication: A reader (pp. 155-165). Belmont, CA: Wadsworth.

Zavalloni, M. (1980). Values. In H.C. Triandis \& R.W. Brislin (Eds.), Handbook of cross-cultural psychology, 5 (pp. 73-120). Boston: Allyn \& Bacon, Inc. 


\section{APPENDIX A}

THE CROSS-CULTURAL ADAPTABILITY INVENTORY (1993 Version)

1. I have ways to deal with the stresses of new situations.

2. I believe that I could live a fulfilling life in another culture.

3. I try to understand people's thoughts and feelings when I talk to them.

4. I feel confident in my ability to cope with life, no matter where I am.

5. I can enjoy relating to all kinds of people.

6. I believe that I can accomplish what I set out to do, even in unfamiliar settings.

7. I can laugh at myself when I make a cultural faux pas (mistake).

8. I like being with all kinds of people.

9. I have a realistic perception of how others see me.

10. When I am working with people of a different cultural background, it is important to me to receive their approval.

11. I like a number of people who don't share my particular interests.

12. All people, of whatever race, are equally valuable.

13. I like to try new things.

14. If I had to adapt to a slower pace of life, I would become impatient.

15. I am the kind of person who gives people who are different from me the benefit of the doubt.

16. If I had to hire several job candidates from a background different from my own, I feel confident that I could make a good judgment.

17. If my ideas conflicted with those of others who are different from me, I would follow my ideas rather than theirs.

18. I could live anywhere and enjoy life.

19. Impressing people different from me is more important than being myself with them.

20. I can perceive how people are feeling, even if they are different from me. 
21. I make friends easily.

22. When I am around people who are different from me, I feel lonely.

23. I don't enjoy trying new foods.

24. I believe that all cultures have something worthwhile to offer.

25. I feel free to maintain my personal values, even among those who do not share them.

26. Even if I failed in a new living situation, I could still like myself.

27. I am not good at understanding people when they are different from me.

28. I pay attention to how people's cultural differences affect their perceptions of me.

29. I like new experiences.

30. I enjoy spending time alone, even in unfamiliar surroundings.

31. I rarely get discouraged, even when I work with people who are very different from me.

32. People who know me would describe me as a person who is intolerant of others' differences.

33. I consider the impact my actions have on others.

34. It is difficult for me to approach unfamiliar situations with a positive attitude.

35. I prefer to decide from my own values, even when those around me have different values.

36. I can cope well with whatever difficult feelings I might experience in a new culture.

37. When I meet people who are different from me, I tend to feel judgmental about their differences.

38. When I am with people who are different from me, I interpret their behavior in the context of their culture.

39. I can function in situations where things are not clear.

40. When I meet people who are different from me, I am interested in learning more about them.

41. My personal value system is based on my own beliefs, not on conformity to other people's standards.

42. I trust my ability to communicate accurately in new situations.

43. I enjoy talking with people who think differently than I think.

44. When $I$ am in a new or strange environment, I keep an open mind.

45. I can accept my imperfections, regardless of how others 
view them.

46. I am the kind of person who gives people who are different from me the benefit of the doubt.

47. I expect that others will respect me, regardless of their cultural background.

48. I can live with the stress of encountering new circumstances or people.

49. When I meet people who are different from me, I expect to like them.

50. In talking with people from other cultures, I pay attention to body language. 


\section{APPENDIX B}

CONTROL GROUP DEMOGRAPHIC SURVEY

1. How old are you?
a) $18-20$
b) $21-22$
c) $23-25$
d) $26-30$
e) $30+$

2. What is your ethnic background?
a) Caucasian-American
b) African-American
C) Asian-American
d) Hispanic-American
e) American Indian f) Other
3. Your gender?
a) Male
b) Eemale

4. Are you a Seventh-day Adventist?
a) yes
b) no

5. How long have you been a Seventh-day Adventist?
a) $0-2$ yrs
b) 2-4 yrs
c) $5-7$ yrs
d) $7-10$ yrs
e) $10+$ yrs

6. Are you a Vegetarian?

a) yes

b) no

7. Have you ever lived in a culture other than your own?
a) yes
b) no

8. If you have lived in another culture, how long did you live there?
a) $0-1$ yr
b) 1-3 yrs
C) $3-5$ yrs
d) 5-7 yrs
e) $7+\operatorname{yrs}$

9. What do you think is the most important thing to consider when dealing with a person from another culture?

10. Have you taken any previous classes in cross-cultural learning? a) yes

b) no

11. What is your native language?

12. What other languages do you speak fluently? 
APPENDIX C

EXPERIMENTAL GROUP DEMOGRAPHIC SURVEY

1. How old are you?
a) $18-20$
b) $21-22$
C) $23-25$
d) $26-30$
e) $30+$

2. What is your ethnic background?
a) Caucasian-American
b) African-American

c)

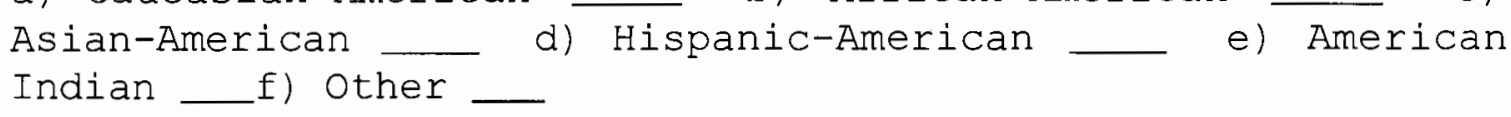

3. Your gender?

a) Male

b) Female

4. How long have you been a Seventh-day Adventist?
a) $0-2$ yrs
b) 2-4 yrs
c) 5-7 yrs
d) $7-10$ yrs
e) $10+$ yrs

5. Are you a Vegetarian?

a) yes

b) no

6. Have you ever lived in a culture other than your own? a) yes b) no

7. If you have lived in another culture, how long did you live there?
a) $0-1$ yr
b) $1-3$ yrs
C) $3-5$ yrs
d) $5-7$ yrs
e) $7+$ yrs

8. What do you think is the most important thing to consider when dealing with a person from another culture?

9. Have you taken any previous classes in cross-cultural learning? a) yes

b) no

10. What is your native language?

11. What other languages do you speak fluently?

12. What country are you planning to go to as an SM? 
13. What will your main responsibility be as an SM? 
APPENDIX D

SM PROGRAM SPONSOR AND CROSS-CULTURAI MINISTRY CLASS TEACHER INTERVIEW QUESTIONS

1. What do you look for in a person when screening prospective SMs?

2. What do you look for in the personality tests that prospective SMs take as part of the screening process?

3. What does the Cross-Cultural Ministry class teach prospective SMs?

4. Why is dating nationals or another SM, at the same assignment, not allowed?

5. What does a christian experience contribute to the sMs overall experience and how do you think it helps in difficult and unusual situations in another culture?

6. What role does adaptability to another culture play in SMS' effectiveness in another culture?

Cross-Cultural Ministry Teacher's Interview Questions

1. What does the Cross-Cultural Ministry class teach prospective SMs?

2. Why is dating nationals or another SM, at the same assignment, not allowed?

3. What alternative education experience are SMs allowed to take if they cannot take the Cross-Cultural Ministry class? How might this affect their overall training?

4. What does a Christian experience contribute to the SMs overall experience and how do you think it helps in difficult and unusual situations in another culture? 
5. What role does adaptability to another culture play in SMs' effectiveness in another culture? 


\section{APPENDIX E}

\section{TABLES ASSOCIATED WITH THIS RESEARCH}

TABLE XVI

TREATMENT SUBJECTS AND ER REPEATED MEASURE ANOVA TABLE

\begin{tabular}{|c|c|c|c|c|c|}
\hline SOURCE & $\mathrm{DF}$ & $\begin{array}{l}\text { SUM OF } \\
\text { SQUARES }\end{array}$ & $\begin{array}{l}\text { MEAN } \\
\text { SQUARE }\end{array}$ & F-VALUE & P-VALUE \\
\hline $\begin{array}{c}\text { Treatment } \\
\text { (A) }\end{array}$ & 0 & 0.000 & & & \\
\hline $\begin{array}{l}\text { Subjects } \\
\text { with } \\
\text { groups }\end{array}$ & 21 & 2348.295 & 111.824 & & \\
\hline $\begin{array}{c}\text { ER } \\
\text { Reptd } \\
\text { Msr } \\
\text { (B) }\end{array}$ & 1 & 63.841 & 63.841 & 2.526 & .1269 \\
\hline $\mathrm{AB}$ & 0 & 0.000 & & & \\
\hline $\begin{array}{c}\text { B x } \\
\text { sbjcts } \\
\text { w. } \\
\text { groups }\end{array}$ & 21 & 530.659 & 25.269 & & \\
\hline
\end{tabular}

Note: One case was omitted due to missing values 
TABLE XVII

TREATMENT SUBJECTS AND PA REPEATED MEASURE ANOVA TABLE

\begin{tabular}{|c|c|c|c|c|c|}
\hline SOURCE & $\mathrm{DF}$ & $\begin{array}{l}\text { SUM OF } \\
\text { SQUARES }\end{array}$ & $\begin{array}{l}\text { MEAN } \\
\text { SQUARE }\end{array}$ & F-VALUE & P-VALUE \\
\hline $\begin{array}{c}\text { Treatment } \\
\text { (A) }\end{array}$ & 0 & & & & \\
\hline $\begin{array}{l}\text { Subjects } \\
\text { with } \\
\text { groups }\end{array}$ & 14 & 179.867 & 12.848 & & \\
\hline $\begin{array}{c}\text { PA } \\
\text { Reptd } \\
\text { Msr } \\
\text { (B) }\end{array}$ & 1 & 14.700 & 14.700 & 3.500 & .0824 \\
\hline$A B$ & 0 & 3.553 & & & \\
\hline $\begin{array}{c}\text { B x } \\
\text { sbjcts } \\
\text { w. } \\
\text { groups }\end{array}$ & 14 & 58.800 & 4.200 & & \\
\hline
\end{tabular}

Note: 8 cases were omitted due to missing values. 
TABLE XVIII

MANN-WHITNEY INEORMATION FOR RESEARCH SUBJECTS AND THE CCAI

\begin{tabular}{|c||c|c|c|c||}
\hline SCAIE & TREATMENT & CASES & SUM RANKS & MEAN RANK \\
\hline \hline \multirow{2}{*}{ ER } & VES & 22 & 801.000 & 36.409 \\
& NO & 34 & 795.000 & 23.382 \\
\hline \multirow{2}{*}{ FO } & YES & 23 & 772.500 & 33.587 \\
& NO & 33 & 823.500 & 24.955 \\
\hline \multirow{2}{*}{ PAC } & VES & 23 & 818.500 & 35.587 \\
& NO & 34 & 834.500 & 24.544 \\
\hline PA & VES & 18 & 513.000 & 28.500 \\
& NO & 31 & 712.000 & 22.968 \\
\hline \multirow{2}{*}{ CCAI } & VES & 18 & 585.500 & 32.528 \\
& NO & 31 & 639.500 & 20.629 \\
\hline
\end{tabular}

Note: Treatment refers to the course in cross-cultural ministry offered at Walla Walla College. 
TABLE XIX

INCIDENCE TABLE OF REPEATED CCAI DIMENSIONS

\begin{tabular}{|c||c|c|c|c||}
\hline GROUP & CASES & MEAN & STD. DEV. : & STD. ERROR: \\
\hline \hline ER-PRE & 22 & 84.227 & 7.837 & 1.671 \\
\hline ER-POST & 22 & 86.636 & 8.699 & 1.855 \\
\hline FO-PRE & 23 & 72.522 & 6.134 & 1.279 \\
\hline FO-POST & 23 & 74.609 & 6.308 & 1.315 \\
\hline PAC-PRE & 23 & 48.348 & 2.902 & .605 \\
\hline PAC-POST & 23 & 50.174 & 4.019 & .838 \\
\hline PA-PRE & 15 & 33.867 & 2.949 & .761 \\
\hline PA-POST & 15 & 35.267 & 2.890 & .746 \\
\hline CCAI-PRE & 15 & 238.8 & 15.129 & 3.906 \\
\hline CCAI-POST & 15 & 247.867 & 17.484 & 4.514 \\
\hline
\end{tabular}


TABLE XX

PEARSON PRODUCT MOMENT CORRELATION COEFFICIENTS ( $r^{\prime} s$ ) AMONG THE CCAI DIMENSIONS

\begin{tabular}{|c||c|c|c|c|c||}
\hline VARIABLES & ER & FO & PAC & PA & CCAI \\
\hline \hline ER & 1 & & & & \\
\hline FO & $.566^{\star}$ & 1 & & & \\
\hline PAC & $.560^{\star}$ & $.703^{\star}$ & 1 & & \\
\hline PA & $.443^{\star}$ & .181 & .204 & 1 & \\
\hline CCAI & $.875^{\star}$ & $.855^{\star}$ & $.807 *$ & $.463 *$ & 1 \\
\hline
\end{tabular}

Note: 57 observations were used in this computation. 8 cases were omitted in correlations involving PA and CCAI. one case was omitted in correlations involving ER and FO due to missing values in ER and FO.

Italicized statistical significance ${ }^{*}: \mathrm{p}<.01$ and other ${ }^{*}: p$ $<.05$ 
TABLE XXI

SPEARMAN RANK-ORDER CORRELATION COEFFICIENTS ( $r^{\prime} s$ ) AMONG THE CCAI DIMENSIONS

\begin{tabular}{||c||c|c|c|c|c||}
\hline $\begin{array}{c}\text { VARI- } \\
\text { ABLES }\end{array}$ & FR & FO & PAC & PA & CCAI \\
\hline \hline ER & & & & & \\
\hline FO & $.595^{\star}$ & & & & \\
\hline PAC & $.477 \star$ & $.654^{\star}$ & & & \\
\hline PA & $.472^{\star}$ & .166 & .200 & & \\
\hline CCAI & $.848^{\star}$ & $.855^{\star}$ & $.805^{\star}$ & $.452^{\star}$ & \\
\hline
\end{tabular}

Note: 57 observations were used in this computation. 8 cases were omitted in correlations involving PA and CCAI. One case was omitted in correlations involving ER and FO due to missing values in ER and FO.

Italicized statistical significance * $\mathrm{p}<.01$ and other: $\mathrm{p}<$ .05 